University of Louisville

ThinkIR: The University of Louisville's Institutional Repository

$12-2014$

\title{
Secondary student outcomes and perspectives on a multiple pathways approach to education : engagement, achievement, and transitions.
}

\author{
Lisa-Anne Ferris \\ University of Louisville
}

Follow this and additional works at: https://ir.library.louisville.edu/etd

Part of the Education Commons

\section{Recommended Citation}

Ferris, Lisa-Anne, "Secondary student outcomes and perspectives on a multiple pathways approach to education : engagement, achievement, and transitions." (2014). Electronic Theses and Dissertations. Paper 1711.

https://doi.org/10.18297/etd/1711

This Doctoral Dissertation is brought to you for free and open access by ThinkIR: The University of Louisville's Institutional Repository. It has been accepted for inclusion in Electronic Theses and Dissertations by an authorized administrator of ThinkIR: The University of Louisville's Institutional Repository. This title appears here courtesy of the author, who has retained all other copyrights. For more information, please contact thinkir@louisville.edu. 
SECONDARY STUDENT OUTCOMES AND PERSPECTIVES ON A MULTIPLE PATHWAYS APPROACH TO EDUCATION:

ENGAGEMENT, ACHIEVEMENT, AND TRANSITIONS

By

Lisa-Anne Ferris

B.A. University of Kentucky, 2008

M.Ed University of Louisville, 2011

\begin{abstract}
A Dissertation
Submitted to the Faculty of the College of Education \& Human Development of the University of Louisville In Partial Fulfillment of the Requirements for the Degree of

Doctor of Philosophy

Department of Leadership, Foundations, and Human Resource Education University of Louisville Louisville, Kentucky
\end{abstract}

December 2014 

SECONDARY STUDENT OUTCOMES AND PERSPECTIVES ON A MULTIPLE PATHWAYS APPROACH TO EDUCATION:

ENGAGEMENT, ACHIEVEMENT, AND TRANSITIONS

By

Lisa-Anne Ferris

B.A. University of Kentucky, 2008

M.Ed University of Louisville, 2011

A Dissertation Approved on

November 25, 2014

by the following Dissertation Committee:

Dr. James R. Stone, III, Dissertation Co-Chairperson

Dr. Namok Choi, Dissertation Co-Chairperson

Dr. Brad Shuck

Dr. Patrick Hardesty

Dr. Pradeep Kotamraju 


\begin{abstract}
Lisa-Anne Ferris

SECONDARY STUDENT OUTCOMES AND PERSPECTIVES ON A MULTIPLE PATHWAYS APPROACH TO EDUCATION: ENGAGEMENT, ACHIEVEMENT, AND TRANSITIONS
\end{abstract}

November 25, 2014

Career and Technical Education, earlier known as Vocational Education, has been formally part of public education since 1917. Federal policies have been used to support linking academic and vocationally-based curricula to give secondary and postsecondary students practical work experience within schools to prepare them for the workforce (Gordon, 2008). The current policy, The Carl D. Perkins Career and Technical Education Act, or Perkins IV, is the most recent policy to integrate academic and vocationally-based curricula's using a career pathway model under Programs of Study (POS) (USDE, 2013). POS are career pathways that students choose in the beginning of their high school careers that enables them to take courses in a determined sequence. Completion of a course sequence in a POS puts students on a career track in high school where, upon graduation, they have the skills and necessary credentials for either postsecondary education or the workforce. Through POS, students make linkages between what they are learning in school and skills that they will apply in the real world.

Research on the effects of Perkins IV implementation is built into the legislated accountability measures (USDE, 2013). This dissertation examined the effects of POS participation on student outcome variables using waves of survey data from secondary 
students in grades 9 and 12 . The student outcome variables were academic achievement, student engagement, and transitions into postsecondary education or the workforce.

Results suggested a positive association between POS participation effects and student outcome variables for the $9^{\text {th }}$ grade survey participants and a positive association between POS participation and student engagement for the $12^{\text {th }}$ grade survey participants. The results also suggested positive, but mixed, associations between gender and student outcome variables. The results were consistent with current literature on the effects of POS participation and gender on student outcome variables, except for the $12^{\text {th }}$ grade participants. These findings from the $9^{\text {th }}$ grade survey suggest a selection effect in school assignment along with early POS effects. The findings from the $12^{\text {th }}$ grade survey show the POS effect.

Recommendations are made that more studies need to be conducted on the participation of secondary students in a POS and the ability of these programs to effectively prepare students for postsecondary education and the workforce. More alignment between academic and vocational education curricula is also recommended to further develop the skillsets of young adults to meet the demands of the $21^{\text {st }}$ century workforce. 


\section{TABLE OF CONTENTS}

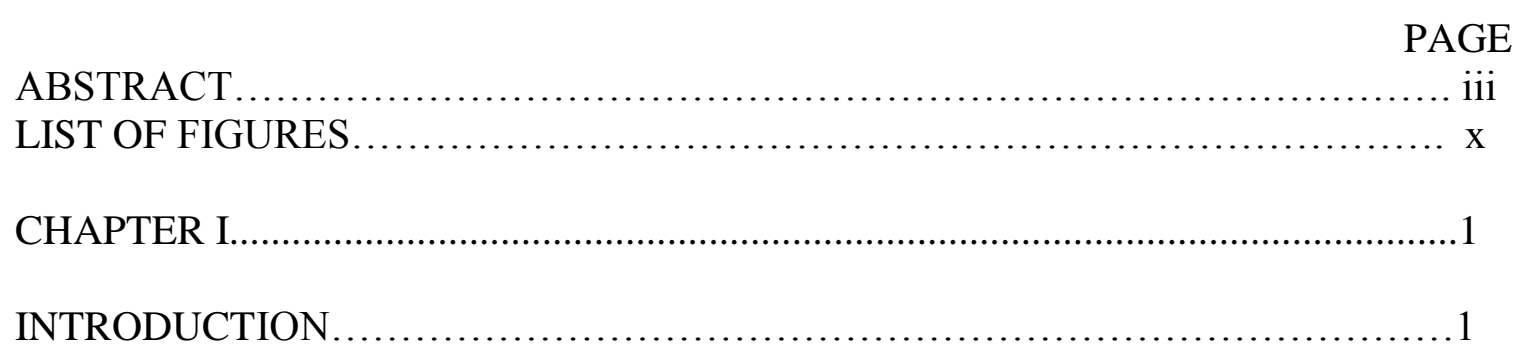

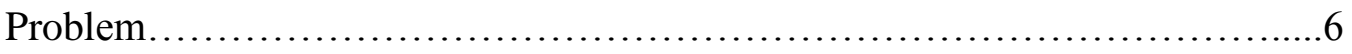

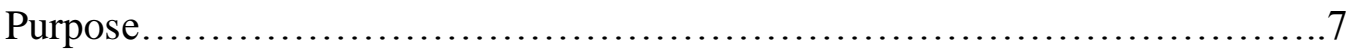

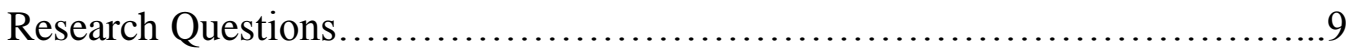

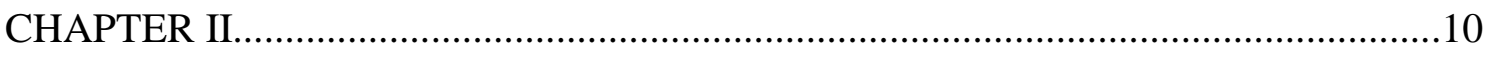

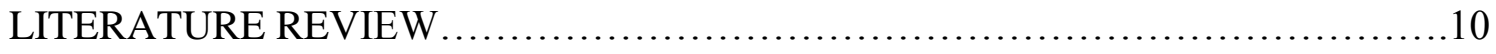

What is CTE?

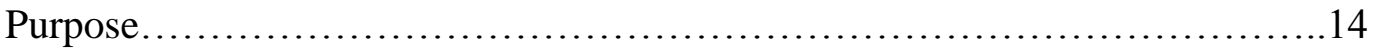

Current CTE Teaching and Learning Frameworks.............................15

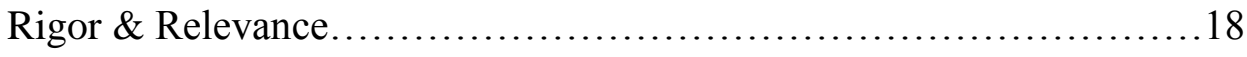

College and Career Readiness.......................................20

European Development and Influence......................................26

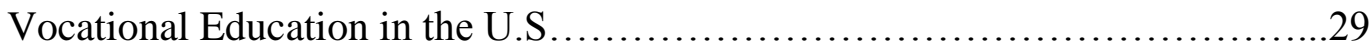

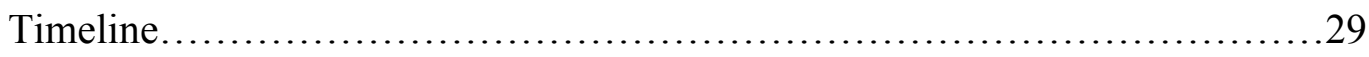

Pre-1917 Legislation and Development................................29

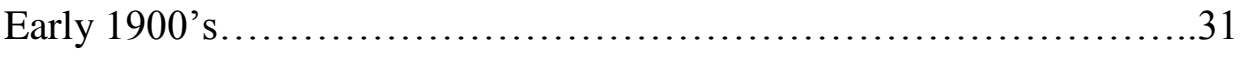

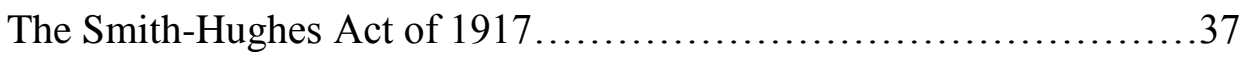




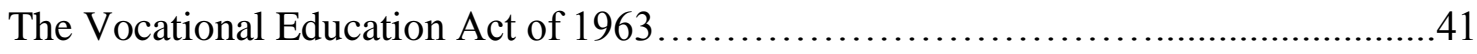

The Need for Reform......................................45

The Carl D. Perkins Vocational Education Act.......................47

Continued Reform.........................................48

The Carl D. Perkins Vocational \& Applied Technology Act.............50

The Carl D. Perkins Vocational \&Technical Education Act..............57

$21^{\text {st }}$ Century CTE.............................................

College for All.................................................................... 59

College and Career Readiness Revisited.........................................67

Carl D. Perkins Career and Technical Education Act..........................68

Development of POS..................................................................... 71

Research on Multiple Pathways................................73

POS Component of Perkins IV .................................. 75

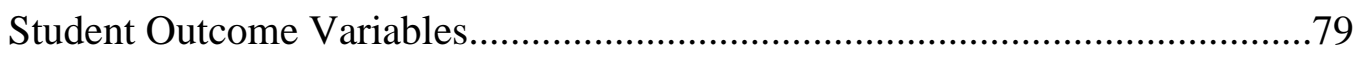

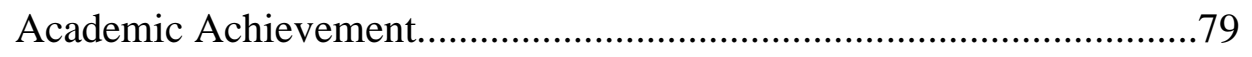

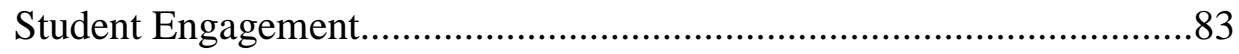

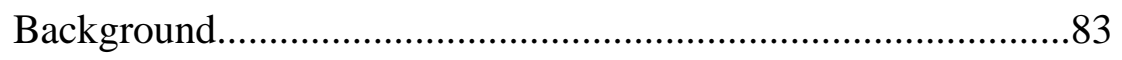

Student Engagement and Burnout........................................8

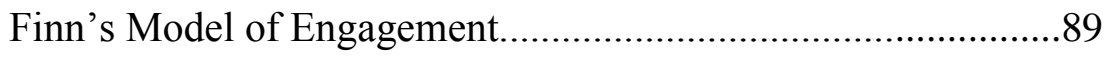

Behavioral Engagement..................................................90

Student Engagement and Curriculum Development.................91

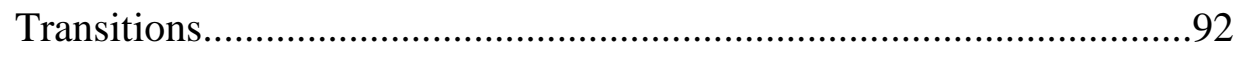

Transitions and CTE.........................................................96 
Relationship Among Outcome Variables.............................................97

Achievement, Student Engagement, and Transitions...................97

Achievement and Student Engagement......................................97

Student Engagement and Transitions..........................................99

Achievement and Transitions.......................................................99

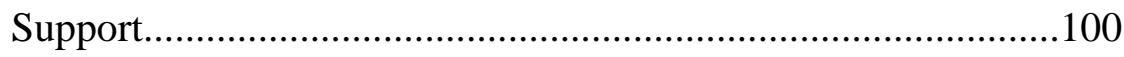

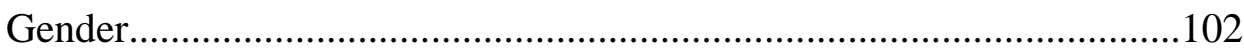

Research Questions.............................................104

Summary ..........................................................

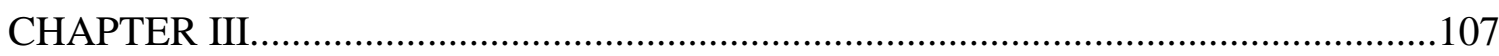

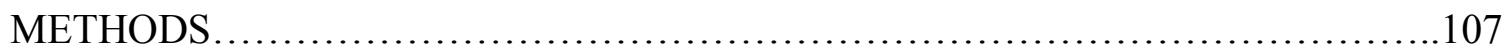

Rigorous Tests of Student Outcomes in CTE Programs of Study........................108

Reliability \& Validity: Triangulation................................111

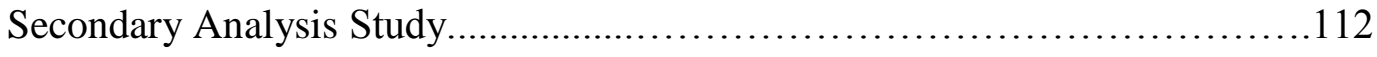

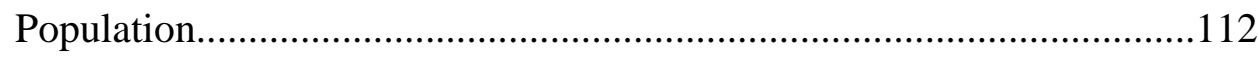

Sample

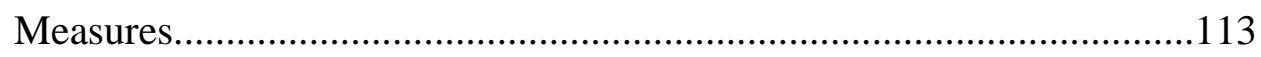

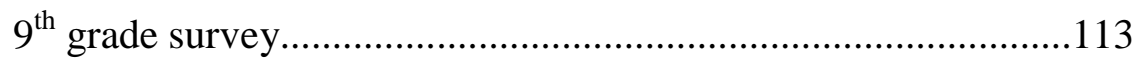

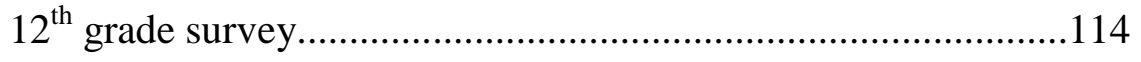

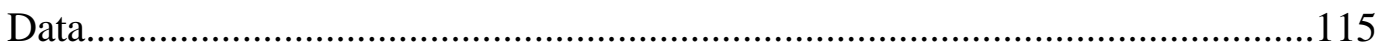

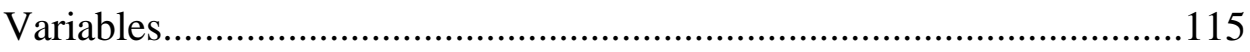

Independent Variables.................................................................

Dependent Variables...............................................................116 
Research Questions.................................................. 125

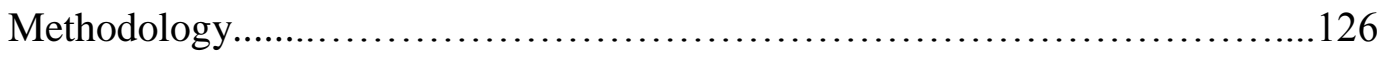

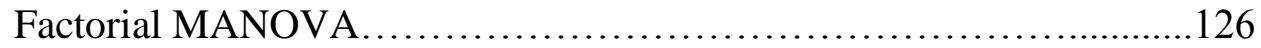

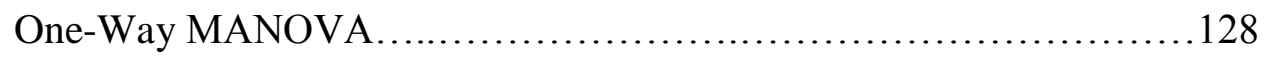

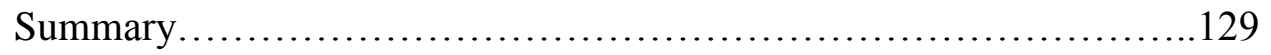

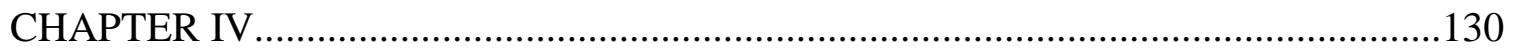

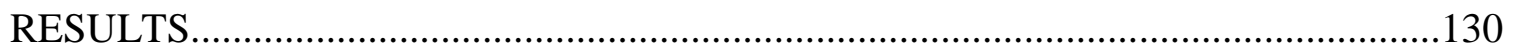

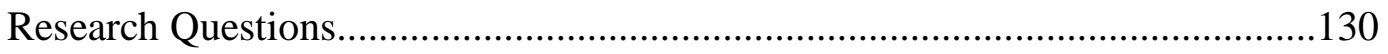

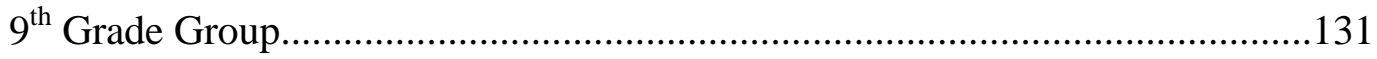

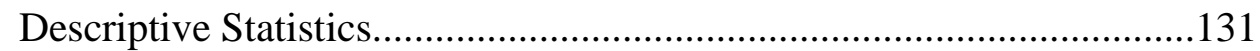

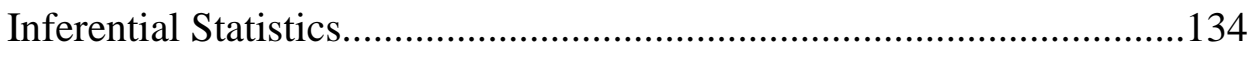

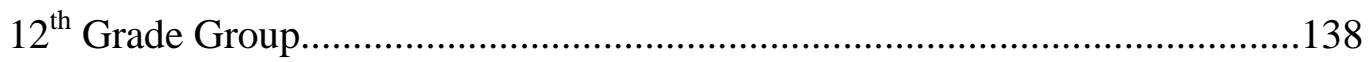

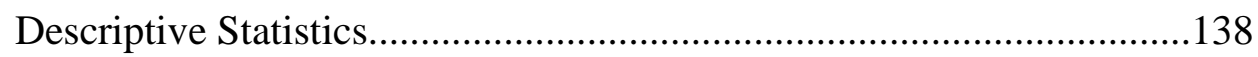

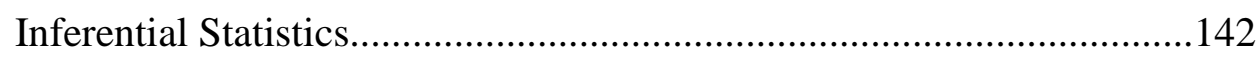

Summary

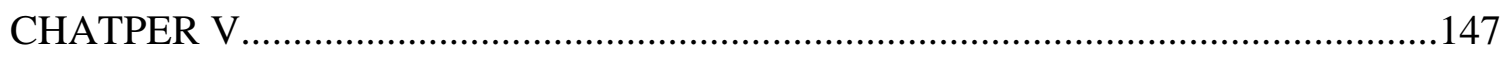

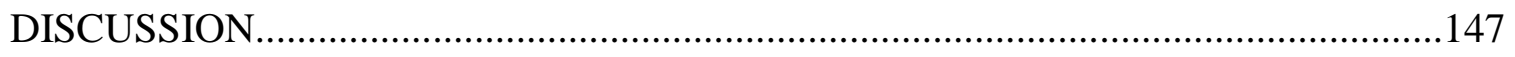

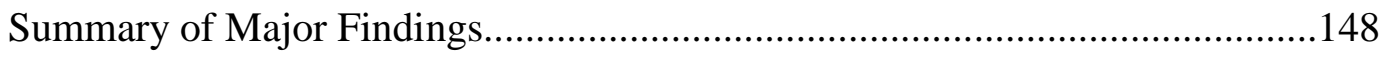

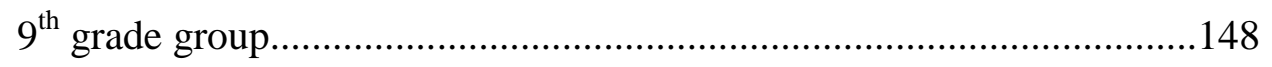

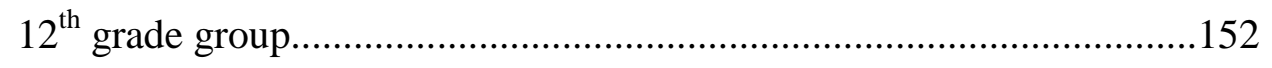

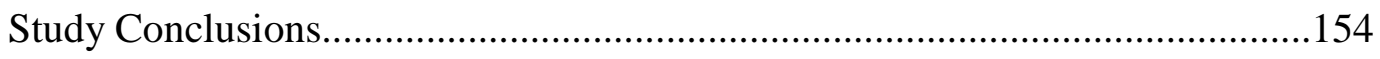

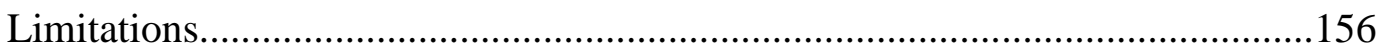


Future Recommendations................................................................... 158

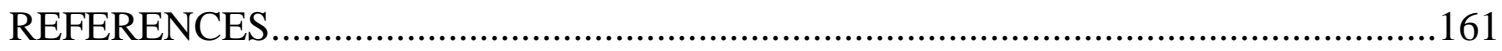

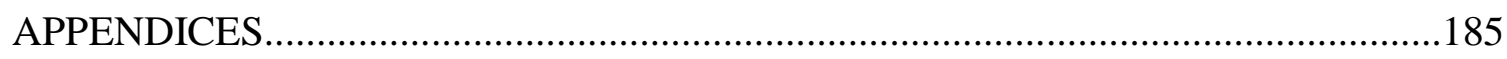

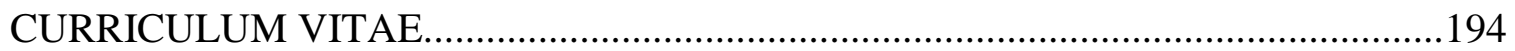




\section{LIST OF FIGURES}

FIGURE

PAGE

1. Means, Standard Deviations, and T-Tests of the Major Variables for the $9^{\text {th }}$ grade

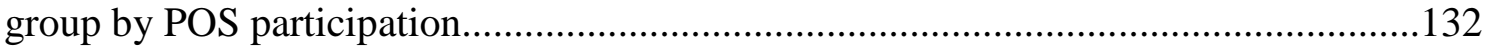

2. Means, Standard Deviations, and T-tests of the Major Variables in $9^{\text {th }}$ grade group

by Gender.

3. Correlations and Significance (Two-Tailed) of Major Variables by Independent

Variables

4. MANOVA Summary.

5. Tests of Between-Subjects Effects Summary.

6. Means, Standard Deviations, and T-values of Major Variables in $12^{\text {th }}$ Grade Group

by POS Participation.

7. Correlations and Significance (Two-Tailed) of Major Variables by POS Participation... 140

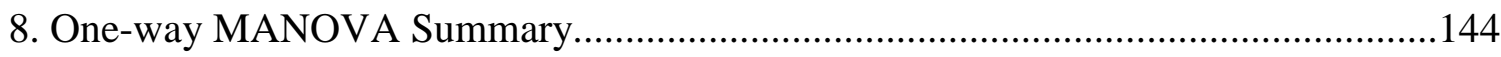

9.Test of Between Subjects-Effects Summary.....................................................144 


\section{CHAPTER I}

\section{INTRODUCTION}

Education within the United States is a means to prepare youth and adults with the skills and knowledge necessary to be individually successful as well as contribute to a national and global economy (Gordon, 2008). The means to achieve such goals has been a point of contention throughout the evolution of the educational system here in the United States. The American educational system, since inception, has experienced times of great variation and differentiation about what students should know for future success, and relatedly, what should be taught in secondary and postsecondary institutions (Gordon, 2008). For the majority of schools, emphasis has been placed on academic education. For the minority of schools, emphasis has been placed on technical skills. Historically, the least amount of emphasis has been placed on employability skills, or "soft skills," skills that are unique to the individual personality (Stone \& Lewis, 2012). Depending on factors such as governmental influence, state and local needs, as well as student demographics, educational programs are developed differently across the nation; some preparing students for college while others prepare students for careers. As such, this kind of diversity has affected the general populations' preparedness for the working world (Symonds, Schwartz, \& Ferguson, 2011).

Diverse educational programs fall under two distinct areas within secondary and postsecondary education. These areas are academic and vocational education, the latter of which has been known as Career and Technical Education (CTE) since the late 1990's 
(Carter, 1998). These two educational pathways have been influenced from past educational developments in Europe and mirror much of the system across the Atlantic (Gordon, 2008; Benavot, 1983). Academic education focuses mostly on postsecondary readiness for its secondary students, with postsecondary readiness synonymous with career readiness. CTE focuses on a more career-oriented approach to secondary students preparation as it considers a multiple pathways approach to education beyond academics (Gordon, 2008; Hayward \& Benson, 1993). The multiple pathways include academic content, technical content, and context dependent learning in real world settings. Both systems seem to have the same goals of workforce preparation and hopes for a productive economy, but the ramifications of how students are prepared for the workplace in this country has created what some authors conceptualize as major skills gaps and a certain lack of preparedness (Symonds et al., 2011).

The overarching goal of workforce preparation that is espoused by academic and vocational education has always been a necessity in the United States as education and training has shifted to meet the needs of the country at different times in history (Gordon, 2008). For example, before the Industrial Revolution and development of public education, an informal apprenticeship system was a preeminent skill development method for U.S citizens. In the early 1900's, the country transformed itself from an agrarian society to an industrial society that introduced the factory system (Hayward \& Benson, 1993). During the 1900's the U.S. opened its first schools that emphasized academic education as well as practical skills development. Spanning more than a century, the American educational system and its constituents have shifted back and forth 
about what workforce preparation is and what are the essential characteristics of successful workers. Even in the second decade of the $21^{\text {st }}$ Century there is much discussion from government officials, policymakers, educators, and the community about workforce preparation and perhaps more importantly, whose job it is to prepare said workforce (Symonds et al., 2011).

The field of Career and Technical Education (CTE) has historically been the leading proponent for workforce development and preparation. Since its inception the field has always emphasized the importance of workforce skills in youth and adult development in secondary and postsecondary intuitions as well as within the workforce (Gordon, 2008; Hayward \& Benson, 1993). As a proponent of workforce development for all secondary and postsecondary students, the field acknowledges that bringing academic and vocational pathways closer together will help students gain the skills and abilities to be successful in the $21^{\text {st }}$ century. The integration of academic education, CTE, and the workforce is supported through current CTE federal legislation that requires the connection of core subjects and relevant, context dependent environments. The most recent is the Carl D. Perkins Career and Technical Education Act of 2006, or Perkins IV as it is also called (USDE, 2013). Perkins IV was developed out of a long but relevant history of federal legislation that dates back to the original vocational education legislation, the Smith-Hughes Act of 1917. All of the iterations and further developments of vocational legislation throughout the $20^{\text {th }}$ Century has brought the field to its current legislation, one that espouses a multiple pathways approach, or Programs of Study, to education and $21^{\text {st }}$ Century workforce preparation. The current CTE teaching and learning frameworks also espouse an integrated academic and vocational education 
pathway system that produces a student who is ready for both college and/or careers. This student is prepared with a three pronged skill set that includes academic, technical, and employability skills, all skills of a $21^{\text {st }}$ Century worker. This framework is called the College and Career Readiness Framework (Stone \& Lewis, 2012).

The necessity of a comprehensive whole school educational reform effort that includes the integration of academic and vocational education with an emphasis on workforce preparation is not new. Reform efforts starting in the 1980's with A Nation at Risk, Workforce 2000, and other reports that argued that the secondary system was not preparing students for careers, and ultimately blamed the system for the decline in U.S global competitiveness during that time (Gordon, 2008; Lynch, 2000; Carter, 1998; Hayward \& Benson, 1993). As the U.S heads farther into the $21{ }^{\text {st }}$ Century, the demand for a prepared workforce echoes louder than ever. The workforce demands of the $21^{\text {st }}$ century have brought a more intense focus on the importance of CTE in secondary and postsecondary institutions as a means to prepare students for all types of skill sets. The new economy brings with it a fast paced, ever changing, technologically grounded work environment that calls for skills that expand beyond the hard skills learned in a classroom setting and instead point to a well rounded, adaptable, and collaborative worker (Lynch, 2000).

To achieve a $21^{\text {st }}$ Century workforce, it is suggested that CTE adopts a College and Career Readiness Framework, mentioned above, that ensures workforce preparation through a multiple pathways approach to high school graduation and beyond (Stone \& Lewis, 2012). This kind of framework is a departure from the "College for All" mentality that swept the nation in the early 2000's. The "College for All" framework, 
along with other initiatives, pushed secondary students through a system of testing and accountability, without focus on what was being tested and what was being learned (Ravitch, 2010). The "College for All" mentality misinformed the public about what postsecondary education was and further increased the stigma attached to CTE. The "College for All” framework did not mean "College for All," it meant "4-year postsecondary institutions for all," an important distinction for the field of CTE. It is an important distinction because only $35 \%$ of postsecondary training includes 4 -year college (Carnevale, Smith, \& Stohl, 2010). The most noted forms of postsecondary training are actually CTE related training and include on the job training, apprenticeships, and industry training, most of which care provided through 2-year or community colleges.

Through its many frameworks and legislations, CTE's current educational platform is a multiple pathways approach to postsecondary preparation and a $21^{\text {st }}$ Century skill set (Symonds et al., 2011). Perkins IV supports the need for a multiple pathways approach to workforce preparation for secondary students. One of the components of this legislation is Programs of Study (POS) which is a career pathway a student chooses in the and a postsecondary 2 or 4-year degree, all dependent on the requirements of that career pathway and specialty (USDE, 2013; POS Joint Technical Working Group, 2010). There have been several other multiple pathway programs that influenced the development of the POS component, and the current legislation mandates the POS component to any state receiving Perkins IV funding (USDE, 2013).

There are several reasons why it is important to examine the multiple pathways approach to education. The first is that current CTE legislation requires states to implement the POS component. Research on the effects of its implementation is built into 
the legislative accountability measures (USDE, 2013). The second is the belief by some authors within the field that the multiple pathways approach to education is best practice for supplying the demands of the $21^{\text {st }}$ Century workforce (Symonds et al., 2011). Studies that attempt to explore this notion are needed, such as this secondary analysis. Departing from an academic curriculum based on the premise of4-year college for all preparation, the multiple pathways approach utilizes a well-rounded system of preparation for all future endeavors that are important to maintaining and improving the U.S.'s position in this global economy. Multiple pathways support that notion that there are important business and industry positions that require high school diplomas, industry credentials, 2year degrees, and 4-year degrees (Lynch, 2000).

\section{Problem}

The multiple pathways approach to secondary education rose not only out of the need for a more prepared $21^{\text {st }}$ Century workforce, but also from the failing status of the secondary system in the U.S. The traditional academic secondary system within the U.S is thought to no longer be preparing students for their futures in this current economy (Achieve Inc, 2004). Not only is the secondary system not preparing students' for postsecondary endeavors, many secondary students are not graduating postsecondary school. In fact, the U.S ranks the highest in high school drop out rates among industrialized nations (Symonds et al., 2011). Many students who are either non-college bound to begin with, or are receiving postsecondary education beyond what their career goals require, are dropping out. It is believed they are dropping out of high school for several reasons. One is because of the high cost of education. The other, and perhaps related to the first, is the lack of perceived connection between what students are learning 
and how they will apply it in the workforce (Stone \& Lewis, 2012; Gordon, 2008; Hayward \& Benson, 1993).

Because the secondary system is not preparing students with the skills necessary to be successful in college and careers, the postsecondary system is also not meeting the demands of the workforce once students have their degrees (Symonds et al., 2011). The current postsecondary system will not meet the growing demand for workers in the $21^{\text {st }}$ Century. It will also not produce enough graduates with skills needed for the growing labor market (Carnevale et al., 2010). There are several reasons why this is occurring. The main reason is the lack of integration of workforce skills in secondary and postsecondary schooling. Another reason is the lack of alignment between job demands and skills taught in secondary and postsecondary schools (Carnevale et al., 2010). Other reasons for the lack of skills are the technology age we live in, and the economic recession we are currently going through. Because of the technology boom, many of the jobs we are used to will never come back and instead new ones will be created, ones that require high technical skills.

The problems that have occurred throughout the beginning of the $21^{\text {st }}$ Century need a remedy. We cannot prepare the youth the same way as we did before, that much is clear. Evidence suggests that one of the ways to prepare secondary students is through secondary and postsecondary multiple pathways that rely on increased skills and job training (Symonds et al., 2011; Carnevale et al., 2010).

\section{Purpose}

The purpose of this dissertation is to examine the student outcome effects of a multiple pathways approach to secondary education. Specifically, the implementation of 
the Perkins IV POS career pathways component and the relationships POS participation has on secondary student outcomes. This dissertation attempts to explore the multiple pathways approach to postsecondary education/workforce as a method of both college and career readiness for secondary students.

The analysis of this legislation within this dissertation includes reports of evidenced based practice, existing CTE teaching and learning frameworks, governmental policy overviews, social and temporal influences before, during, and after legislation development, and multivariate statistical testing of student outcomes from an existing data set that measures Perkins IV POS implementation and student outcomes.

The overarching goal of this dissertation is to inform decision-making and further developments within Perkins IV legislation as well as the field of CTE. This will be achieved by providing a better understanding of the field of CTE through a historical approach coupled by an understanding of the present day needs of a $21^{\text {st }}$ century high performance work system; exploring evidence-based practices of students outcomes of the multiple pathways approach to secondary education.

This dissertation is a secondary analysis of an existing data set. The data set is from the "Rigorous Tests of Student Outcomes in CTE Programs of Study" or "RTPOS" which will be discussed in detail in following chapters (Castellano, Sundell, Overman, Richardson \& Stone, 2014). From a statistical perspective, the research questions within this dissertation attempt to explain secondary student differences outcomes based on POS program participation. The educational outcomes are the most studied outcomes for CTE implementation and include engagement, achievement, and transitions (POS Joint Technical Working Group, 2010). The RTPOS collected multiple sources of data with 
two groups of students, $9^{\text {th }}$ grade and $12^{\text {th }}$ grade, which will be used for this secondary analysis. Below are the research questions.

\section{Research Questions}

The research questions for the $9^{\text {th }}$ grade group are:

RQ1: Is there a significant main effect of POS participation on the linear composite of academic achievement, engagement, support, and transitions of $9^{\text {th }}$ grade secondary students?

RQ2: Is there a significant main effect of gender on the linear composite of academic achievement, engagement, support, and transitions of $9^{\text {th }}$ grade secondary students?

RQ3: Is there a significant interaction effect between POS participation and gender on the linear composite of academic achievement, engagement, support, and transitions of $9^{\text {th }}$ grade secondary students?

The research question for the $12^{\text {th }}$ grade group is:

RQ4: Is there a significant main effect of POS participation on the linear composite of academic achievement, engagement, support, and transitions of $12^{\text {th }}$ grade secondary students? 


\section{CHAPTER II}

\section{LITERATURE REVIEW}

Chapter I provided a rationale for the importance of preparing students for the workforce through Career and Technical Education (CTE) based curriculums. $21^{\text {st }}$ Century job projections, as well as further technological advances, highlight the need for a prepared workforce through a multiple pathways framework that is college and career ready (Stone \& Lewis, 2012; Symonds et al., 2011; Carnevale et al., 2010). As our labor market and economy continue to change through technological advances, curriculums need to adapt in how they prepare their students, a viewpoint that has been espoused by CTE for a long time.

The field of CTE is a dynamic field that changes with the times. CTE arose from the needs of the nation pre-World War I (WWI) in the beginning of the $20^{\text {th }}$ century (Hayward \& Benson, 1993). That was a much different CTE than we see today. Even the name of the field has gone through evolutions dependent upon the perspectives and viewpoints of practitioners and scholars. Given any conversation about CTE it is necessary to understand the history, as the evolution of the field is highly relevant to its current status (Gordon, 2008). This chapter attempts to present a comprehensive literature review on frameworks within CTE; its evolution from inception to its current status; and an examination of the variables within this dissertation that will be used to measure the impacts of Programs of Study (POS), as well as report on evidence based 
practice with relevance to the multiple pathways approach to education, specifically the POS component of the Perkins IV federal legislation.

\section{What is CTE?}

Before delving into the subject areas of CTE that are of importance to this dissertation, it is necessary to create a foundation of what exactly is meant by CTE. There is much discussion and debate circling the question, "What is Career and Technical Education?" Historically, the federal government defined vocational education as “...preparation for employment in positions requiring less than the baccalaureate degree" (Hayward \& Benson, 1993, p. 9). Almost a century later, the National Center for Research in Vocational Education defined CTE as a field that “...prepares all individuals for lasting and rewarding employment and lifelong learning” (Carter, 1998, p. 57). This shift within vocational education from sub-baccalaureate training to general workforce and lifelong learning is an important implication for the evolution of the field. Policies, reform efforts and programs have shifted to prepare students for both college and careers within secondary and postsecondary training, ensuring students and employees' the ability to choose their career paths (Levesque, Lauen, Teitelbaum, Alt, Librera, \& Nelson, 2000).

The breadth of what constitutes CTE is up for much discussion and debate. CTE can span from including all areas in the 16 Career Clusters developed by the U.S. Department of Education (USDE) and the Office of Vocational and Adult Education (OVAE) to the limits of a state's federal funding eligibility, as well as secondary programs that are sub-baccalaureate (USDE, 2013). There is a new taxonomy for CTE programs developed by the National Research Center for Career and Technical Education 
(NRCCTE) that utilizes codes for CTE programs and subject areas. These codes categorize an unstandardized method of program implementation across the country (Aliaga, Kotamraju, \& Stone, 2012). For the purposes of this dissertation, CTE is delimited to states that are eligible for federal funding in CTE and are housed within secondary educational institutions.

With a definition and understanding of what constitutes CTE, it is still important to note that states, local agencies and schools by nature offer a variety of programs and course sequences depending on the career interests of individual students. CTE is also offered by entities other than educational institutions, including employers, labor organizations, military and correctional facilities (Hayward \& Benson, 1993). There are also state-funded CTE programs and programs that are funded by federal legislations. Differences in program offerings and environments segue to another important subject matter within the field: what constitutes a CTE student? Gordon (2008) outlines two CTE student categories. The first is CTE course takers who are students that take vocational coursework on an academic track. The second is CTE occupational investors who earn three or more CTE credits in a given school year. The occupational investor category is divided further into two groups: an occupational concentrator who is earning three or more credits in a single program area, and an occupational explorer who is earning three or more credits in more than one program area. The occupational concentrator is of interest in this dissertation, because these are the students who have chosen a specific Program of Study (POS) to complete during their high school and postsecondary/industry careers. 
CTE programs, teachers, students, and coursework vary within such a diverse field that offers students the ability to take courses that are of interest to their individual career goals. Most programs vary as a result of state needs and funding eligibility. As mentioned above, it is programs that are funding eligible, housed within secondary educational institutions, and provide students the option of being an occupational concentrator are of interest in this dissertation. These specific CTE requirements align with the purpose of this dissertation, which is to explore the current CTE federal legislation: the Carl D. Perkins Career and Technical Education Act of 2006, or Perkins IV (USDE, 2013). Perkins IV provides funding to states that are eligible under the tenets of the policy and mandates that any state receiving funding from this legislation needs to provide at least one career pathway system, or Programs of Study (POS). More specific to the purpose of this dissertation is the POS component of Perkins IV. The POS that a school offers is a career pathway or single program that the occupationally concentrated student desires. POS were developed to help increase student outcomes, such as achievement and engagement, as well as ease transitions as secondary students progress through high school and move onto postsecondary training and/or business and industry. POS also helps to standardize national CTE program implementation (USDE, 2013; Stipanovic, Stringfield, \& Lewis, 2012; POS Joint Technical Working Group, 2010).

To examine the effectiveness and impact of POS and Perkins IV legislation, a secondary analysis will be conducted from an existing study that measured POS participation effects on high school student outcomes. The study from which data were drawn was from the National Research Center for Career and Technical education entitled, "Rigorous Tests of Student Outcomes in CTE Programs of Study" or RTPOS. 
The purpose of the RTPOS was to analyze the participation effects of POS on student achievement (Castellano, Sundell, Overman, Richardson, \& Stone, 2012). The RTPOS was conducted over four years from 2010 - 2014 to gauge secondary students' academic and technical skills achievement as they participated in POS. The study included two districts from two different states in the Unites States. The RTPOS used multiple groups of students to examine grade level and individual differences of POS participation, as well as non-POS participation, on students' academic achievement outcome variables, such as engagement and transitions. The RTPOS was multi-method, longitudinal and quasi-experimental (Castellano et al., 2012). The RTPOS is explained in detail in Chapter III.

As a secondary analysis, this dissertation examines one district that the RTPOS included in their sample. Using two groups, grades 9 and 12, this dissertation examines student outcome variables of academic achievement, student engagement, transitions and an additional variable of support on POS participation, as well as gender using student self-report surveys. More details about the characteristics of this secondary analysis can also be found in Chapter III.

\section{Purpose}

The purpose of this chapter is to provide a comprehensive literature review on relevant aspects of the field of CTE. Relevant aspects include two teaching and learning models of CTE that are espoused by Perkins IV and Programs of Study, a historical outline of past federal legislation that have influenced the current Perkins IV mandate and current research on relevant variables seen within this secondary analysis that speak to the importance of this current study, as well as future studies for the field of CTE. The 
two relevant teaching and learning models of CTE, Rigor and Relevance and College and Career Readiness, look to inform current best practice as to how to the American secondary system should prepare students for college and careers (Stone \& Lewis, 2012; Gordon, 2008). These two frameworks have evolved from past frameworks and highlight the importance of contextual and relevant educational experiences, ideas that are also espoused by the Perkins IV legislation. The historical outline of past federal legislation and practice within the field of CTE explain in detail the evolution of the field from its beginning through the present day. Knowledge of past events in CTE is essential for understanding its present and future (Gordon, 2008). Stemming from this notion, current evidence and research outcomes within the field of CTE are woven throughout this literature review. Impacts of CTE on variables such as student achievement, engagement and transitions are discussed in relevance to the secondary analysis, as well as how those student outcomes relate to labor market preparation and needs. These studies relay the effectiveness of CTE from both a policy perspective and an educational standpoint (NRCCTE.org, 2014).

\section{Current CTE Teaching and Learning Frameworks}

The field of Career and Technical Education (CTE) is marked by theories that emphasize experiential aspects of learning and encourage the blending of theory and practice. Historically, CTE teaching and learning has its roots in behaviorism, constructivism, and contextual learning models that explain what CTE is and what the promised effects are of its lessons (Gordon, 2008). Behaviorism at one point used to be the overarching framework of CTE. As the field grew and evolved, behaviorism was replaced by constructivism, because of the need to prepare students with skills hat 
included high-order level thinking, not just job skills (Doolittle \& Camp, 1999).

Constructivism and contextual learning have become major frameworks that have influenced CTE practice as they highlight the importance of student-directed learning, learning by doing and hands-on experiential learning in real world settings.

Constructivism has influenced the field of CTE with its foundational tenet that all humans have a desire, need and drive to make sense of the world around them through self-action (Gordon, 2008; Mahoney, 2004). It is believed that one cannot discuss teaching and learning without using the word constructivism, because of its basis for learning in the construction of new knowledge and information (Rahman, Jalil, \& Hassan, 2008). Constructivism has its roots in psychology, as well as philosophy, and invites learners to use subjectivism and relativism to create and integrate new knowledge and experience (Doolittle \& Camp, 1999). The mechanism through which people make sense of their world is through past experiences that are relevant and readily integrated into new experiences with foci on self and action (Gordon, 2008, Mahoney, 2004). Examples of the constructivist framework in CTE include programs such as Tech Prep and School-to-Work, among others that support work-based learning. These programs integrate both academic and vocational education and include experiential learning through industry certifications, internships, cooperative education and work experience. This type of educational model can be understood by comparisons with more academic education that centers on learning to know. Constructivist CTE programs focus on learning by doing situations using action (Gordon, 2008).

Contextual learning has also influenced the field of CTE with its task-based curriculum (Gordon, 2008; Lynch, 2000). The contextual learning method was espoused 
in the late 1980s and stemmed from the document $A$ Nation at Risk that reported on low student achievement across the nation and blamed secondary schools as the culprit for not preparing students with the skills needed to be competitive in a global economy (Dyer, Reed, \& Berry, 2006). As a result of $A$ Nation at Risk, major school reform efforts ensued that attempted to change how students were being taught in high school. One of these new methods was contextual learning.

The contextual learning framework offers teachers and students realistic learning experiences that align with relevant contexts through which new information can be readily integrated and applied (Gordon, 2008). On the basis that students do not learn the same ways, contextual learning allows students to be self-directed and apply themselves. Foundations within this framework include hands-on learning approaches and real world settings. Contextual learning integrates context with a student's subjects to increase achievement, mostly in technical areas, which is where CTE fits in since it is an applied field. In this way, technical classes become reinforcement for core subject learning and retention (Dyer, et al., 2006). Examples of contextual learning in school include shop classes where students learn and are tested through the action of building and constructing matter. Another example is curriculum integration within core subjects such as the NRCCTE's Math-in-CTE study (Stone, Alfeld, \& Pearson, 2008). This is a study that used an integrated CTE/Math curriculum to test context dependent learning. Results indicated significant increases in academic achievement with contextual, relevant learning versus context independent learning when studying mathematics. Through the contextual learning framework, students learn academic skills and vocational skills along 
with life skills, all skills that are necessary for the $21^{\text {st }}$ Century workplace (Gordon, 2008).

Both constructivism and contextual learning are relevant introductions to the two CTE frameworks: Rigor and Relevance, and College and Career Readiness (Stone \& Lewis, 2014; Gordon, 2008). Both frameworks take notes from constructivism and contextual learning in that learning, by nature, happens most often and most effectively when students can place new experiences in a relevant context. Both Rigor and Relevance and College and Career Readiness find themselves on the spectrum of providing students with skills to become self-directed, life-long learners. Providing these skills to students falls necessitates that educators not only teach students what they need to know to be successful, but prepare them for the world outside of education as well. These two frameworks are strongly tied to the Perkins IV legislation and the development and implementation of POS that are examined in this secondary analysis.

\section{Rigor and Relevance.}

The Rigor and Relevance framework is founded in the belief that learning is enhanced when there is alignment between standards, curriculum, instruction and assessment (Gordon, 2008). The framework was first proposed by the International Center for Leadership in Education as a means of examining the tangible teaching methods of curriculums, instruction and assessments. The framework acts as a curriculum pathway where all points on the path are aligned with the curriculum. All aspects of education are aligned with one another to give a student the most direct education possible: curriculum planning and development, teaching from the curriculum, testing and assessing from the curriculum. 
This framework is an extension of the report $A$ Nation at Risk, which prompted major school reform efforts in the late 1980's into the new millennium (Gordon, 2008). The recommendations from the report consisted of increased standards, requirements and accountability in secondary education, as well as developing more rigorous and relevant curriculums that prepared students for success beyond academia (Gordon, 2008). Current research on students' preparation still supports A Nation at Risk. The majority of high school students are not prepared for college, according to the National Center for Education Statistics (NCES). For example, in 2005, less than 23\% of students scored at the proficient level of mathematics. There are currently more students who score below average in mathematics than there are students who score average or above. This is directly linked to postsecondary mathematics preparation, as $22 \%$ of the same students need to be placed in remedial education in mathematics in college (Stone et al., 2008; Grigg, Donahue, \& Dian, 2007; Parsad \& Lewis, 2003). The lack of preparation in mathematics, one of the core subjects in high school, shares insight into the general lack of preparation within secondary schools.

The case of a new framework like Rigor and Relevance extends directly from the research described above. The words Rigor and Relevance are integral to the nature of this framework and have many implications for the field of CTE. One such implication comes from Gordon (2008), "Rigor and relevance must be the cornerstone of career and technical education" (page 325). As we know, learning is best achieved when students can make some kind of connection with how they will apply what is being taught, either experientially, contextually or through relevance to their lives. Creating experiences that are relevant to students' lives are how students will be motivated and connected to 
learning rigorous material (Gordon, 2008). Creating relevant opportunities for students to rigorously learn material not only helps them in school, but also gives them the tools for lifelong learning, another concept integral to CTE and a $21^{\text {st }}$ century workplace.

Stone et al., (2008) took the Rigor and Relevance framework and studied its impacts. Using the components of rigor and relevance, the authors studied the effects of using occupational specific mathematics on students' academic achievement on standardized testing, need for remedial mathematics, and performance on applied mathematics tests. Through cooperation of math and CTE teachers, math was introduced to students in a context specific fashion, much like contextual learning models of teaching through rigor and relevance. Results indicated that students in the experimental situation performed better than control students on standardized tests, as well as college placement tests. All of these results have implications for postsecondary school preparation, one of the most researched variables in CTE implementation programs (POS Joint Technical Working Group, 2010).

Developing, implementing and assessing curriculums, using the components of this framework, enables educators and policymakers to become more specific in their goals and desired student outcomes for teaching and learning. Through an aligned curricular pathway, a more standardized approach can be developed that can be used nationwide. Rigor and Relevance is a framework that can be used for other fields besides CTE as a means to better prepare students for the $21^{\text {st }}$ Century and their futures.

\section{College and Career Readiness.}

Another CTE framework developed in the midst of the changing face of vocational education and the need for $21^{\text {st }}$ Century worker preparation that stemmed from 
the Rigor and Relevance Framework that encourages educators to incorporate relevant course work to enhance the learning of rigorous material. The College and Career Readiness framework exemplifies the evolution of the field. This framework, which will be discussed in detail in the following paragraphs, combines both academic and vocational education, as well as other skill sets that are needed for the $21^{\text {st }}$ Century using a multiple pathways approach. Historically, academic and vocational education have been purposely separated. This framework closes the gap between the two pathways for a more general approach to workforce preparation.

The College and Career Readiness framework proposed by Stone and Lewis (2012) is a diversion from the "College for All" school reform efforts of the 1990's and early 2000's. Specifically, College for All, which will be discussed within the historical timeline of CTE, contended that preparing students for college while in high school also prepared them for the workforce. There are many assumptions embedded in that contention; one is that college readiness and career readiness are the same, and two, that all students go to college. One serious misunderstanding of school reform efforts in the beginning of the $21^{\text {st }}$ Century was that college readiness and career readiness were one and the same. The evolution of what college and career readiness meant started in 2003 with the first definition. The Standards for Success Initiative was the first to define what students needed to know in high school and what they needed to be able to do once out of high school. Although not specifically termed College and Career Readiness, it was certainly relevant (Conley \& McGaughy, 2012). The next wave of College and Career Readiness was the American Diploma Project that brought educators, business and industry together to discuss what it meant to be ready for college and careers, an 
influential initiative to say the least (Achieve Inc., 2004). Shortly after the American Diploma Project of 2004, ACT published a report in 2006 that insisted college and career readiness were the same, because the general skill sets needed for one were similar to the other. Stemming from ACT's report, it was once believed, and potentially still believed by some, that if a student was college ready, they had the skills needed to be career ready. However, evidence suggests that the two are quite different and one does not equal the other, so support for a secondary school that prepares students just for college readiness will not suffice for all students. It is important to highlight that the two do have cross sets of skills as suggested by ACT. These cross sets of skills fall under the Common Core State Standards that almost all 50 states have adopted that prepare students for the workplace (Conley \& McGaughy, 2012). With College and Career Readiness at the forefront, Stone and Lewis (2012) created a framework to help secondary schools prepare students for both college and careers, regardless of the pursuits students take after high school graduation.

The need for this framework came out of the realization that while secondary schools prepare students for college, they hardly prepare students for employment, as many employers report that students are unprepared when they enter the workforce (Achieve Inc, 2004). Preparing some students for college, those that are college bound, forgets a majority of students who are not college bound. The College and Career Readiness framework suggests changing the "college for all" reform efforts to either "career for all" or College and Career Readiness. This framework prepares students for both college and careers through reform efforts that include curriculums that help develop academic skills, employability skills and technical skills, all of which are necessary in 
both college and careers (Stone \& Lewis, 2012). CTE's role in this framework is to provide context dependent, rigorous learning that is nested in initiatives and programs that directly involve students in real life work situations. CTE's other role is to provide secondary students with a choice of multiple career pathways to ensure successful achievement, engagement and transitions.

One of the goals of the College and Career Readiness framework is to make secondary education matter again, from a workforce preparation standpoint. Support for a new secondary school system in the United States is widespread (Ravitch, 2010; Angus \& Mirel, 1999). It is argued that the high school diploma does not guarantee that a student has the skills needed to be successful in the labor market, but instead prepares them for postsecondary education, (Stone \& Lewis, 2012; Symonds et al., 2011), if it even does that. Postsecondary preparation is a good thing, but not all students go on to a traditional four-year school after high school. High schools today offer a mainly academic curriculum, yet almost half of high school students today "major" in CTE. These CTE majors have been aptly named "the forgotten half" (Symonds et al., 2011). Various reasons explain why students don't go on to college, including the increasing cost of higher education, student's academic ability, and not all careers require a postsecondary degree. It is more important that ever to ensure that when a student leaves high school that they are equipped for whatever endeavor they want to accomplish. This is called "career readiness." Being career ready after high school means being able to go to a four-year college, two-year college or into industry. Stone and Lewis suggest that there should be a credential at the end of high school, which signals that a student skillset is aligned with industry standards (2012). 
Stone and Lewis (2012) define college and career readiness as mastery of three sets of skills that build on each other: academic, technical, and employability. Academic and technical knowledge are in part taught within secondary schools already, although their integration is of interest in this framework. Skills in these areas not only include the knowledge of subjects, but also their applications to real world occupational settings, a hallmark of CTE. The third set of skills is employability skills, which is what sets this framework apart from other school reform efforts. Employability skills, also known as $21^{\text {st }}$ Century skills or "soft skills," are individual skills that include responsibility, integrity, flexibility, adaptability, global awareness and self-management, among others. Together, academic, technical, and employability skills create a career ready individual who has the skills necessary to compete in this ever changing, fast paced, technologically advanced global society we live in.

College and Career Readiness uses a multiple pathways approach to increase chances of completion as well as prepare students for their futures (Stone \& Lewis, 2012). This approach includes academic students, as well as the forgotten half. Multiple pathways is at the heart of the vocational education approach to education in which students can choose career pathways as early as $9^{\text {th }}$ grade to lead them into industry certifications, college credit attainment during high school, and two or four year colleges. Programs such POS, the basis for this dissertation, use a multiple pathways approach to high school education and beyond. The use of multiple pathways ensures that every student is given the education that fits his or her interests and abilities. The current college focused curriculum does not serve those students who are not planning to go to a 
four-year degree bearing school. Stone and Lewis (2012) present different approaches for utilizing multiple pathways.

Conley and McGaughy (2012) indicated the importance of creating this kind of culture in a secondary school. Mechanisms to create this culture include alignment of courses to college and career readiness standards; development of measurement and accountability standards to ensure implementation (which supports Perkins IV legislation); and finally, partnerships with business and industry that highlight the importance of labor market preparation across a variety of skill sets. Additional support from the Common Core State Standards Initiative on the College and Career Readiness framework introduces college and career ready student characteristics (Common Core State Standards Initiative, 2012). The characteristics include: "independence; strong content knowledge; response to the varying demands of audience, task, purpose, and discipline; comprehension, as well as ability to critique; value evidence; use technology and digital media strategically and capably; and an understanding of other perspectives and cultures" (p. 1). Those characteristics represent the efforts of a field that is trying to educate and prepare a new generation of workers for the good of individuals and the greater society.

CTE as a field has evolved and worked to integrate academic and vocational education to prepare all individuals for their futures. It was not always this way as the pre-WWI vocational education system developed out of a need to train individuals for the war effort, essentially separating academic and vocational education from the start. The frameworks that were discussed in this section evolved from over a century of legislation, changing needs of the country, and stigmatization. The next section outlines in detail a 
historical timeline of vocational education to further explain how the field evolved into what it is now, starting from the European influence through the current Perkins IV legislation.

\section{European Development and Influence}

The development of Europe's educational system, specifically its vocational education system, is highly relevant to understanding the development and current status of the American vocational education system. In the beginning of the $19^{\text {th }}$ Century, secondary schooling in Europe, specifically England, France and Germany, expanded at a fast rate. In particular to this educational expansion and of relevance to the purpose of this dissertation is the introduction of vocational course taking, as well as apprenticeship programs (Benavot, 1983).

Secondary schooling expanded during this time with the onset of an educational class system, as well as the changing needs and wants of citizens. Education was quickly divided by differentiation of class systems. Students' curriculums were extremely different, depending on their wealth and social status (Gordon, 2008). Academic subjects were taught to the elite citizens in hopes that they would go onto postsecondary school and become lawyers, theologians or doctors; modern subjects were taught to the middle class in hopes they would become managers and generalists; and vocational education subjects were taught to the lower class with the expectation that they would become manual laborers throughout Europe (Benavot, 1983). Three educational tracks emerged and are still relevant today, as they have influenced the development of the American educational system. In Europe, these tracks were: 1.) elite/traditional, 2.) modern/middle class and 3.) technical course/industrial schools for lower class. Stemming from these 
tracks, apprenticeship programs and vocational/industrial schools were developed to prepare the lower class for work through applied learning methods, also known as the beginning of vocational education (present day CTE).

The apprenticeship programs and developing vocational schools in Europe during the $19^{\text {th }}$ Century were informal compared to the formalized apprenticeship programs that first developed in the United States. Germany in particular had strong educative vocational programs for the lower classes (Gordon, 2008). Students in Germany attended primary school where they would receive traditional course work. After school, students went to work for a master craftsman in an apprenticeship where contextual and applied learning took place. Students would be placed in apprenticeships with a craftsman without much division of age, ability and without any certification or licensure at the culmination of their training. A speculated reason for not having certification or licensure during this time was the use of the class system, which did not permit the lower class to achieve middle class jobs through the control of skill development. However, as the need for more technological skills increased throughout the $19^{\text {th }}$ Century, the apprenticeship system, as well as the introduction of vocational schools, formalized.

The need for more skilled and educated workers was apparent as Europe faced the Industrial Revolution (Benavot, 1983). With influences from figures such as Jean Jacques Rousseau and Johann Heinrich Pestalozzi, vocational education throughout Europe was combined with academic curricula's and individual technical schools were developed (Gordon, 2008). The first "technical-vocational schools" were built in response to the need for more skilled workers through the educating and training of youth. Some of the first reported schools in Europe include Mechanic Institutes of 
England and Scotland, trade schools in Germany and Switzerland, and schools that specialized in commerce and industry in France (Goldin, 1999). These schools provided a combination of vocational education coursework and on the job training. These schools also subsequently provided the United States with vocational education frameworks such as formalized schooling and apprenticeship programs. It was during this time that the vocational education system became incorporated into public education schools in Europe and then the United States at the turn of the $20^{\text {th }}$ Century.

The United States initially borrowed many ideas about education from the frameworks already developed and implemented in Europe. Such ideas included the need for vocational education courses, the division of academic and vocational education, and the development of formalized vocational schools and apprenticeship programs. These influences did not happen in a vacuum, however. The United States tailored most educational frameworks to fit the needs of Americans and its society (Gordon, 2008, Hayward \& Benson, 1993). From the start, Europe's system included vocational education in its coursework, albeit not for everyone that was in school. The American educational system, however, put much more emphasis on academics than vocational education as it transformed from an agrarian to an industrial society (Goldin, 1999). The United States prided itself on education and at one point in the 1840s exceeded Germany in primary school enrollment and held the title of the most literate country in the world (Goldin, 1999). It was not until the turn of the $20^{\text {th }}$ Century did the need for vocational education become clear in the United States. This will be discussed in detail in the next section as the history of vocational education in the U.S is outlined. 


\section{Vocational Education in the U.S.}

The United States is a country that prides itself on the education of its citizens. Education in itself serves a multitude of factors for an individual, community and greater society (Goldin, 1999). In order to understand where vocational education is today, it is important to understand the evolution of the country's educational system, as well as how vocational education developed out of that system. A timeline of vocational education is presented that outlines federal legislation regarding vocational education, as well as enrollments and program demographics that align with the ongoing development of the field in the U.S. All federal legislation from the past have influenced the development and implementation of Perkins IV and, more specifically, the Programs of Study (POS) component that is the basis for this secondary analysis.

\section{Timeline.}

Pre-1917 Legislation and Development. Vocational education in United States started with apprenticeships and dates as far back as the Colonial times (Gordon, 2008). Apprenticeships were a means to educate individuals in the workplace and modeled much of the English Apprenticeship system under the English Statute of Artificers of 1562. Apprenticeships during this time were a main source of education for most lower class people as the American education system had not been developed yet. Both girls and boys were apprentices from around the ages of eight or nine and programs lasted about five to 10 years. The apprenticeship system was formalized in that there was a binding public apprenticeship contract that included the student's responsibilities, as well as what the student would be given. The apprenticeship contract included life supports such as food, clothing, and shelter, as well as educational supports such as religious studies, 
general education, techniques, and training (Goldin, 1999). In addition to the apprenticeship system, before the 1800's the government showed much interest in the vocational education of the country via Ordinances. The first pre-1917 legislation for education was the Ordinance of 1785, followed by the Northwest Ordinance of 1787 . Both of these ordinances expressed the need for the education of citizens. During this time, Congress was dividing up land into sections across settled parts of the U.S. Under these ordinances every $16^{\text {th }}$ section of a township was set aside for education (Gordon, 2008). This system of education was followed until around 1807, the start of the Industrial Revolution and the development of free public education.

Several events in the history of the United States prompted the Industrial Revolution. The Embargo Act, The Non-Intercourse Act and the War of 1812 all created the need for a more mass-produced, consumer oriented system (Gordon, 2008). The factory system was introduced to meet the needs of a consumer system, and the apprenticeship system declined. Free public education developed at this time as well (Gordon, 2008). The first half of the 1800's were marked with educational expansion; many of the first schools in the United States were developed (Goldin, 1999). From 1814 to 1835 , schools in Boston and New York were developed that centered on academic and vocational education for factory workers and practical studies. By 1833, there were over 1,000 schools. In 1835 the first engineering school, the Rensselaer School, was opened in New York.

The school system in the United States during this time focused on manual training, much like the apprenticeship system, but this system was academically focused and more formalized. The late 1800's were named the Manual Training Movement that 
helped students received education for the price of manual labor for their school (Gordon, 2008). The Manual Training Movement provided theoretical classes, production and mechanics, as well as engineering. This is an important movement to the development of vocational education in the United States, because this movement was the first introduction of curriculum development. During this movement, educators decided what material and content should be taught in public schools; this was influential in the development of further curriculums after the movement (Gordon, 2008). As the $19^{\text {th }}$ Century came to a close, the need for vocational education was only beginning.

Early 1900's. The beginning of the $20^{\text {th }}$ Century brought about concerns for a national approach to vocational education to meet changing times and the needs of a new nation for educated and trained workers. These factors set the stage for federal legislation that quickly followed. The major influences on the development of CTE in the United States during the early 1900's were factors surrounding multiple wars, study panels, and the Association for Career and Technical Education (Gordon, 2008). It also became clear at the beginning of the $20^{\text {th }}$ Century that many people were emigrating from Europe and many more children going to secondary schools (Hayward \& Benson, 1993). With more people available for education, and the need for a trained workforce, a more formalized approach to education, specifically vocational education, was on the brink of development.

During the early part of the 1900's most of the educational conversations were geared toward preparing workers for the needs that came with WWI. Much like the introduction of the factory system in the U.S. that answered the needs of the Industrial Revolution, the mass population of citizens in the United States needed new skills at a 
fast rate for the war. Once again, a new system was born (Gordon, 2008; Hayward \& Benson, 1993). The fast development of a system came about with the Federal Board of Vocational Education. The board was called upon by the War Department and the U.S. Shipping Board to train citizens in numerous combat activities, as well as practical and applied skills training in mechanics, radio operations, driving, engine technicians, etc. The Federal Board of Vocational Education devised and implemented an educational plan. By the end of the first World War, 62,161 people had been trained in those skills (Gordon, 2008).

As a result of the knowledge gained about education and the efforts put forth during WWI, the U.S. was more prepared in skill acquisition during World War II, the Korean War and the Vietnam War. These wars proved to be major influencers in Career and Technical Education for reasons similar to the needs of WWI. For instance, the training of women during those times was pertinent, as men were at war and women stayed home to take over industries. Also, there were new needs during those war efforts that expanded beyond the mechanical skill shortages that were seen before WWI. For example, there was a great need for training in food production. There were also rises in unemployment from veterans returning from war, so new programs and areas were created to help combat unemployment (Gordon, 2008). The war efforts during the 1990's spoke to the need for a skilled and trained workforce in a variety of disciplines that later impacted the CTE programs in secondary and postsecondary schools. The next influencing factor, study panels, did the very same thing, but from a research-oriented, federal perspective. This is discussed below. 
Besides war efforts that spoke to the skill need of a budding workforce, the early 1900's also brought about National Study Panels that prefaced much of the federal legislation before 1917. There were several national study panels that helped influence the development of vocational education in the early 1900's (Gordon, 2008). Of most importance were the National Association of Manufacturers, The Douglass Commissions of Massachusetts, the National Society for the Promotion of Industrial Education, and the Commission on National Aid to Vocational Education.

For the purposes of the development of vocational education, these panels, or councils as they were also called, were a structured support for the importance of vocational education in the United States. The National Association of Manufacturers issued a report in 1905 that outlined the decline of the apprenticeship system and the need for two separate systems, academic and vocational, to train workers through funding by public or private vendors (Gordon, 2008). The Douglass Commission of Massachusetts, also in 1905, criticized the manual training movement and introduced the idea of industry specific occupational training programs, as well as supported the notion of vocational public schools separate from academic high schools. This report also influenced the Smith-Hughes Act of 1917. In 1906, the National Society for the Promotion of Industrial Education brought a lot of public attention to the need and importance of vocational education through the dissemination of research studies on the field, as well as reported on the development of separate vocational school systems.

Perhaps the most important panel was the Commission on National Aid to Vocational Education, created in 1914 by President Woodrow Wilson (Gordon, 2008). This was the first group to examine what the needs of vocational education were from a 
funding standpoint. It is important to note that this council was developed three years before the Smith-Hughes Act of 1917, which was the first legislation to fund vocational education. Other panels were also created to help aid federal legislation that came about during the 1900's, such as the National Advisory Committee on Education and the National Advisory Council on Vocational Education. Each of these panels helped influence the Smith-Hughes Act of 1917 and the Vocational Education Act of 1963, respectively. The development of these panels essentially provided the nation with formalized coalitions that supported not only the need for vocational education, but the need for funding vocational education by the government. The Association for Career and Technical Education was another prominent influencer in the development and maintenance of vocational education that came about in the 1900's. It is discussed below.

The third and final early 1900 's influencing factor to the development and current status of CTE was the creation of the Association for Career and Technical Education (ACTE) (ACTE, 2013; Gordon, 2008). ACTE went through three iterations of names before landing on the Association for Career and Technical Education. The name changes in themselves have implications for the history and future of vocational education, not withstanding what the actual organization has done for the field. The name changes all sparked from the want and need to re-brand the organization to align with the changing of times from the early to late $20^{\text {th }}$ Century. In the early 1900 's, the organization was named the National Society for Vocational Education, much like the National Study Panels of that time. In 1925, the name was changed to the American Vocational Association; in 1998, it was changed to the Association for Career and Technical Education. This was the same year that the field itself changed from 
Vocational Education to Career and Technical Education. The change from 'vocational' to 'career and technical' was not just to rebrand, but also to reduce stigma. In the past, 'vocational' often meant, and to some degree still is today, described with synonyms such as lower skilled or non-college bound training (Gordon, 2008).

ACTE has had profound effects on the field of CTE; the organization continually seeks to keep the needs of the nation, the government, and its citizens in a healthy balance where CTE is at the forefront (ACTE, 2013). ACTE is the most relevant organization for the field and is comprised of scholars, educators, students and government officials. ACTE's current objectives include professional development, program improvement, policy development and marketing, all of which help to develop and sustain the field of career and technical education, a job well done since the early 1990's (ACTE, 2013).

Together, the war efforts, national study panels and ACTE have exercised a comprehensive influence on the field of CTE since the early 1900's. From skill shortages and acquisition, to support for the separation of academics and vocational education, to decreasing the stigma associated with vocationalism, the developmental evolution of CTE is clear. Stemming from war efforts where there was an urgent need to train many people in industries, national study panels that devoted countless years to the support for vocational education, and ACTE whose objectives led to the development of teachers, policies and programs, the development of the vocational system in the United States became mainstream. These three broad areas were the main influencers to the development of the vocational education system in the United States and still have merit to its current status, especially the agreement that a comprehensive vocational system was 
necessary for the success of Americans in the workforce, as well as the nation as a whole in the beginning of the $20^{\text {th }}$ Century.

Although there was agreement that there should be a system, there was no agreement on what kind of system should take place, and this had implications on how the system was set up. One of the most salient characteristics of the development of vocational education in the U.S. was that it was initially a function of local agencies and states (Hayward \& Benson, 1993). This one characteristic has set the stage for the entire system since its inception in the early 1900's. From the start, the field was developed out of a decentralized way of thinking with less emphasis on federal influences and more emphasis on the needs of individual states. This stream of thinking differed from vocational education programs in other nations that were developed through a more centralized route. It is often argued that the vocational education system in the U.S. was not a system at all, because of its decentralized structure and lack of federal input from the start (Hayward \& Benson, 1993). This created a wide variation in quality, size and diversity of vocational education programs, as most were a reflection of local and regional needs.

With a decentralized system of development, vocational education in the United States began without any unified standard or commonalities; each state was preparing Americans as it saw fit. Two implications readily seen from the decentralized structure of the vocational education system were the size and diversity with which states offered such programs (Hayward \& Benson, 1993). This system started with the first federal legislation on career and technical education. 
The Smith-Hughes Act of 1917 was enacted to better streamline the emergence of this new field in education and to better meet the needs of a nation in a more organized manner, with help from the government. What came from these changes were "comprehensive high schools" and the addition of vocational education programs within these schools as a means to train students in both academics and vocational education. However, most students took either an academic track or vocational track and the segregation of school systems was maintained (Hayward \& Benson, 1993). Three tracks developed in high schools: the academic track, the vocational track and the general education track. Those in the academic track were prepared for postsecondary education; those in the vocational track were prepared for the world and work; and those in the general education track were prepared for neither postsecondary education nor the world of work. The development of the Smith-Hughes Act, one of the driving forces for the development of CTE in the United States, is discussed below.

The Smith-Hughes Act of 1917. The Smith-Hughes Act of 1917 was the first vocational education act conceived by the Federal government. It was developed in reaction to the Industrial Revolution and WWI as a means of providing working class youth with industry skills (Lynch, 2000). Industry skills under this act included agriculture, homemaking and trade and industrial education (Gordon, 2008). As discussed above, the U.S. government always had an interest in vocational education. The Smith-Hughes Act was the first of its kind to provide funding for vocational education as the needs of the country changed from an emphasis on literacy to an emphasis on skills training. 
The Smith-Hughes Act accomplished two important things. The first was that it was a large stepping-stone for a unified system of vocational education in the United States. The federal government, under this act, provided funding to states strictly for vocational education. Similarly, the act clearly and purposely separated vocational education from academic education through the requirements that the act mandated (Gordon, 2008). It is believed that this act influenced the segregation of vocational education from academic curriculums in comprehensive high schools (Hayward \& Benson, 1993).

The mandates that segregated education for the United States under this act survived until the 1960's. Such requirements insisted that states developed Vocational Education Boards separate from general Boards of Education that are common today. Other requirements separated vocational teachers and students from academic teachers and students on the basis of courses, experiences and payment. The act could fund teachers with vocational teaching experience, but not academic teachers. As such, academic students could not be taught from vocational teachers, because there were strict rules regarding the ratio of students' academic learning, vocational learning and applied learning. This was known as the 50-25-25 rule. A vocational student, taught by a vocational teacher, would have 50\% applied learning (ex: shop work), 25\% content related work, and 25\% academic work. Vocational students were segregated by content areas, such as agriculture and homemaking. These separations had many implications for student outcomes as students were educated based on the track that they pursued. Gordon (2008) contends that the evidence of this act (the division of academic and vocational education) has been seen up until the present status of vocational education. The Smith- 
Hughes Act was a major influence in the current system of vocational education as it set the tone for the division of vocational and academic education that scholars, educators, and practitioners have been trying to lessen for decades.

Although the Smith-Hughes Act separated vocational education and academic education in a way that, perhaps in hindsight, was far too explicit, the act did set the path for funding, programs, increased enrollments and the future of vocational education. In 1917 , there were 200,000 vocational education students in the country with less than $\$ 3,000,000$ spent on their training. Within 40 years, there were 3.4 million vocational students with \$176 million dollars spent on their training (Hayward \& Benson, 1993).

From 1917 - 1963, before the enactment of the second major vocational education act, there were seven smaller acts that helped to shape and support vocational education (Gordon, 2008). During these times, there were many changes that the United States went through including World War I, unemployment problems throughout the 1930's, the Great Depression and World War II. These acts essentially either increased federal funding for vocational education or introduced new fields and programs for the changing needs of the U.S. after the Great Depression and WWII. The George Reed Act of 1929 increased funding to $\$ 1,000,000$ for four years for vocational education specifically for agriculture and homemaking. The George Deen Act of 1936 introduced marketing and the development of teacher education programs, along with authorizing an annual \$14 million of funding for vocational education. With such funding, a new educational system emerged in the 1930's. "Junior colleges," which are now community colleges, were developed to provide vocational education courses outside of secondary schools for other populations. Junior colleges and training programs were vital resources for the thousands 
of returning veterans that needed services, education and employment after WWII (Gordon, 2008). Vocational education was at the forefront of federal funding for many reasons: the need for skilled workers, support for returning veterans and to stay globally competitive.

As the United States hit the halfway mark of the $20^{\text {th }}$ Century, the vocational education system went through a transition from an industry supporting the war effort, to growth of junior colleges and adult education. There were new perspectives about training, experience and work throughout one's education. There were new technologies and new industries that came out of those fronts, such as the emergence of healthcare occupations (Gordon, 2008; Hayward \& Benson, 1993). Other acts throughout the 1950's and 1960's served opened new doors for vocational education and education in general in response to global competitiveness and national needs. Amendments to acts such as the George Barden Act of 1946 that raised funding for vocational education turned into Title II, Vocational Education in Practical Nursing, as well as Title VIII, which supported technical training programs. The National Defense Education Act of 1958 was introduced in response to the Soviet Union's launch of Sputnik I. It was the first of its kind to relay the importance of and give funding to the sciences, mathematics, foreign language and technical competencies. It was also the first act to give federal funding to all educational pursuits, not just vocational education (Gordon, 2008). Another act, the Manpower Development Training Act of 1962, was unlike any other act during this time in that it focused on the training and retraining of disadvantaged populations, such as the unemployed, underemployed and unskilled workers both in training programs and out of trainings programs. This act had many implications for the 
current acts in vocational education that serve all populations of people, especially the disadvantaged.

Benavot (1983) reported vocational education student enrollments over a 30-year period from 1950 through 1975. In 1950, vocational-technical students made up 25\% of secondary school enrollment. In 1965 that dropped to $19.2 \%$, and in 1975 the national averaged dropped even more to $17 \%$. Enrollment was either maintained or steadily dropped during the 1980 's up to the mid 90 's, both nationally and internationally, even though vocational-technical school offerings were on the rise. There were technological advances during this time, but also huge gaps between classes in the United States, especially in areas of economic depression. To help combat this, Congress enacted the Manpower Development and Training Act of 1961 (MDTA), as well as the Vocational Education Act of 1963 (VEA). The latter will be discussed in the next section.

The Vocational Education Act of 1963. The Vocational Education Act of 1963 was the second most influential act in the development and influence of vocational education (Gordon, 2008). The Vocational Education Act of 1963 increased federal influence over how funds were allocated for vocational education. The Smith-Hughes Act and ones that followed essentially "funded" vocational education, but without a systematic means of usage, allotment or division. The Vocational Education Act developed a system for funding allotments called "set asides." Under these set asides, the government mandated that each state use $25 \%$ of their funds for either or both training for high school drop outs/completers and for vocational school development. Another set aside were for "experimental programs" that could meet the needs of disadvantaged communities. 
The Vocational Education Act of 1963 had a two level goal. The first was an organizational/educational goal to maintain the existing state of vocational education, as well as expand and improve it in many ways for the benefit of the economy and the country. The second was on an individual level in that this was the first act where student's needs were targeted (Gordon, 2008). The act essentially mandated that all individuals, of all ages and in all communities, could receive vocational training and/or retraining, depending upon their needs, abilities and skills. The 1960's brought about many changes for the United States, which affected vocational education, as well as general and academic education. Such influencers were the Civil Rights Acts of 1964 and 1972, and President Johnson's "War on Poverty." These influences impacted acts such as the 1963 Vocational Education Act, which responded to the unemployment needs of the time (Carter, 1998). Vocational education adopted programs that met the needs of all individuals as a means to support disadvantaged populations. In so doing vocational education came under increased scrutiny and stigma. The field became known for educating the "...most difficult to educate youth of the country" (Carter, 1998, p. 18). The majority of people that had been discriminated against in the U.S. sought educational and social refuge in vocational education as a means of equality and life improvement, one of the goals of the act. The act targeted youth, as well as disadvantaged populations and helped employ youth part-time (as long as they were full time students). Programs were set up for youth who were disadvantaged socially, economically or academically. The repercussions of this enlightening and progressive move painted a dull picture for the field compared to academic education, however. 
From a policy standpoint, federal influence over funding allotment and targeted programs/populations increased heavily from the original Vocational Education Act of 1963 through two Amendments of the act in 1968 and 1976 (Gordon, 2008). Under these Amendments, all other previous acts, except the Smith-Hughes Act, were rescinded. Issues at the forefront of the amendments included an approach to bring vocational and academic education closer together and increased funding for research and training, cooperative education, and work study's (Gordon, 2008). Another important implication of the amendments included expansion of vocational education to include postsecondary training. With the inclusion of postsecondary education, a pertinent issue that came up was the duplicative manner through which some students received their education within secondary and community colleges. These are still relevant discussions today (Hayward \& Benson, 1993).

During this time, states became accountable for the government money that they used. This was the first time that states had to create plans for evaluation and measurement of their programs and projects for the government. Data collection on achievement, skill increases, employment preparation and program completion were used as valid indicators of program success, much like today (Gordon, 2008). The amendments also introduced the National Assessment of Vocational Education (NAVE) conducted by the National Institute of Education, now the Office of Educational Research and Improvement. This assessment was conducted at the end of every five year funding cycle to examine if states were complying with federal regulations on the "set-asides," as well as their implementation of vocational education (Gordon, 2008). 
Both the Smith-Hughes Act of 1917 and the Vocational Education Act of 1963 were major influences to the present day policies that operate the field of CTE. The Smith-Hughes Act was the first federal legislation that gave funding specifically for vocational education to meet the needs of a growing industrial country, as well as provide mass skills training for war efforts. The Smith-Hughes Act also divided academic and vocational education and increased enrollments and programs over an impressive 40 -year period. The Vocational Education Act of 1963 maintained the importance of funding, but increased the government's influence on how the funding was used. This act broadened the influence of state government, private industry and the federal government's role in training programs for vocational education. It targeted youth and disadvantaged populations, which increased the stigma of vocational education, and implemented the first accountability measures for the field. Stemming from these two policies, the third most influential and present day policy through which the field operates (although it its fourth iteration) was developed.

This policy, the Carl D. Perkins Act of 1984, was a direct response to the NAVE assessments described above. The results of the NAVE assessments suggested that states were not complying with how the government mandated the funds to be distributed. NAVE also pointed to poor overall program implementation, especially for disadvantaged youth (Gordon, 2008). Three lessons surfaced from analysis and evaluation of the NAVE assessments. These lessons directly influenced the development of the Perkins Act of 1984 and subsequently affected the status of vocational education today.

1. The legislation was written unclearly and at times contradicted itself; 
2. The funds given were too small to achieve the goals and objectives sought in the legislation; and

3. The programs for disadvantaged youth were not helping youth to succeed. Instead, they were being used as a tracking process into dead-end careers to make room for more mainstream students in better careers (Gordon, 2008).

The lessons learned from the NAVE assessments, as well as the changing times of vocational education and education in general in the United States, prompted an entire movement of educational reform. The NAVE assessments not only called for another vocational policy, but also opened up conversations about how students were being prepared in high school and what else could be done for better results. Before discussing the first Perkins Act, it is important to explain the basis for the reform efforts of the 1980's and how they shaped the Perkins Act.

The Need for Reform. The Smith-Hughes Act of 1917 and the Vocational Education Act of 1963 were two of the most influential acts in vocational education until this point in time. The NAVE assessments, as mentioned, insisted on a better vocational policy to combat the issues raised in the assessments. What the NAVE assessments also did was raise other questions about vocational education and education in general in the United States. The Carl D. Perkins Act of 1984 arose out of the NAVE assessment results, but there were many other factors that influenced the need for vocational policy reform during the mid-1980's into the 1990's. When NAVE assessment results indicated that policy outcomes were not as hoped, several other reports came out that explained the failure of educational policies from student achievement and global competitiveness 
perspectives. The reports were sparked by a major decrease in enrollment and achievement outcomes in vocational education in the United States. During this time, enrollments decreased in almost every secondary school environment (Benavot, 1983). One of the reasons for the decrease in enrollments included the stigma about vocational education. The stigma was that vocational education was just for disadvantaged youth, which was an implication of how the government responded to the Civil Rights movement discussed in the previous section. Another reason for decreased enrollment was that students either chose an academic track or vocational track, so programs essentially competed against each other (Lynch, 2000). Finally, one of the biggest reasons for the drop in enrollment for vocational education programs was that secondary education in general was not preparing students or meeting their needs. Evidence that high school education, both academic and vocational, was not preparing students for the skills needed in a changing global economy came from employer reports that high school graduates lacked necessary skills to enter the workforce. More evidence suggested that American students were performing low on achievement tests, compared to each other and international students (Gordon, 2008).

One of the most influential reports to suggest this kind of evidence and prompt serious school reform efforts was A Nation at Risk produced in 1983 by the National Commission on Excellence in Education (Carter, 1998; Hayward \& Benson, 1993; National Commission on Excellence in Education, 1983). The report blamed the American secondary system for setting low standards and expectations that resulted in poor academic performance and directly linked those issues to why the U.S. was not as competitive in a global market (Gordon, 2008). It explained that current reform efforts 
resulted in little change compared to other countries (Hayward \& Benson, 1993). As a result of this report, a standards-based education reform movement developed in the United States. The focus of education policy shifted from school inputs to student outcomes, and from minimum competency to high proficiency standards (Dyer et al., 2006; Lee \& Wong, 2004).

The first reform movement was academically directed and called for an increase in standards and expectations for high schools, teachers and students, including more course requirements, changes to college entrance requirements and longer schools days and years. In the mid 1980's, another reform movement began that was based on a restructure of the system, mostly in part because it was believed the first academic reform movement did not go far enough. This second movement brought about major changes that are still seen today (Gordon, 2008). At the state level, there was a focus on graduation requirements, curriculums focusing on college prep, testing and teacher professional development. At the local level, standards for attendance and graduation increased, as well as homework requirements. Up until the 1990's, vocational education was not a part of school-wide reform efforts, primarily because of the separation between vocational education programs and the greater school/community programs (Hayward \& Benson, 1993). During the 1990's and into the $21^{\text {st }}$ Century, however, school-wide reform efforts took two paths: an academic "College for All" pathway, and a more vocational multiple pathway approach of which the current Perkins IV legislation espoused. The first Perkins Act was enacted in 1984 and will be discussed briefly below.

The Carl D. Perkins Vocational Education Act. Congress developed the Carl D. Perkins Vocational Education Act of 1984 in response to the NAVE findings and 
replaced the Vocational Education Act of 1963, as well as the Amendments of 1968 and 1976 (Gordon, 2008; Hayward \& Benson, 1993). The two major goals of the Perkins Act were economic and social (Gordon, 2008). The goals included improving existing and developing new vocational education programs, as well as ensuring that those who were disadvantaged had access to quality vocational programs. From an economic standpoint, the policy aimed at increasing the skills, productivity and economic growth of the current workforce, as well as providing the same services for a new generation of workers. From a societal standpoint, the policy intended to raise the skills and productivity of the individual workforce in the United States. Populations included in this goal were mainstream individuals, those incarcerated, disadvantaged, disabled, single parents/homemakers, and English language learners, among others (Gordon, 2008).

Continued Reform. The inclusion of vocational education in school-wide reform efforts meant bridging the gap between academic and vocational education, as well as a new approach to preparing youth for life after high school. It became pertinent to discuss other skills that students needed to be successful in the workplace. It was evident that academic skills were not necessarily sufficient, as employers were continuously reporting that students were ill prepared (Carter, 1998). Reform discussions appeared to shift from achievement to an overall general competence perspective that students needed to be successful.

Reports such as America's Choice: High Skills or Low Wages, the Hudson Report's Workforce 2000, and the SCANS reports all highlighted other skill sets that were important, such as job skills, interpersonal skills, workforce behaviors and employability skills, in addition to academic and vocational skills (Gordon, 2008; 
Hayward \& Benson, 1993). In particular, Workforce 2000 was one of the first publications to discuss the importance of "cross pollination" of high school and labor market course work (Carter, 1998). It highlighted the skills gap that employers were reporting and suggested that secondary education was not teaching students what they needed to know for the workforce, but instead preparing students for postsecondary education. Regarding college, Workforce 2000 was the first to highlight that a college degree did not immediately mean success as most thought it did. Instead, other important skills were necessary to the success of students, such as employability skills that included flexibility and adaptability, among others (Carter, 1998). The SCANS report: What Work Requires of Schools, from the U.S. Department of Labor, was also influential in school reform efforts to raise multiple skill set standards. This report supported reform efforts aimed at preparing secondary students for the $21^{\text {st }}$ Century. It highlighted that students should be prepared to go on to postsecondary education, as well as the workforce. Giving students this kind of preparation would help them to become more competitive as the United States moved deeper into the technology age (Carter, 1998).

One prominent figure in vocational school reform efforts in the early 1990's was Dale Parnell (Parnell, 1986). He created the idea of "Tech-Prep," a term adopted by the second iteration of the Carl D. Perkins Act of 1990. He is most known for his 1986 book The Neglected Majority, as well as the creator of the " $2+2$ Tech-Prep/Associate Degree" model of secondary and postsecondary course taking programs, one of the very first multiple pathway approaches to education (Parnell, 1986). Parnell, in his book The Neglected Majority, outlined a need for more linkages from high school to college, specifically the first two years of college, because there was a majority of students who 
were successful in completing high school but did not earn a Bachelor's degree from a four-year institution. Parnell provided examples of barriers within the education system that limited students' abilities to move along a steady path in secondary school and succeed in industry. Linking the last two years of high school and the first two years of college through articulation agreements enables schools and students to develop and sustain a pathway approach to graduation specific to that student. In a school that offers tech prep, students chose a vocational program in the junior year of high school after taking two years of both academics and vocational education. Choosing a program allows the student to graduate high school and immediately go into postsecondary training in that field of study. The program's outcome included a two-year associate degree or certificate in STEM related fields, practical art of trade, agriculture, health or business. The main objective was to build academic and vocational knowledge and skills that led to employment (Gordon, 2008).

\section{Carl D. Perkins Vocational and Applied Technology Education Act. Several} events prompted a second iteration of the Carl D. Perkins Vocational Education Act of 1984. From a policy standpoint, the results of the second NAVE assessment, which was an evaluation of the first Perkins Act, were not as positive as originally expected. This was again due to states' noncompliance with implementation, as well as poor evaluations of accountability (Gordon, 2008). Through reports such as A Nation at Risk, Workforce 2000, and the SCANS report, it was clear that school reform was of relevance and importance beyond what the first Perkins Act could offer. Dale Parnell and his vision of Tech-Prep gathered enthusiasm, as well as a promising method of school reform to prepare students for the $21^{\text {st }}$ Century with academic, vocational, and employability skills, 
which were topics of interest going into the next millennium. With those influences, Congress passed the Carl D. Perkins Vocational and Applied Technology Act in 1990, also named Perkins II.

Not only did Perkins II replace the first Perkins Act, but the name change also symbolized governmental support for the need and importance of academic and vocational education from both individual and society perspectives (Gordon, 2008). Perkins II represented a significant shift in federal policies regarding funding of vocational education (Hayward \& Benson, 1993). Perkins II's purpose was twofold: 1.) to increase both academic and occupational skills sets of individuals and 2.) to include all populations of people in the United States (Gordon, 2008; Hayward \& Benson, 1993). The message that Perkins II sent to the United States, as well as other countries, was that in order to become and maintain global competitiveness, every single citizen needed preparation both academically and occupationally. Funds were put into one stream of accountability, which helped to decrease the stigma about "special populations" or "disadvantaged youth." Perkins II set out with three major components that have influenced the field vocational education to this day. The components were:

1.) The integration of academic and vocational education;

2.) Tech Prep; and

3.) Bridging the gap between school and work (Hayward \& Benson, 1993).

These components aligned with school reform efforts that centered on preparing students for the future, whether through postsecondary education and/or the workforce. Perkins II was the first legislation to allocate funding directly to the integration of academic and vocational education as a means to highlight the importance of a unified 
field of education, much like the College and Career Readiness framework suggests. The integration of academic and vocational education painted a picture of secondary and postsecondary students who were highly skilled in both academic and vocational education, as well as had employability skills that enabled them to work in high performance work systems.

The second component, Tech Prep, placed emphasis on the linkage between secondary and postsecondary programs. With curriculum integration, as well as articulation agreements between secondary and postsecondary programs, students were able to streamline their individual program options to fit their needs. Benefits of Tech Prep for students included non-duplicative course sequences, better preparation, efficiency, and the ability to earn college credit in high school (Parnell, 1986). One of the main benefits for secondary schools was reduced drop out rates. This was the first time that studies showed that vocational education programs increased both achievement and engagement in school settings (Hayward \& Benson, 1993; Parnell, 1986). Students in Tech Prep could make clear connections between what they were learning in class and how it would be applied to their field experience and jobs. They could complete relevant coursework in high school that would directly apply to their postsecondary training or towards an industry certification. Tech Prep introduced the use of multiple pathways for student success, which directly influenced the development of Perkins IV and the Programs of Study approach examined in this dissertation. Another main focus of Perkins II was the connection between school and work. This was supported by the integration of academic and vocational education, as well as the introduction of Tech Prep programs. The school to work connection is similar to youth based apprenticeship, 
cooperative education models and other school-based enterprise programs (Hayward \& Benson, 1993).

Accountability was also more stringently focused on, as the previous two NAVE assessments fell short of evaluation expectations. Perkins II included many more accountability measures (Gordon, 2008). Student outcomes became a measure of accountability. For the first time, states were mandated to develop measureable performance and accountability standards for secondary and postsecondary education. Examples of performance measures included student achievement, occupational competencies, employment skills, and placement in further education, military and/or employment. Further funding opportunities for states were dependent on Tech Prep implementation and student successes within the programs. Measures such as employment placements, transfers to four-year institutions, and business and industry partnerships were used as measures of accountability. All of the accountability measures were aligned with the three goals and objectives of the legislation. This was key to the success of the programs.

The accountability measures worked for Perkins II and the school reform efforts that it highlighted, as program availability and enrollment increased throughout the 1990's. Hayward \& Benson (1993) reported that vocational education was offered in 33,500 public and private institutions during this time, which was a major increase from the drop in vocational education enrollment in the 1980's. Secondary school programs and enrollments, as well as public and private school enrollments, increased during this time as programs developed in most educational institutions. A brief breakdown of program participation includes: 11,335 comprehensive high schools, 225 vocational high 
schools, 1,395 area vocational centers, 720 degree-granting community colleges, 162 technical institutes, 504 postsecondary area vocational schools, 308 postsecondary schools, 70 postsecondary schools for disadvantaged youth, 7,400 proprietary schools, 2,400 of them postsecondary institutions.

Stemming from the third component of Perkins II, the school to work movement, the U.S. Department of Education and the U.S. Department of Labor under the Clinton administration, created the School to Work Opportunities Act (STWOA) in 1994. The STWOA emphasized a training system within and outside educational institutions with the goal of preparing all individuals for career, colleges, and importantly, citizenship. This was mainly achieved through business and industry partnerships with education (Gordon, 2008; Hayward \& Benson, 1993). Following Perkins II, the STWOA sought to provide experiences to students so that they would increase their skills, knowledge, and abilities, and come out of high school as a competitive and prepared workers. It also emphasized the importance of transitioning from high school to the workforce, a new insight offered by this legislation. Major components of the act included business and industry partnerships, curriculum integration, technology, flexible workers, career counseling, and work-based learning (Gordon, 2008). The STWOA has been influential to present vocational education policies, because of the ways in which it emphasized teacher team collaborations, introduced the portfolio method of assessment, and perhaps most relevant to this dissertation, did away with the "tracking system" of students and introduced the term "career pathways." Almost 20 years later, career pathways are the best practice for vocational education as it provides students with clear course sequences in both secondary and postsecondary education that directly align with their career goals 
and industry certification needs. In the current Perkins legislation, career pathways take the form of Programs of Study. The impact of a career pathways approach to secondary and postsecondary/industry education and training on student outcomes is the main question this dissertation examines using the RTPOS data set.

The STWOA created a new career pathways framework that the U.S. Department of Education, OVAE, the National School to Work Office, and the National Skills Standards Board adopted and further developed in 1996. It was named the Career Clusters Initiative (Gordon, 2008). Career Clusters are used today as the major operating framework for vocational programs and career pathways participation as it gives a comprehensive and adaptable system for grouping and linking programs, schools, and business and industry partnerships. The developers of the Career Cluster's framework envisioned a national and widespread career pathways initiative to better streamline the educative path students were on during and after secondary school (Gordon, 2008). The creation of links between secondary and postsecondary education, as well as education and industry, supports the importance of preparation of students in both academic and occupational skills. It also emphasized the importance of transitioning into different roles throughout a student's educational and occupational experiences, much like the STWOA.

There are 16 Career Clusters within the National Career Clusters Framework. These clusters are aligned and represent 79 Career Pathways, as well as over 1,800 career specialties that stem out of the career pathways (NASDCTEC, 2013; Gordon, 2008). The clusters are: agriculture, food, and natural resources; architecture and construction; arts, audio/video technology, and communications; business, management, and administration; education and training; finance; government and public administration; health science; 
hospitality and tourism; human services; information technology; law, public safety, and security; manufacturing; marketing, sales, and service; science technology, engineering, and mathematics' transportation, distribution, and logistics.

According to ACTE (2007), since its inception, the Career Clusters Initiative has been successfully used and shared amongst all stakeholders. By providing a roadmap through curriculum integration and design, the career clusters and career pathways model of vocational education prepares students both academically and occupationally and has positive student outcomes on academic achievement, career preparation, successful transitions. It also provides a framework for assessments and accountability measures. On a local and state level, the Career Cluster framework offers state-by-state implementation to better meet the needs of individual states regarding which career clusters are adopted. The Career Cluster framework has influenced further federal legislation and policies regarding vocational education in the United States.

With the continuous evolution of vocational education as seen from the timeline approach in this literature review, it is not surprising that another iteration of the Perkins Act was needed after Perkins II, the STWOA, and the introduction of the Career Clusters Initiative. As time progressed with Perkins II, major flaws were seen that impinged on its successful implementation (Gordon, 2008). First, the system was still segregated and the need for integration was absolutely necessary for the legislation to be successful (Hayward \& Benson, 1993). Other flaws included a lack of cohesiveness between funding and purpose (much like in the Vocational Education Act of 1963); micromanagement by Congress within training and development; and the legislation of learning and teaching (Swanson, 1991). Many of the positive aspects of Perkins II were 
taken into Perkins III, such as the integration of academic and vocational education, Tech Prep, and the emphasis placed on school to work, however, the methods to achieve those goals were reworked for Perkins III.

Carl D. Perkins Vocational and Technical Education Act. In 1998 Congress enacted the Carl D. Perkins Vocational and Technical Education Act, or Perkins III. As mentioned in the previous section, Perkins III held much the same funding structure and core components of Perkins II (Gordon, 2008). Perkins III's additional objectives included increased technology within vocational programs, the use of benchmark assessments, and professional development programs (Carter, 1998). Another factor within Perkins III included an increase in state leadership roles and responsibilities, which marked a change from the micromanagement seen from Congress in Perkins II. Activities that state leaders needed to accomplish surrounded professional development programs, special population programs, and assessments. New accountability core indicators of performance were also added for Perkins III for both student outcomes and state plan implementation (Gordon, 2008).

The timing of Perkins III also marked a major shift in the field of vocational education as reform efforts and subsequent reports pointed to a new and improved version of the field. One influential report was the Hudson Report's Workforce 2020, an update from Workforce 2000 that helped prompt the school wide reform efforts in the 1980's (Carter, 1998). Workforce 2020 put most of its focus on the need for technological skills and advances for the United States during the turn of the century to stay competitive in a global economy. This report discussed the changing demographics of the current and future workforce, as baby boomers were getting older. Another 
important topic was the growth and prosperity of developing nations, another global factor, and what that could mean for the United States.

From reports and reflections on the evolution of vocational education, it became clear that the mission of the field had changed. In 1998 the definition of vocational education was changed. The old definition provided by the federal government defined it as, “...preparation for employment in positions requiring less than the baccalaureate degree" (Hayward \& Benson, 1993, p. 9). The National Center for Research in Vocational Education re-defined the mission of vocational education as a field that “...prepares all individuals for lasting and rewarding employment and lifelong learning" (Carter, 1998, p. 57). From preparation for non-college bound students to a field that prepared all individuals for life-long learning, the evolution of vocational education was clear and meaningful.

It was not just the definition and mission that changed in 1998. As a means to represent the changing workforce as well as an evolving field of vocational education, the field was renamed Career and Technical Education (CTE). In 1998 the American Vocational Association (AVA) became the Association for Career and Technical Education (ACTE) as mentioned in previous sections, and many other entities within the field espoused the change for themselves. These new changes represented the belief that students should be prepared for education and employment at the same time (Lynch, 2000). Examples of this belief in action included the development of new curricula's that used industry standards, high academic standards, and technical and general employment competencies. At the end of the 20 Century, the field of Career and Technical Education was that of high standards both for academics and industry. 
The $21^{\text {st }}$ Century $\boldsymbol{C T E}$. The turn of the century marked a new and improved Career and Technical Education (CTE) that was bursting with ideas of how to best prepare students for their future endeavors. In the early 2000's, CTE was offered in $93 \%$ of comprehensive high schools in the United States (Lynch, 2000). Types of programs offered in these comprehensive high schools mostly covered general labor market preparation classes that included computers and family and consumer sciences. About $75 \%$ of comprehensive high schools offered a variety of CTE programs such as agriculture, business, marketing, health, and communications. There were also about 1,000 other CTE high schools aside from comprehensive high schools (Gordon, 2008). At the turn of century there were more programs added to include new CTE subjects such as public and protective services, childcare and education, food service, hospitality, and technology and communications (Levesque et al., 2000).

College for All. With an increase in CTE across the nation, and support for a more expanded curriculum that was contextually integrated, their came to exist two paths for workforce preparation. One pathway consisted of the "College for all" framework that will be discussed through the context of the legislation No Child Left Behind. This pathway was not necessarily aligned with CTE and lacked a career readiness focus but it is still of relevance to the evolution of CTE and education in general. The other framework which is directly related to this dissertation is the College and Career Readiness Framework that is supported throughout this literature review as it reflects the current status of the field with support from Perkins IV and other educators and reformers. The latter framework and legislation will be discussed following College for All. 
Throughout the 1990's and into the new millennium there were always reformers and educators that did not support CTE and the importance placed on occupational and employability skills. Academics insisted that a College for All framework was necessary and sufficient to prepare students for their futures, with the main premise that if students were prepared for college than students would be prepared for careers. Supporters of this framework essentially believed that college and career readiness were the same sets of skills, knowledge, abilities, and mindsets. On the contrary, there was and is countless evidence that says otherwise which is supported by the College and Career Readiness Framework (Stone \& Lewis, 2012). Two major components were the basis of the College for All Framework: 1.) the mission and purpose of secondary education was to prepare students for postsecondary education and 2.) every secondary student should go to college. Curricula's designed in a purely academic manner were supported within this framework, much like the curricula's designed in the early 1900's that did not support CTE.

The College for All framework essentially held certain assumptions about students and their learning habits that eventually led to the downfall of the framework. The first assumption was that every student should and does go to college. Evidence suggests that more than half of $9^{\text {th }}$ grade students will not complete a four-year degree (Stone \& Lewis, 2012). Students may not go on to college for many reasons that were outlined in previous sections that have to do with finances, careers interests, and skill sets. The second assumption the College for All framework espoused was that every student learns the same way, as evidence by their academic curriculum. As field of education, most people know and understand that this claim in untrue. The framework 
did not take into account individual differences between students (Stone \& Lewis, 2012), which is a stark difference between this framework and CTE frameworks. The other assumption was that college and career readiness were the same, which we also know not to be true.

The College for All framework supported an academic curriculum for secondary students as the best method to prepare them for the future. The strictly academic nature of College for All had many implications for the stigma of CTE. Rosenbaum, in his book Beyond College for All, argued three distinct misinterpretations that come from the assumptions of College for All (2001). The first misconception was about the Bachelor's degree. First, the College for All framework implied that getting a Bachelor's degrees equaled economic success. That is no longer the case. Second, the framework did not take into account differences in degree or program areas. Certain degree areas have more promise of economic success, but they are generally harder degrees to attain. The second misconception was that college is accessible for every student. Postsecondary education is costly and time consuming. Depending on a person's resources, a 4-year institution may not be a person's best bet for future success and actually may become a hindrance. The third misconception was the cultivation of stigma-free remediation. Rosenbaum contended that the United States postsecondary system actually accepts more students than they should. When a student is accepted to go to college who may not actually be prepared for postsecondary coursework, they are often placed in remedial classes in order to catch up on material. Remedial classes have become a go-to answer for many postsecondary institutions that find themselves filled with students who are not prepared for college (Rosenbaum, 2001). Many of these 
students also don't wind up finishing college, perhaps because they were not supposed to be there in the first place.

Along with the College for All framework, a major school reform legislation was enacted in 2001 that made a promise that every children would be proficient in math and reading by 2014. No Child Left Behind (NCLB) replaced the Elementary and Secondary Education Act and was enacted under President George W. Bush (Gordon, 2008). The major goal of the legislation was that a student in any school system would not be "left behind" because the school they were attending was a failing school that created an environment full of failing students, essentially trapping the students for failure. A failing school meant that the students were not being prepared with the skills they needed to succeed in higher grades and into their careers, mostly because the schools were not proficient enough to be teaching certain subjects or standards. Two major components of NCLB that were set in place to remedy failing school situations were accountability and choice.

Accountability became the focal point within this policy. It became the means of comparison across schools and the mechanism through which the second component of choice could be carried out. The accountability component of NCLB required states to develop proficiency plans for grades 3-8 that outlined how the states were going to reach a level of proficiency and be considered a good school (Ravitch, 2010). The plans were called Adequate Yearly Progress (AYP) and became the baseline measure for successful and failing schools through their outline of standards and objective that aligned with state proficiency. The AYP made it possible for NCLB to put major emphasis on improving students' achievement in the core academic areas of mathematics, science, language arts, 
and social studies (Dyer et al., 2006). Standardized testing became the main source of school quality across the nation (Ravitch, 2010) as student's achievement scores were direct reflections of how well schools implemented their AYP. Under this assumption, student's achievement on test scores were the best measure of not only school performance, but also of student, teacher and principal quality. These results went into the AYP and were reported to the state where parents and students could access that material. This made it possible for parents and students to easily see which schools were successful and which schools were failing based on comparative standardized testing scores as well as AYP proficiency plans. Taking it a step further, not only were local agencies mandated to report on successful and failing schools, they also reported on which schools had violence or drugs within the system (Ravitch, 2010). The accountability measures of NCLB were a means for educators, parents, students, and states to have access and gain knowledge about the school systems in their states and make informed decisions regarding that particular school system and the children that were sent to them.

The second component, choice, came directly from the reports of the AYP to the states and the dissemination of the information to parents and students within those states. As parents and students had access to information about successful, failing, and potentially unsafe schools and environments, they were able to make educated decisions on their children's education. After parents received the state reports, the legislation allowed parents the option to change and transfer schools if the school their child was attending was a failing school or an unsafe school. As part of the state report it was mandated that the report gave options for students for better schools as well as 
transportation to those schools (Ravitch, 2010). While attending a failing school, local agencies were mandated to allow students to get supplemental education activities that met educational standards, all coming from allocated funds (Gordon, 2008). NCLB was meant to help parents and students attain the education that would help propel the student into secondary school and beyond through accountability and choice. It was the first legislation to put the parents in the drivers seat instead of the system, and called for more involvement of all stakeholders to better the educational system as well as help students in need. NCLB was supported by a huge system of educators, policymakers and reformers for these reasons. However, there were several problems that rested in the actual implementation of NCLB that did not surface until a couple years after its implementation. These issues will be discussed below.

The problems that ensued after NCLB was enacted turned known advocates of the act into opposing forces that relinquished their support. One of these people was Diane Ravitch. She is a strong example of a valuable supporter of the idea's of NCLB who then withdrew support. She wrote about the flaws of NCLB in the American education system in her book The death and life of the great American education system: how testing and choice are undermining education (2010). Briefly, Ravitch was the former assistant secretary of education, published author of countless journals and books, a curriculum designer, has witnessed several presidential administrations where she was invited to the White House on many occasions as a consultant, and calls herself a historian of education, among many other roles she has played.

Speaking specifically about NCLB, Ravitch writes in her book, "Where once I had been hopeful, even enthusiastic, about the potential benefits of testing, 
accountability, choices, and markets, I now found myself experiencing profound doubts about these same ideas" (Ravitch, 2010, p. 1). One of the reasons she changed her mind about NCLB was because of what she witnessed when the law became reality. Ravitch argues that NCLB did not work for several reasons. As time progressed it became clear that an accountability system based off of testing (not learning) was not working and never going to work. She described a system that was supposed to be based off of standards and accountability, but instead was based off of achievement scores on standardized tests. Furthermore the tests that were put in place were not created by educators but by politicians who went beyond their scope of practice. The achievement tests, therefore, could not possibly align with what the students were learning and what the students needed to learn to be better educated, which was the point of the legislation. The main downfall of NCLB, according to Ravitch, was that it did not follow any kind of curricular or standards-based system. Ravitch recalled A Nation at Risk for its two important reforms efforts: to increase achievement and competitiveness of students and the greater workforce, and comprehensive curriculum standards with more time for "learning." These two reform ideas were not included in NCLB (Ravitch, 2010).

Other more specific issues that Ravitch had with NCLB was the competitiveness that came from schools being showcased in the AYP reports to the states (Ravitch, 2010). Schools were essentially pitted against each other and often schools were punished for not performing at proficient levels. Ravitch wrote, "NCLB was a punitive law based on erroneous assumptions about how to improve schools" (Ravitch, 2010, p. 110). There were great ideas within NCLB but the implementation of it sporadically worked. For instance, the legislation assumed that given choice, parents would transfer their children 
from a failing school to a successful school. Most of the time, however, this did not happen. Furthermore, more assumptions of NCLB indicated that all students would be proficient in math and reading by 2014. According to Ravitch, this painted a negative and "pie in the sky" picture of proficiency for the United States. Ravitch lost all support for NCLB in 2006, she reported, 4 years after it was enacted (Ravitch, 2010).

In the latter parts of her book, Ravitch suggested some ideas to improve school reform from what has been learned and implemented from NCLB (Ravitch, 2010). These ideas included incorporating educators in development and decision-making, devising a national curriculum where a word like "proficiency" would be standardized, and all testing or accountability measures aligned with that national curriculum. The reform ideas came from the experiences Ravitch had before and during NCLB. These ideas have implications for the current status of CTE that essentially espouses all of those reform components.

NCLB and the College for All framework transformed reform into a means of pushing students through the system with testing, measurement, data, and high stakes expectations for every student, from every race, background, and in every school. The purpose of NCLB was to better educate and prepare students, yet the outcomes did not support the goals. College for All was also a framework to prepare students for college and beyond. In 2002, however, only $34 \%$ of high school graduates were prepared for college (Green \& Winter, 2005). Angus and Mirel (1999) contended that the promises were there but the execution of the American high school to prepare students for their futures failed. The authors give a historical approach to explain why the American high school failed students; most of the blame is due to assumptions and conclusions without 
much evidence to support and back major changes that came about. More than a half decade later, Ravitch explained the same failure due to standards and curriculum perspectives as well as the lack of educators in decisions making. All authors were at one time very supportive of the initiatives but quickly saw the reality of the initiatives after implementation.

These reforms, good ideas in and of themselves, did not pan out on paper as planned for many reasons that were clear after implementation. Although these reforms did not necessarily work, they did shed light on future school reforms that put learning and students first, that looked at students and postsecondary education and training, industry training, and the idea that education was not a catch all. These reforms also shed light on the American high school system and the failure of the high school diploma. For those purposes they are important and relevant to the current status of education in the United States.

College and Career Readiness Revisited. Other movements during this time attempted to "close the achievement gap" for those for schools and students that were not performing at the standards expected of such reform efforts (Gordon, 2008). There was a need for more rigor, more engagement, and more students going on to school or work beyond high school. Evidence of the need for a new system included the new economy, public expectations for students, new research on student learning and motivation and effective teaching, and a loud call for reform of the American high school (Lynch, 2000). It was the job of high school to prepare students for adulthood, not just college. This achievement gap, according to ACTE, needed to close between races, international students, and all students. Recommendations from ACTE included establishing a clear 
system of college and career readiness, creating a new school culture that stressed planning and decision making, and promotion of positivity around personalization and relationships (Gordon, 2008).

Achieve Inc, The Education Trust, and the Thomas B. Fordham Foundation created the America Diploma Project which essentially tried to link secondary and postsecondary education and re-instate what the high school diploma was supposed to symbolize (Achieve Inc, 2004). This project targeted English and Mathematics and reshaped what students learned in high school based on the foundational needs of the workplace and postsecondary education. The America Diploma Project includes workplace readiness benchmarks through which college and career readiness can be operationalized and defined. The benchmarks are turned into practical applications such as workplace tasks and postsecondary assignments that can then be measured and analyzed against the benchmarks. Stemming from the American Diploma Project, the college and career readiness framework incorporated academic, occupational, and employability skills to prepare students for college and careers while in high school (Stone \& Lewis, 2012). As a transformed field, the new CTE is more challenging, academic, and relevant to meet the needs of the youth and adult workers in the United States (Gordon, 2008).

Carl D. Perkins Career and Technical Education Act. The Carl D. Perkins Career and Technical Education Act of 2006 (Perkins IV) is an amendment and improvement of Perkins III that was enacted in 1998 (USDE, 2013). The government, as a way to improve CTE and education in general in the United States, overwhelmingly supported Perkins IV. The legislation was put into effect in January of 2006. It was the 
first act to include the words Career and Technical Education.

The purpose of Perkins IV is to increase academic and CTE skills of high school and college students who are enrolled in CTE programs. Main components of this legislation mirror much of the same components of past Perkins Acts including an improved CTE, accountability, secondary and postsecondary links, and business and industry partnerships (Gordon, 2008). Improvements to Perkins IV included an increase in academic rigor in classes, new local requirements, indicators for postsecondary education as opposed to just secondary education, and the inclusion of NCLB as a measure of student educational attainment (Gordon, 2008). Another improvement of Perkins IV incudes an additional program component that extends beyond the Tech Prep programs within Perkins II and III. This component is called Programs of Study, which are specifically examined in this dissertation.

The overall purpose of Perkins IV is to increase the skill sets of students (USDE, 2013). To do this, many program improvement initiatives were developed with 7 specific guidelines to increase student's skills in secondary and postsecondary education and lead them into business and industry.

The guidelines are as follows:

1.) use existing academic and technical standards developed by States and localities and refine them in terms of rigor and challenge; help students achieve those standards and prepare them to be competitive for "...high skill, high wage, and high demand occupations in current and emergent professions" (USDE, 2013, p. 2);

2.) integration of academic and CTE in secondary and postsecondary education 
3.) use State and local initiatives that help further develop CTE services and activities;

4.) conduct and report research on best practices to improve CTE nationwide 5.) develop and further improve technical assistance programs in professional development for the CTE community;

6.) encourage and support partnerships throughout the CTE community and greater education and workforce community;

7.) create an environment within CTE to encourage lifelong learning opportunities that can increase skills, knowledge, and competitiveness within the U.S. (Perkins IV) (USDE, 2013).

The guidelines promote communication between the government and state and local agencies to create a rigorous and challenging CTE community. Through technical assistance, increased standards, and support for lifelong learning, Perkins IV initiates a conversation that goes beyond short term educational goals, and instead offers a community-wide approach that students can be apart of for their entire lives. Perkins IV emphasizes the importance of research-based practice that helps to inform the field of new developments that can strengthen and improve programs within the field. Perkins IV also sets out to improve CTE services and activities that increase student's skill and knowledge that make them competitive in a global economy. These programs incorporate the career pathways approach to graduation and employment. One of those programs is Tech Prep, which has been discussed in Perkins II and III. The other is Programs of Study, a new addition to Perkins IV. Before a discussion of Programs of 
Study it is important to distinguish some influencing career pathway programs that predated POS and essentially paved the way to where the field is today (USDE, 2013).

Development of POS. The addition of POS as a component of Perkins IV evolved from years of career pathway program development used to attempt to prepare high school students for both college and careers. The precursors to POS have influenced the development of the current pathway model and an understanding of these past programs is vital in knowing where the field came from and how POS were developed and implemented within Perkins IV. Three initiatives predated POS: Tech Prep, Career Pathways, and Dual/Concurrent Enrollment (POS Joint Technical Working Group, 2010). Another initiative of the 1990's that influenced the development of POS was youth apprenticeships (Stipanovic, Stringfield \& Lewis, 2012).

Tech Prep, which was explained in the timeline section of this literature review under Perkins II, was started by Dale Parnell as an attempt to link the last two years of high school with the first two years of postsecondary training (POS Joint Technical Working Group, 2010). Tech Prep was the first initiative to ease the transition of these students who were never going on to a 4-year degree and instead allowed them to move into a 2-year degree program and/or earn an industry credential that was required of their field. To ease the transition, Tech Prep used articulation agreements between secondary and postsecondary institutions that linked the programs together as well as designed curriculum's that integrated both academics and vocational education; all developments that are still used today. Research on the effects of Tech Prep on student enrollment and achievement resulted in minimal significant effects if any (Bragg, 2002; Stone \& Aliaga, 2003). One of the proposed reasons that Tech Prep did not work was that there was not a 
standardized definition or structure of Tech Prep within the legislation, so measuring and evaluating outcomes was difficult on a wide-ranging scale.

The second initiative to predate POS was Career Pathways or the "next generation" of Tech Prep (Hull, 2004). Career pathways are tied directly to the Career Cluster Initiative that was developed in the late 1990's (POS Joint Technical Working Group, 2010). As mentioned in the previous section, career clusters are the 16 broad field areas that represent the current labor market. The career pathways initiative streamlines a specific field and occupation into a manageable framework where secondary school and the labor force are connected. By choosing a career pathway in secondary school and following it through graduation and onto whatever postsecondary requirement is expected of that field, students are prepared for the workface directly out of high school. This is the same notion as Programs of Study that links secondary, postsecondary, and the labor market through a career pathways approach.

Research conducted on career pathway models indicate that students involved in a career pathway in secondary school transition to postsecondary training better than non career pathways students, earn more first year college credits mainly because of the dual credit option in secondary school, perform better at the end of high school, and are better prepared for the labor market because of such learning models of work-based learning, or contextual learning (Leakes, 2007, Castellano, 2007; Stone \& Aliaga, 2003). This initiative is the most related program to POS. The influence of career pathways to POS is uncanny; the only difference may be the name.

The last precursor to the development of POS is dual/concurrent enrollment (POS Joint Technical Working Group, 2010). The dual/concurrent enrollment initiative was 
developed to allow students to receive college credit while in high school.

Dual/concurrent enrollment is relevant to Tech Prep and Career Pathways, as well as helped with the development of POS because of the linkages between secondary and postsecondary training. Components of all these initiatives relay the importance of postsecondary and industry preparation while in high school. The research reported on career pathways in the previous paragraphs mentioned that career pathway students earned more credits in their first year of college than non-career pathways students. This is in part because these students have the option to take postsecondary credits while in high school and are more prepared for course work once they get in to college. Plank (2001) reported that students in dual enrollment programs perform at almost the same achievement standards as academic concentrators with regard to academic achievement.

Research on Multiple Pathways. Over the past 10-15 years, research conducted on the effects of CTE on students and the economy has informed current practice. Many longitudinal studies have been conducted that follow secondary students to graduation and onto either postsecondary training or into business and industry. Most of the studies examine variables such as academic achievement, transitions, and drop out rates comparing academic students with vocational students. Other studies explain the effects of CTE on enrollment as well as the labor market. Research on the effects of secondary students CTE course taking within programs such as dual enrollment, career pathways, school to work, or Programs of Study have positive implications on both the individual student and the economy (Gordon, 2008; Bishop \& Mane, 2004; Plank 2001).

Students who embark on vocational course work throughout their high school careers tend to have better attendance rates as well as completion rates than their non- 
CTE counterparts (DeLuca, Plank \& Estacio, 2006; Bishop \& Mane, 2004). According to Plank (2001) instances of decreased dropout rates are further exemplified when there is an almost equal ratio of CTE courses to academic courses, a ratio of 3:4. DeLuca et al. (2006) further explained that the decreased drop out rates of CTE students in high school are due to the preparation CTE coursework gives students (2006). Research on the effects of CTE on non college bound students indicates that students stay in school longer and often graduate as CTE courses are more relevant to their future plans of business and industry (DeLuca et al., 2006; Plank, 2001). Similar to the perceived relevance of CTE coursework, the contextual learning frameworks that are embedded within CTE have implications for academic achievement in secondary and postsecondary institutions as well (Karp, Calcagno, Hughes, Jeong, \& Bailey, 2007). CTE students have performed better than non-CTE students in core subjects (Karp et al., 2007; Lekes et al., 2007) as well as do not report needing remedial mathematics as they enter postsecondary training compared to non CTE students (Stone et al., 2008). Interaction effects have also been seen with CTE coursework and coursework related to STEM training (Lekes et al., 2007), which have implications for the $21^{\text {st }}$ century global economy.

Transitions from secondary school to either postsecondary training and/or industry are also important topics researched in the field. Research indicates that CTE students, compared to non-CTE students report feeling more prepared for college and careers through the use of the College and Career Readiness framework (Stone \& Lewis, 2012). College and career preparation through dual enrollment, career planning, as well as employability skills training have been reported as being helpful with transitions and at times have led to more CTE than non-CTE students enrolling in postsecondary education 
(Karp et al., 2007; Lekes et al., 2007). Stemming from college and career preparation to the labor market, CTE programs have many implications for the global economy from a human capital perspective (Wallenborn, 2010). Human capital theory rests on the tenet that investing in the skills and knowledge of students and employees will have direct impacts on the labor market for the greater society and nation. From this perspective, CTE operates under a human capital framework as it provides students with opportunities of growth through career pathway programs. Directly from the labor market, students in these programs earn $12 \%$ more one year after graduation and $8 \%$ more seven years later, especially with computer based occupations (Bishop \& Mane, 2004). All of these studies inform the field about the effectiveness of multiple pathways; Programs of Study will be discussed below as the current status of the career pathway approach to education.

Programs of Study Component of Perkins IV. The development of POS came out of an expansion of the initiatives discussed in the previous section. Research on the other initiatives resulted in increased knowledge regarding the importance of implementation, standardization, and effects on student achievement (POS Joint, Technical Working Group, 2010), all constructs that were reworked in the development of POS. Also, developing POS as a component of a federal legislation enhanced the efficacy and accountability of the program. All of the history, developments, research, and expansions within CTE have brought the field to this point: POS as an integral component of the current CTE legislation.

Programs of Study was one of the new components of Perkins IV that espoused a career pathways approach to graduation and employment within CTE (USDE, 2013). As a Perkins IV requirement, each participating state is mandated to offer at least one 
Program of Study to secondary students involved in CTE. The Perkins Collaborative Resource Network gives an operational definition of programs of study. "A program of study is a comprehensive, structured approach for delivering academic and career and technical education to prepare students for postsecondary education and career success" (2013, p. 1).

Programs of study essentially builds off of Tech prep, career clusters, career pathways, and the career academies methods of educating youth in CTE (Gordon, 2008). Programs of Study are career pathway programs that secondary students choose to be in as soon as they enter high school. The student takes a sequence of courses that follows the POS through high school. Depending on the requirements of the industry the student goes into postsecondary training or the workforce.

There are four main components of Programs of Study that are standardized for every program, school, and state that offer the career pathways (Perkins Collaborative Network, 2013). These components ensure that secondary and postsecondary institutions are aligned with each other as well as aligned with current and emergent business and industry standards and requirements.

The components are:

"1.) incorporate and align high school and college educational elements

2.) include content that is both academic and CTE in a coordinated non duplicative progression of courses

3.) offer high school students to acquire college credit when possible 4.) lead to industry-recognized credential or certificate at college level, or an associate or bacc degree" (Perkins Collaborative Network, 2013, p. 1). 
Programs of Study support the College and Career Readiness Framework as it creates multiple pathways for students to be successful in high school and beyond (Stone \& Lewis, 2013). During high school, students can start to attain the requirements needed for their industry pathway. The goals of POS are to increase the academic and CTE achievement of students in both secondary and postsecondary education; to increase engagement and retention of students within secondary education through rigorous and relevant course sequencing; and promote the ease of transitions to postsecondary education and the workforce through linkages and partnerships with business and industry (Perkins Collaborative Network, 2013).

The mechanisms to attain all of these goals are imbedded within the career pathways system. POS supports context dependent learning and offers students access to college credit while in secondary school. Context dependent learning invites students to become more engaged through the Rigor and Relevance framework as the framework suggests that students who learn concepts that are closely tied to their own experiences and career aspirations can learn rigorous material. Learning rigorous material in this manner also increases achievement, creating a CTE community that is highly skilled and knowledgeable for the $21^{\text {st }}$ Century. The links between secondary and postsecondary education provide an environment that encourages a smooth transition from high school to college and into the workforce.

Additionally, POS provides a 10-component framework that OVAE and other national associations created that align with the goals mentioned above (USDE, 2013). These components help standardize the implementation of POS across the nation and are guidelines to help states consider what works for them. This design framework 
encompasses all the components of POS which in and of themselves is comprehensive. Depending on the state and what programs are offered, states and institutions may choose to incorporate all or some of the components as they see fit (Perkins Collaborative Network, 2013).

The 10 components include:

"legislation and policies; partnerships; professional development; accountability and evaluation systems; college and career readiness standards;

course sequences; credit transfer agreements; guidance counseling and academic achievement; teaching and learning strategies; and technical skills assessments" (Perkins Collaborative Network, 2013, 1-5).

Within the states and schools that offer POS, students choose career majors from the 16 career clusters and then develop Individual Graduation Plans (IGP). With the help of guidance counselors, teachers, and parents, the IGP is tailored to the student's course needs and requirements within a specific POS. The student follows these course sequences until high school graduation and is then able to go onto to postsecondary training or earn an industry credential and enter the workforce. This dissertation examines the POS participation effects on student outcomes in the RTPOS using two groups of students $\left(9^{\text {th }}\right.$ grade and $12^{\text {th }}$ grade) from one state (Castellano et al., 2012).

The RTPOS is part of a larger research initiative of the National Research Center for Career and Technical Education (NRCCTE). The NRCCTE has been conducting longitudinal studies on the effects of POS since Perkins IV was enacted. The RTPOS is one of several studies that were conducted for implementation impacts and outcomes of Perkins IV legislation and specifically POS in both secondary and postsecondary 
institutions (Shumer, Stringfield, Stipanovic, \& Murphy, 2011). Findings from these studies will help inform the field and future developments and implementation of POS across the nation.

\section{Student Outcome Variables}

This section of Chapter II discusses in detail the literature and support surrounding each variable of interest in this secondary analysis. There are several dependent variables used to measure POS participation effects on student outcomes such as academic achievement, student engagement, support, and transitions. The variables include: dependent variables of academic achievement, student engagement, support, and transitions as they relate to the independent variables of POS participation and gender. Below is a literature review on each of those variables. The research on POS was described in the historical timeline section of this chapter.

\section{Academic Achievement.}

Academic achievement is one of the most studied variables when it comes to student outcomes in education. It "..reflects the extent to which students attain learning objectives as defined in curricula and syllabuses for specific subjects (Levpuscek, Zupancic, \& Socan, 2012, p. 524). Academic achievement important not only for educational matters but also for postindustrial societies in general (Levpuscek, et al., 2012), as modern societies place much emphasis on the construct for further academic and industry placement. Achievement is one variable known to be relevant for later career choices (Steinmayr, Dinger, \& Spinath, 2011; Blecker \& Jacobs, 2004). The ramifications of poor academic achievement have both individual and societal level effects. Literature suggests that as grade level increases, academic achievement often 
decreases (Bursal, 2013). For adolescents, low academic achievement affects the educational level attainment in young adulthood, and often sets the stage for long-term unemployment (Levpuscek, et al., 2012; Kokko, Bergman, \& Pulkinen, 2003). Those who do not matriculate past secondary school often use social services, report more physical and mental health problems, and are less likely to be involved in a communityoriented lifestyle (Vitaro, Trembley, Brendgen, \& Laros, 2005). Parents who do not complete secondary school put their own children at risk for decreased educational attainment (Levpuscek et al., 2012).

On an individual level, academic achievement involves many psychological, emotional, and behavioral components. One of the most noted constructs studied within academic achievement is academic self-concept (Pinxton, De Fraine, Damme, \& D'Haenens, 2010; Marsh \& Craven, 2006). Self-concept is the way in which someone conceptualizes his or her individual beliefs, values, strengths, and weaknesses (McInerney, Cheng, Mok, \& Lam, 2012). Because of the ways in which self-concept is integrated into daily life, such as with economic success, health, and well being, it is one of the most studied psychological constructs (McInerney, et al., 2012; Marsh \& Cravan, 2006; Williams, 2003). The relationship between self-concept and achievement, then, is important not only for individual student level success but also important for educational policies (McInerney et al., 2012).

Research is mixed on the causal and/or reciprocal nature of self-concept and achievement. Some studies suggest that academic achievement is caused by self-concept, and others suggest that self-concept stems from academic achievement (McInerney et al., 2012; Pinxton, et al., 2010). Others suggest that there is a reciprocal relationship between 
academic achievement and academic self-concept (McInerney, et al., 2012; Pinxton, et al., 2010; Guay, Marsh \& Boivin, 2003; Marsh, Hau, \& Kong, 2002). Learning strategies play a crucial role in the reciprocal relationship between academic achievement and selfconcept (McInerney, et al., 2012; Covington, 2000). Achievement goals help to explain why students choose certain learning strategies or engage in certain behaviors in school such as for a goal of mastery (deep learning) or performance (surface learning) (Diseth, 2013). The way a student learns is also related to their level of engagement in that certain task (McInerney, et al., 2012). Students who have higher self-concepts are more likely to engage in tasks and self-regulate their learning. These are functions of student engagement which will be discussed in the next section (McInerney, et al., 2012). Still other researchers report a correlational effect between academic achievement and academic self-concept (McInerney, et al., 2012; Seaton, Marsh \& Craven, 2010).

Directly relating to the importance of discussing self-concept with academic achievement, many intangible variables that effect academic achievement grow out of this relationship. Variables such as intelligence, openness, class participation, and selfcontrol all have direct and positive effects on academic achievement (King and Gaerlan, 2014; Fakeye and Amo, 2013; Levpuscek et al., 2012; Tangney et al., 2004). There are relationships between achievement, self-efficacy, attitudes, and study habits as well (Aquino, 2001). Moreover, those students who are able to set goals and monitor those goals are more likely to have high achievement on knowledge tests (Ilgan, 2013). Most of the variables that can effect academic achievement have much to do with academic self-concept as well as motivation for success (Bjornebekk, Diseth, and Ulriksen, 2013). Motivation for success can also mean motivation to avoid failure as achievement goal 
theory states, which circles back to a students self efficacy and self-concept (Bjornebekk et al., 2013; Elliot \& Church, 1997).

Another body of research in academic achievement points to the examination of emotional responses in students. There are both positive and negative emotions felt in school at any given day, time, or class period. These emotions have differential impacts on learning and achievement (King et al., 2014; Pekrun, 2006). Emotional responses in school can increase or decrease academic emotions, which will significantly impact other constructs such as engagement, disaffection, and perceived achievement (King et al., 2014). Academic emotions can also predict levels of engagement in schools (King et al., 2014).

Although there is much emphasis placed on the construct of academic achievement, there is much debate around programs aimed at increasing academic achievement as well as how it should be measured (Bellei, 2013; Pinxton et al., 2010). The related concepts discussed above are often intangible, making it hard for educators and researchers to concretely measure academic achievement. Generally, academic achievement is measured through course grades, GPA, teacher ratings, or national examination tests (Levpuscek et al., 2012; Pinxton et al., 2010). Other indicators of school success are important such as drop out, increased enrollment, advanced coursework, extracurricular activities, and credits earned (Newman, 1992). Recently, more social indicators that include family and culture have been used to also measure academic achievement along with academic variables such as grades to explain individual differences (Levpuscek et al., 2012; Chiu \& Klasson, 2010). These factors 
include student's perceived support, parental pressure, and course experiences.

(Richardson \& Price, 2003; Lizzio, Wilson, \& Simons, 2002).

One specific factor that has received attention is the education level of parents, which has direct effects on academic achievement as mentioned previously (Ilgan, 2013; Levpuscek et al., 2012; Diaz, 2003). The education level of parents has been studied recently as a major factor of academic achievement in adolescents (Diaz, 2003) There are a couple ways to examine this factor that has several layers to it. One of those factors is the SES of parents. It is common knowledge that education and SES are extremely correlated, and as such this relationship will effect the academic achievement of one's children. SES is also positively correlated with academic achievement (Tsai \& Liu, 2013). On one side, the education level of parents will dictate how much help parents can give children with their homework (Tsai \& Liu, 2013). Another line of thinking is that the more educated a parent is, the more support they will provide their children not just from an academic standpoint but in terms of concern for development, and will have more time to devote to such support because of a higher SES (Tsa \& Liu, 2013). Both self-report grades and parents' education level will be used as the two achievement measures for this dissertation.

\section{Student Engagement.}

Background. Student engagement has been actively studied for decades as a mechanism of student success. As such, student engagement is a construct that is intangible, making it difficult to measure and quantify. Literature on the field of student engagement spans elementary education through adult education, with most of the focus 
on secondary and postsecondary student engagement efforts. One of the main variables of interest in this secondary analysis is student engagement.

It is important to study constructs like engagement to help ensure students leave secondary schools with competences and a commitment to learning (Appleton, Christenson, Kim, \& Rechly, 2006). Engagement is considered the cornerstone of high school reform efforts (National Research Council \& Institute of Medicine, 2004) and is useful for guiding university policy development (Tison, Bateman, \& Culver, 2011). Policies and reforms that take an engagement perspective enhance human capital and drive economy productivity through the promotion of creativity and innovation (Hanushek \& Woessmann, 2008). There are, however, high rates of disengagement worldwide. $25-60 \%$ of students in the United States are not engaged in school (Lee, 2012; Klem \& Connell, 2004)

Engagement is considered a "meta-construct" in the field of education (Fredricks, Blumenfeld, \& Paris, 2004), that brings together many lines of research under one conceptual model (Appleton, 2008). There is a lack of distinction between what engagement is, how to measure it, and what influences engagement in the short and long term (Kahu, 2013). This secondary analysis attempts to streamline the construct. In general, student engagement is a construct that surrounds the meaning students place on their academics (Lichtinger \& Kaplan, 2011; Zimmerman, 2008). Engagement can be conceptualized as a mental understanding that encapsulates a student's perception and interpretation of the relationship between their schoolwork and their emotions and actions (Zimmerman, 2008). Engagement has positive outcomes for students such as well-being and life satisfaction (Connor \& Pope, 2013; Lewis, Huebner, Malone, \& Valois, 2011) 
and is one of the best predictors of learning and personal development (Connor \& Pope, 2013; Carini, Kuh, \& Klein, 2006). Based on the pretense that that more involved you are in something, the more opportunities you have to receive feedback or learn in a selfdirected manner, students who are engaged develop sound habits that provide the capacity for lifelong learning (Shulman, 2002).

There are several definitions of student engagement, and there are many ways to conceptualize the construct. From a theoretical perspective, engagement is grounded in Hirschi’s Social Control Theory as well as Bronfenbrenner's Ecological System’s Theory, both of which relate to the attachment students have with their systemic environments (Archambault, Janosz, Fallu, \& Pagani, 2009; Martin, 2009). Social control theory dictates that individuals have a certain attachment and belonging to social institutions, such as schools, where bonds include commitment, beliefs, attachment, and engagement. In the Ecological Systems Theory, Brofenbrenner depicts social institutions like schools in the mesosystem where it is extremely important for development and engagement. Factors within that system such as peers, classrooms, school, and family foster engagement when those bonds are strong (Martin, 2009). Schools often fail on their side of this partnership as they do not distinctively link student outcomes with other systems like the "real world," (Martin, 2009). This idea has many implications to the current study that attempts to examine the transition effects of students from secondary to postsecondary education and the workforce.

There are also many definitions of engagement that span the field and go beyond theory. These definitions take both individual student perspectives as well as school partnership perspectives. Schaufeli, Martinez, Pinto, \& Bakker define engagement as the 
"persistent, positive, fulfilling, and work-related state of mind that is characterized by vigor, dedication, and absorption," where vigor is much like energy, dedication is involvement, and absorption is the immersion in work" (2002, pp. 465). This definition of engagement espouses the belief that engaged individuals are resourceful, have positive coping styles, mental resilience in the face of obstacles, enthusiasm, pride, and function through inspiration and the broadening of actions (Alarcon, Edwards, \& Menke, 2011; Schaufelli, Salanova, Gonzalez-Roma, \& Bakker, 2002).

Student engagement is also marked by a student's agency or initiative in achievement, motivation, and support (Reeve, 2013). Agentic engagement is defined as, "students constructive contribution into the flow of the instruction they receive" (Reeve and Tseng, 2011, p. 258). This kind of engagement relates to how students proactively learn through communication, contribution, asking questions, and offering suggestions (Reeve, 2013), as well as relates to teacher effects. Using this framework, there are two constructs within student engagement that students use a way to approach learning in their learning environments. These approaches are surface and deep (Hermann, 2013; Biggs \& Tangs, 2011). These approaches explain students strategies for learning that produce distinct learning outcomes. The surface approach is where students act on the bare minimum to pass a class whereas the deep approach involves personal interest and engagement. This is different from student motivations, which is important to differentiate. Engagement and motivation are sometimes held under the same category but support for both constructs clearly divides them even though both deal with autonomy and competence (Appleton, 2008). Motivation can be thought of as why someone behaves and involves their intensity, direction, and energy; but engagement 
involves a student's actions using that energy. For example, a student can be motivated without being actively engaged (Appleton, 2008).

Student Engagement and Burnout. The surface/deep approach is also related to another common method of addressing engagement, using burnout. Literature on student burnout and student disengagement is comprehensive, and one cannot talk about student engagement without mentioning the constructs opposite (Shih, 2010). Where there is engagement, there can be burnout, as both run a slippery slope that includes perfectionistic tendencies, achievement goals, adaptive tendencies, and motivation levels (Shih, 2010). Burnout, or lack of student engagement, is a huge problem in the United States (Hermann 2013, Rocca, 2010; Fritschner, 2000). Specifically, secondary students in the United States report the most academic boredom out of all students (Bujs \& Admiraal, 2013; Larson \& Richards, 1991). 40-60 \% of high school students are chronically disengaged (National Research Council 2011, Connor \& Pope, 2009). The most common boredom complaints include: uninteresting material, lack of interaction with teachers, and lack of challenge (Yazzie-Mintz, 2010; Connor \& Pope, 2009) Across the lifespan, elementary students are more motivated and engaged than secondary and postsecondary students, and postsecondary students are more motivated and engaged than high school students, with engagement levels generally declining after middle school (Connor \& Pope 2009; Martin, 2009).

Burnout, as well as disengagement, impedes the learning process and promotes passivity within the school environment, where as engagement promotes action, a prerequisite for learning (Shih, 2010). There have been many studies examining the predictors of engagement and burnout with outcomes suggesting the two may not be so 
different as they relate to intensity and duration of such variables like the ones mentioned above. In one perspective engagement and burnout are on the same matrix with students endorsing both adaptive (hope of success) and maladaptive (fear of failure) traits in a dual process model of perfectionism (Shih, 2010; Slade and Owen, 1998). Other perspectives render burnout as the erosion of engagement (Shih, 2010) in that burnout is a gradual process of disconnecting and disengaging with the likely outcome of dropping out of school (Archambault et al., 2009; Appleton, 2006; Finn, 1989).

Other definitions of burnout come from the original context of studying burnout, which was within the workplace. Job burnout is caused by stressed on the job with characteristics such as emotional exhaustion, cynicisms, and reduced efficacy (Shih, 2010; Maslach, Schaufeli, \& Leiter, 2001). In students, burnout can be seen as a psychological construct manifesting in exhaustion and disinterest (Gonzalez-Roma, Schaufeli, Bakker, \& Lloret, 2006; Maslach et al, 2001).

Adolescents are already in a vulnerable state of development that makes them more apt to experience burnout and potential drop out (Shih, 2010). Academic burnout is caused by stress, course loads, and emotional exhaustion, however little is known about adolescent burnout as studies are usually in the college setting (Shih, 2010). It is known that burnout is associated with low motivation, low satisfaction, and increased risk of health impairments, social conflicts, low efficacy, and personal dysfunctions such as physical exhaustion, trouble sleeping, drug and alcohol, and dropout (Shih, 2010; Deary, Watson \& Hogston, 2003). Predictors of burnout include personality, social support, and coping styles, which are also predictors of engagement (Alarcon et al., 2011; Salanova, Schaufeli, Martinez, \& Breso, 2010; Halbesleban, 2006; Maslach, et al., 2001). 
Engagement is also the primary theoretical model for understanding school dropout (Finn, 1989), and a way to prevent it (Appleton, 2008).

As for disengagement, there are multiple frameworks to view the construct. One lends to the systemic nature of engagement/disengagement mentioned above using sociocultural and psychological factors, self-regulation, and adaptive/maladaptive coping strategies (Sullivan, Mornane, Prain, Campbell, 2009, Deed, Drane, Faulkner, McDonough, \& Smith, 2009). Other frameworks support the systems perspectives and focus on school factors that promote disengagement such as inappropriate curricular content, misaligned and unchallenging curriculums, changing cultural and technological conditions, and inappropriate student tasks (Gonzalez-Roma, Schaufeli, Bakker, \& Lloret, 2006; Maslach et al, 2001). Literature on burnout and disengagement provide support for how to foster engagement using self-regulation and social support (Sullivan et al., 2009; Zimmerman, 2008). Other elements necessary to foster engagement include stated vocational aspirations, mastery of key and core school subjects like math and science, linking schools to the workforce through introduction of career directions as early as middle school, and addressing the role of coping strategies for student success (Alarcon et al., 2011; Sullivan et al, 2009). Other reform efforts that align with fostering engagement include: offering students challenging and compelling instructional work, providing schools and classroom environments supportive of learning, and involving parents with their children's schooling (Martin, 2009).

Finn's Model of Engagement. Along with the extensive literature base on burnout, disengagement, and their relationships to engagement, there is also another model of engagement that is most noted in the field that will be used to conceptualize 
engagement in this secondary analysis. Finn's model of engagement (1989) uses these three components: cognitive, affective, and behavioral as the main mechanisms of student engagement. Support for these components is rather unanimous across the field (Hermann, 2013; Rocca, 2010; Archambault et al., 2009; Appleton, 2008; Fredericks et al., 2004; Jimmerson, Campus \& Greif, 2003; Marks, 2000).

Engagement is an ongoing process of a student's active involvement in their education and learning. It is comprised of behavioral, emotional, and cognitive aspects that include attention, interest, and investment (Gonida, Voulala, \& Kiosseoglou, 2009; Marks, 2000; Finn, 1989). Behavioral engagement is the engagement variable of interest in this secondary analysis, but it is important to define all three for clarity. Cognitive engagement relates to self-regulation, investments made in learning, learning goals, strategies employed, and time on task. Affective engagement relates to school identification, belonging, the value placed on learning, and attitudes about learning, emotions during tasks, and acceptance of school goals. Finally, behavioral engagement refers to attendance, interest, participation, conduct, persistence, extra curricular participation, contributions in class, and initiatives. Behavioral engagement has been shown to make significant contributions in predicting drop out. (Hermann, 2013; Reeve, 2013; Rocca 2010; Archambault et al., 2009; Appleton, 2008, Marks, 2000).

Behavioral Engagement. Within behavioral engagement there are certain mechanism that can foster student engagement. For instance, there are instructional practices to better engage students. All of these practices aim at increasing all three components of engagement but mainly focus on behavioral engagement. Barak (2006) examined engagement and developed five practices to engage students that have direct 
implications to this secondary analysis: 1.) that learning is contextual, 2.) learning is an active process, 3.) learning is a social process, 4.) learning is involved in a community of practice, and 5.) learning is a reflective process. Students in general benefit more from active and participatory learning compared to passive learning, and passivity relates to burnout and dropout as previously mentioned (O’Connor, 2013; Smith \& Cardaciotto, 2011; Yoder \& Hochevar, 2005; Prince, 2004). Consistently, students also prefer active approaches to classroom instruction where they can experience lessons (Basow, Phelan, \& Capoloslo, 2006; Levy \& Peters, 2012). More participatory education is active, fun, and motivating (Buijs \& Admiraal, 2013). Participatory education not only involves students more, it also holds student more accountable to their work (O’Connor, 2013). This secondary analysis used two measures of behavioral engagement for secondary students: participation and interest.

Student Engagement and Curriculum Development. Specific to instructional practices that provide environments for active learning, literature on student engagement, curriculum development, and reform is extensive. As mentioned there are curricular and pedagogical approaches that enhance engagement such as class size, schedule, and student-voice initiatives (Connor \& Pope, 2013), but curriculum design is often overlooked as a means to engage students (Nixon, 2014). Curriculum design not only engages students in the learning process within school but if developed with the workforce in mind like programs such as POS, it can become vital to employability and individual skill awareness through experience (Nixon, 2014). Using relevant curriculum that is interactive and hands on can have many positive effects for both students and school-community partnerships (Yazzie-mintz 2010; Belland, Ertmer \& Simons, 2006; 
Brush and Saye, 2008). Authentic experiences acquired through community engagement with professional scientists has been reported (Rahm, Miller, Hartley, \& Moore (2003). This means successful school to community partnerships that enable students to work with professionals over time (Watters \& Diezmann, 2013). Benefits of community engagement extend from students to industry. Specifically, formation of relationships and partnerships in which students have a high degree of autonomy and sense of responsibility is paramount to positive dispositions towards STEM (Watters \& Diezmann, 2013). There is currently a skilled shortage in STEM and ongoing issues with adolescent engagement, especially in secondary school. Wallace, Venville, and Rennie (2005) suggest reforms to curricula underpinned by thematic, integrated, project-based, and community-focused approaches. Dowden (2007) advocates a student-centered integrated curriculum in which students have opportunities to engage with the community in which they live, rather than specific subject areas, as the locus of educational interest (Waters \& Diezmann, 2013). Using a curricular approach to engagement supports the longstanding idea that school environment can influence both engagement and academic achievement, as both constructs are closely related (Lee, 2012).

\section{Transitions.}

One of the salient outcome variables of this secondary analysis is the effect of POS participation on student transitions into either postsecondary education or the workforce. Since at least the 1970s, the transitions from secondary school to postsecondary school as well as postsecondary school to the workforce has been a focus of national researchers as well as holds an international focus with the Organization for Economic Co-operation and Development (OECD) (Woods, 2008; Glenn, 1971). These 
two transitions that young people undertake in a rather short amount of time are transitions that mark major developmental shifts (Salmela-Aro, \& Tuouminen-Soini, 2010; Lefkowitz 2005; Schulenberg, Bryant, O’Malley, 2004; Shanahan, 2000).

Developmental shifts during this time include moving away from home for the first time, choosing a career pathway, starting romantic relationships, and holding more responsibilities than ever before (Litalien, Ludtke, Parker \& Trautwein, 2013; Plessis, Corney, Broadbent. \& Papadopoulos, 2011; Allen \& Miga, 2010; Zarrett \& Eccles 2006; Arnett 2000) Systemically, the transition from secondary to postsecondary education or the workforce is a time for young adults to integrate themselves individually into society (Heinz, 2002; Masdonati, 2010). Integration can start from successful career development (Pinquart, Juang, \& Silbereisen 2003). A smooth and successful transition during this time in a young adults life is important to the long-term effects of their adulthood. The transition into postsecondary education or the workforce can promote life long learning (Litalien, et al., 2013; Creed, Muller, \& Patton, 2003). Setting the correct pathway in secondary school can allow them to use the transitional period as a support. (Sheridan, \& Dunne, 2012). Not all students make this transition successfully, however. There is a large population of students who are not prepared to make this transition and do so unsuccessfully (Sheridan \& Dunne, 2012), particularly for those from disadvantaged backgrounds (Carolan, 2013).

Examining factors of effective school to work transitions can help students from multiple reform perspectives including counseling, policy, and education (Phillips, Blustein, Jobin-Davis, \& White, 2002). An adaptive transition from school to work has been defined in a variety of ways, from intra-personal psychological components such as 
well-being, lower anxiety, less homesickness, lower depression, concrete vocational identities, to societal and/or economic gains (Lowe \& Cook, 2003; Phillips, et al., 2002; Blustein, Phillips, Jobin-Davis, Finkelberg, \& Roarke, 2000). Of the intra-psychological components, there are two similar frames that current literature examines: life satisfaction and subjective well being (SWB). Life satisfaction is an important factor in the ability of an adolescent to transition smoothly in developmental shifts such as when graduating secondary education. Successful transitions and life satisfaction have a reciprocal relationship. Successful transitions from high school to postsecondary or the workforce have predicted life satisfaction and subjective well being in both boys and girls as well as correlated to their school engagement and educational track (Salmela-Aro \& TuouminenSoini, 2010) SWB has been examined as an outcome of goal regulation and successful transitions (Litalien et al., 2013). Goals help to shape SWB especially during a transition phase where some instances are more abstract than others in this time period (SalmelaAro, \& Nurmi 2010). Through SWB, the quality of personal goal motivation can have a meaningful impact on subsequent life satisfaction, positive affect, negative affect, and self-esteem over long periods of time and during major life transitions (Litalien, et al., 2013).

There are many other characteristics of students who have successful transitions that relate to the intra-psychological components mentioned above. From the life span and life-space theory literature, students who adaptively transition have the following characteristics: generalizable work skills, an optimistic transition plan, and resilience. (Blustein, Schulteiss, \& Flum; 2004; Flum, 2001). These are examples of factors that exemplify a student who is ready to transition and are characteristics that are directly 
involved in POS implementation (Phillips et al., 2002). Literature in the career development field term these characteristics "objective readiness," which will be used as one of the measures of transitions in this secondary analysis via student report of transitioning plans. Objective readiness refers to many things such as a realistic plan, work skills, and parts of behavioral engagement that help student's link school to work (Phillips et al., 2002).

Other support for readiness to transition point towards the availability of resources and work based learning activities and opportunities, as well as support within programs and schools, another unit of measurement regarding transitions in this secondary analysis which will indicate career planning activities (Kenny, Blutsteain, Haase, Jackson \& Perry, 2006; Phillips et al., 2002). The use of these resources enables a student to further their career planning transitions through multiple pathways, a hallmark of POS participation. A multiple pathways approach to education and transitions enables students to gain access to work readiness skills they would not generally have access to in academic tracks. Utilizing the current labor market as a way to prepare students for the transition to the workforce is an integral concept in successful transitions (Cieslik \& Simpson, 2006). There is an important role of stakeholders and community members involved in this transition to help enable students to have unlimited access to resources in the environment and facilitate a successful transition (Plessis et al., 2011; Masdonati, 2010). The person-environment fit theory has also been used to relay the importance of schools in providing the correct social context to appropriately develop students to facilitate further engagement and maturity that mimics the workforce (Eccles, 2004). POS and Perkins IV attempt to provide this kind of environment. An example of a 
consequence of not providing this environment is disengagement. Authors suggest that the transition itself may not make students disengaged or feel more anxious about the major shift but more because the nature of the school does not provide such preparation.

Transitions and CTE. Disengagement in the transition process occurs more often in the United States compared to European countries that hone in on vocational education more often (Salmela-Aro, \& Tuouminen-Soini, 2010). Countries such as Germany, Austria, and Switzerland have a vocational education and training (VET) system that is both academic and workforce related to facilitate successful transitioning for students as they enter the workforce. Students split time between academic subjects and relevant performance oriented work that is linked to the workforce (Masdonati, 2010). The outcomes of this approach point in favor of more CTE oriented programs. For instance, in Australia, VET students have better employment outcomes compared to academic counterparts (Woods, 2008). Furthermore, programs that are specifically linked to resources within the workforce have rapid success in terms of transitions. Programs linked to the workforce also have optimistic outcomes for students that drop out of programs (Shih, 2010).

Other outcomes for VET/CTE programs are consistent with the above research. Those that graduate from CTE programs are less likely to be unemployed by age 21 than academic counterparts as well as have the potential to earn higher wages over the long term (Gørgens \& Ryan, 2006; Anlezark, Karmel, \& Ong, 2006; Dockery, Koshy, \& Stromback, 2005). This is true for both boys and girls as VET/CTE programs provide clear pathways to industry certificates as well as the specific workforce sector they would like to work in (Woods, 2008). 


\section{Relationship Among Outcome Variables}

\section{Achievement, Student Engagement, and Transitions.}

The context through which achievement, student engagement, and transitions will be examined has been explained in detail in the above sections using current evidence to support each definition and unit of measurement of those variables. These outcomes variables are related to every other variable within the data set as well as related to each other. It is important to explain these relationships to better understand the effects of POS participation with these variables. Throughout the literature search on the relationships between these three variables, another variable consistently presented itself as an important additional variable to be measured: support. Support will be included in this section as it relates to each outcome variable.

Achievement and Student Engagement. The three outcome variables in this secondary analysis: academic achievement, student engagement, and transitions are related. It is important for the analysis and understanding of the data set and the larger interest of this dissertation to explore these relationships. Student engagement, student academic achievement, and student transitions to postsecondary education or the workforce have been studied both individually and collectively over several decades of educational and social science research.

This secondary analysis attempts to explain POS program participation effects and gender effects on these outcome variables using measures supported by the literature. As mentioned in the above section, the measures for achievement are: parents educational level and self-report student grades; behavioral engagement are: interest and participation; and for transitions: career planning activities, and self-report objective 
readiness. The relationships between these variables and their measures are of importance to the full understanding of student outcomes on POS participation as well as broader educational policy implications.

As the literature reviews on engagement and achievement mentioned, both variables are related and have reciprocal effects on each other. Research has been mixed on whether engagement causes achievement, or achievement causes engagement, but the majority of research indicates that there is a reciprocal effect for the relationship between student engagement and academic achievement (Kahu, 2013; Fredricks et al., 2004; Wu, 2003; Marks, 2000.) Engagement and achievement have had a strong and consistent relationship across all levels of socioeconomic statuses and disadvantaged or at risk populations. (Appleton, 2008; Klem \& Connell 2004; Marks, 2000; Finn, 1989). Furthermore, engagement is a protective factor for risky behaviors in addition to being linked to achievement, creating more of a reciprocal relationship (Connor \& Pope, 2013; Schochet, Dadds, Ham, \& Montague, 2006).

Engagement has been linked to academic achievement through academic variables such as GPA, ACT, and GRE scores (Carini et al., 2006; Hughes \& Pace 2003; Ewell, 2002) and is a predictor of student success (Lee, 2012; Klem \& Connell, 2004). As a predictor of school success, engagement can decrease the chance of drop out (Lee, 2012). Engagement can also enhance achievement. The achievement of students could perhaps be argued to depend on the level of engagement as one cannot be expected to achieve or perform if they are not engaged in specific learning tasks (Newman, 1992). Engagement that leads to academic achievement does so by inviting the students to find rewards in learning, and these students are more likely to graduate and go onto 
postsecondary education as they make a psychological investment in learning (Martin, 2009; Marks, 2000; Newman, 1992).

Student Engagement and Transitions. The relationship between engagement and transitions is not reciprocal as engagement and achievement is, but instead engagement can influence a student's ability to successfully transition into postsecondary education or the workforce, especially those within a vocationally tracked program. Studies have shown that students who are on a vocationally tracked program are less likely to experience school burnout than students on an academic track during the transitional period (Masdonanti, 2010; Salmelo-Aro, Kiuru, \& Nurmi, 2008; Anlezark, Karmel, \& Ong, 2006; Dockery, Koshy, \& Stromback, 2005). Measures of engagement that include participation, interest, and drop out have been shown to predict better adjustment and well being as students transition into postsecondary education because of inter and intra psychological components such as interpersonal skills and networking, and self-identity (Clark, 2005; Feldman \& Matjasko, 2005; Eccles, Barber, Stone, \& Hunt, 2003). Specific to vocational education, high engagement through participation in student activities is related to higher earnings during the transitional period into the workforce (Wang, Cullen, Yao, \& Li, 2013; Hu \& Wolniak, 2010).

Achievement and Transitions. The relationship between academic achievement and transitions is similar to the relationships between engagement and transitions where academic achievement can influence the ability of students to make a successful transition to postsecondary education or the workforce. As mentioned in the achievement literature review, as children get older and progress in school, achievement declines and transitions become harder (Bursal, 2013; Levpuscek, et al., 2012; Kokko, Bergman, \& 
Pulkinen, 2003). Also mentioned is the relationship between academic achievement and constructs such as life-satisfaction explained by adaptive behaviors, self-efficacy, selfconcept and well-being, constructs that also relate to the ability of students to transition successfully (Samela-Aro et al., 2010; Pinquart et al., 2003). These intra-personal indices join together to form a positive correlation between academics and achievement and transitions. It is noted that well-adjusted students have more concerns for career aspirations, planning, and degree of knowledge and skills needed to be successful in postsecondary education and workforce (Tate \& Swords, 2013; Pinquart et al., 2003).

Poor academic performance leads to several potential issues for student transitions. Occupational and social success can be predicted from secondary students academic performance in school (Tate \& Swords, 2013; Kenny et al., 2006; Gørgens \& Ryan, 2006). Students who have low achievement in high school are linked to factors such as unemployment, delinquency, early pregnancy, and mental health issues (Freudenberg \& Ruglis 2007; Pinquart et al., 2003). High performancers are more likely to get a job, as well as a job within their career interests as performance is usually one of the strongest criterions for vocational placement (Dockery et al., 2005; Pinquart et al., 2003; Vinokur \& Schul, 2002).

\section{Support.}

One of the early findings in this secondary analysis was the need to add an additional outcome variable of support to better explain the relationships between POS participation and other outcome variables of engagement, achievement, and transitions. Literature pointed to the variable of support as a predictor and influencer of student engagement, achievement, and transitions in secondary school and to postsecondary 
school and the workplace. This secondary analysis included this variable. The relationships between the added variable and the other outcome variables will be explained in this section.

The term support can mean a variety of things from peers, self, parents, schools, community, society, and so on. Literature on support for secondary students includes peer, parental, and teacher relationships that provides an enhanced environment where students can flourish academically, socially, developmentally, emotionally, and behaviorally (Lee, 2012; Salmela-Aro et al., 2010; Carini et al., 2006). Supportive teacher student relationships are significantly related to behavioral and affective student engagement as well as academic achievement (Hughes, Luo, Kwok, \& Loyd, 2008; O’Connor \& McCartney, 2007). These relationships are important for students' selfconcepts and school adjustment, and are negatively associated with burnout and drop out (O’Connor, Dearing, \& Collins, 2011; Shih, 2010; Baker, 2006).

Academically, both parental support and teacher-student relationships play key roles for student success (Moreira, Dias, Vaz, \& Vaz, 2013; Levpuscek et al., 2012). Involvement often depends on the resources parents have and the time they are able to give to their children, which is related to other variables such as SES (Jeynes, 2007; Gonzalez-Dehass, Willems, \& Holbein, 2005). For instance, depending on the amount, intensity, and availability of support parents can provide, their lack of support can have negative effects on student achievement. Generally, parents who have high expectations and value education, and participate in school activities with their children, have children who perform better compared to children who have less supportive parents (Levpuscek et al., 2012). However, there are negative effects of parental support on academic 
achievement when this support turns into academic pressure and unrealistic expectations (Moireira et al., 2013; Lee, 2012; Levpuscek et al., 2012; Gonzalez-Dehass et al., 2005).

Lastly, support has significant effects on student's ability to successfully transition into postsecondary education and the workforce (Serbin, Stack, \& Kingdon, 2013). These kinds of supportive networks gives students hope for the future, cooperativeness, social independence, resilience, as well as the belief that they can accomplish anything, which is essential in youth development and in turn helps with a students readiness to transition (Plessis et al., 2011; Gillham and Reivich, 2004). When that active support is not there, transitioning or readiness to transition becomes difficult (Serbin et al., 2013; Phillips et al., 2002).

Because of the importance of support in regards to the other student outcomes of engagement, achievement, and transition, it was clear that measures of support needed to be used to better explain post participation effects and student outcomes. Therefore, measures of support include all three components: parent, teacher, and peers through student self-report surveys.

\section{Gender}

For this secondary analysis gender is another independent variable to examine outcome variables of achievement, engagement, support, and transitions alongside POS participation. Gender was added to the study to further explain individual differences on the variables explained in the above sections.

For all variables, research on gender differences in education is highly mixed (Bursal, 2013; Steinmayr, et al., 2012; Shih, 2010; Sirin, 2005). Some studies state girls 
are more engaged, achieve more, and transition better than boys, and then there is research that says the opposite. Still other research indicates that there are no gender differences in education.

For engagement, most research points towards girls being more engaged than boys across the educational lifespan (Connor \& Pope, 2013; Lewis et al., 2011; Yazziemintz 2010; Marks, 2000). Women place more expectations about themselves on academic success and portray more behavioral engagement factors such as participation, supportive relationships, and attendance (Tison et al., 2011; Sax, 2008). Other lines of research point to men being more highly engaged than women with women still being generally engaged (Hu \& Kuh 2002).

There is also mixed research on gender differences and academic achievement (Bursal, 3010; Bacharack, Baumeister, \& Furr, 2003; Evans, Schweignruber \& Stevenson, 2002). Although research is mixed, examining achievement gaps in gender is a common method of differentiating individuals. Most research points to girls having slightly higher academic achievement than boys, more specifically as grade level increases. This is conceptually due to some of the similar elements mentioned in the above paragraph on girls' academic expectations, attitudes toward school, fear of academic failure, and feelings of stress (Ilgan, 2013; Shih, 2010). However, international research generally points to boys achieving more than girls (Bursal, 2013). On a per subject comparison, research indicates that boy achieve higher in math and science, while girls are higher in language and arts (Evans et al., 2002). There are still other lines of research that report no gender differences (Bursal, 2013; Goldin, Katz, \& Kuziemko, 2006; Spelke, 2005; Evans et al., 2002). 
Historically, one of the prominent international trend studies that examine gender differences in academic achievement is the TIMMS study: Trends in International Mathematics and Science Study Reports (Bursal, 2013). From 1995, 1999, and 2007, international trends in science and mathematics across multiple grade levels and gender have been examined. Results indicate trends consistent with current research efforts.

Data from 1995 resulted in elementary and middle school boy's outperforming the majority of girls in participating countries in science with the gap increasing over grade level (Mullis, Martin, Fierros, Goldberg, \& Stemler, 2000). However, this science gap closed in the 1999 TIMMS results for elementary boys (Martin, Mullis, Gonzales, \& Chrostowski, 2004). The 2007 results indicated girls outperforming boys, including some countries such as Turkey, which had been a chronic low performing country (Martin, Mullis, Foy, Olson, Erberger, Preuschoff et al., 2008). Mixed and inconsistent results indicated the importance of studying gender differences in academic achievement.

Gender differences also affects the ability of students to successfully transition to postsecondary school and the workforce. Much of the literature on school transitions, as explained in the above sections, is related to life satisfaction, with the more satisfaction the more successful transitions. Some research on life satisfaction and transitions have no gender differences, and other research indicates that girls who have higher life satisfaction than boys will successfully transition. Research also indicates the opposite as girls experience more academic burnout and stress, which can hinder the ability to transition smoothly (Salmela-Aro et al., 2010).

\section{Research Questions}

The research questions for the $9^{\text {th }}$ grade group are: 
RQ1: Is there a significant POS participation main effect on the linear composite of academic achievement, engagement, support, and transitions of $9^{\text {th }}$ grade secondary students?

RQ2: Is there a significant gender main effect on the linear composite of academic achievement, engagement, support, and transitions of $9^{\text {th }}$ grade secondary students?

RQ3: Is there a significant interaction effect between POS participation and gender on the linear composite of academic achievement, engagement, support, and transitions of $9^{\text {th }}$ grade secondary students?

The research question for the $12^{\text {th }}$ grade group is:

RQ4: Is there a significant main effect of POS participation on the linear composite of academic achievement, engagement, support, and transitions of $12^{\text {th }}$ grade secondary students?

\section{Summary}

The literature review presented in this chapter outlined current CTE teaching and learning frameworks, provided an in-depth historical outline of past federal legislations plus influencing factors in the field development, reported on evidenced-based practice for the support of CTE and the multiple pathways approach to secondary education, as well as an extensive review of relevant student outcome variables used in this dissertation as well as the field of CTE. Providing this literature review supports the Perkins IV legislation that espouses a multiple pathways framework for education. This dissertation further supports the legislation through its purpose of conducting a secondary analysis on an existing data set using the RTPOS (Castellano et al., 2014). Common CTE student 
outcomes will be measured within this study to examine the impacts of Perkins IV POS on salient student outcome variables of academic achievement, student engagement, support, and transitions as well as the demographic variable of gender. 


\section{CHAPTER III}

\section{METHODS}

This chapter presents the information on the RTPOS, the study that was examined in this secondary analysis along with the research questions and methodology of the secondary analysis. The RTPOS is presented first with background information as well as the methods of sampling, data collection, and reliability and triangulation. The secondary analysis that was conducted for this dissertation is also presented which explains what data set/groups/surveys were taken from the RTPOS and how those data were used to examine POS participation effects. The research questions and plans for analysis are presented at the end.

\section{Background}

CTE frameworks, history, and relevant research supported this secondary analysis that analyzed the Perkins IV policy implementation from a longitudinal, quasiexperimental research study called the "Rigorous Tests of Student Outcomes in CTE Programs of Study" (Castellano, Sundell, Overman, Richardson, \& Stone, 2014), or RTPOS. States that received Perkins IV funding, were mandated to offer at least one Program of Study in each school district (Hammond et al., 2012). POS are career pathways that students choose in the beginning of their high school 
careers. Under POS, students follow a specific course sequence that helps them transition into postsecondary training and/or business and industry depending on the requirements of their chosen field. Educational constructs through which students are successful in POS are achievement, student engagement, and transitions, variables that were also included in this dissertation (USDE, 2013). An examination of the relationship between POS and major variables of achievement, student engagement, and transitions was the purpose of this secondary analysis using the RTPOS data set.

This chapter presents a detailed description of the existing research study, the RTPOS, through which this secondary analysis was conducted. The secondary analysis data set from the RTPOS examined two groups: $9^{\text {th }}$ and $12^{\text {th }}$ graders. The secondary analysis used the data from both groups in a parallel analysis with treatment and control groups of POS participation, as well as used a demographic variable of gender.

\section{Rigorous Tests of Student Outcomes in CTE Programs of Study}

The purpose of the "Rigorous Test of Student Outcomes in CTE Programs of Study" was to examine the participation effects of POS on student achievement (Castellano et al., 2012). A central rewuirement of Perkins IV mandated each secondary school to incorporate at least one POS in their curriculum. The goal of the RTPOS was to examine the effects of POS participation on student outcomes. This secondary analysis added to that goal and used the student survey data from both $9^{\text {th }}$ and $12^{\text {th }}$ grade to examine POS participation and gender effects on major outcomes of achievement, student engagement, support, and transitions.

The RTPOS was conducted over four years (2010-2014) to gauge secondary students' academic and technical skills achievement as they participated in Programs of 
Study (Castellano et al., 2012). The RTPOS examined student outcomes of the abovementioned variables for students in POS and students who did not participate in POS as a way to measure program effectiveness. The methodology of the RTPOS was multimethod, longitudinal, and quasi-experimental. The RTPOS included two districts from two different states in the United States. This dissertation that uses a secondary analysis approach used one of the two districts within the RTPOS.

The RTPOS examined two districts in two states, East and West. For sampling, the study sought out multiple types of schools that espoused career education reforms as well as performed lotteries for student enrollment in POS programs. After discussions with experts in the field, searching for schools, and researching national organizations on websites, the researchers of the RTPOS found two districts that met all of the criteria; they were then named East and West (Castellano et al., 2012).

The study design of the RTPOS was both experimental and quasi-experimental, dependent upon the district that was analyzed. Demographic variables were collected on districts and included gender, race, achievement prior to high school, SES, ESL, and IEP's. The district that was chosen for this dissertation was West, where a quasiexperimental design was carried out. West was chosen because it had the most student survey data and added to the already existing analysis that the researchers conducted. Demographic variables for the district are found in the RTPOS preliminary analysis (Castellano et al., 2012). The West district was located in the Western part of the United States. This district included: $64 \%$ of the students were of ethnic minority, $40 \%$ were eligible for free lunch. 
A lottery for the West region was conducted every year for POS enrollment. Requirements for eligibility of students included behaviors, attendance, and achievement that were measured by the schools. Students were able to apply to up to 10 programs of their choosing. The lottery for this sample was conducted in 2008 for the high school class of 2012. The treatment group was comprised of students who were picked for the lottery. The control group students were those that applied to POS schools but were not selected to be in the lottery (Castellano et al., 2012)

The measures used in the RTPOS were self-report student survey data (the data used in this secondary analysis) as well as student achievement data provided by the district such as CTE GPA, academic GPA, and tracks for graduation. Other data that were used included components within POS such as completion rates and college credits earned in secondary school. The student survey will be explained in detail in the following sections (Castellano et al., 2012).

There were quantitative and qualitative analyses conducted in the mixed methods RTPOS that examined student outcomes of POS. The qualitative analysis was conducted from site visits every year to the districts where teachers, students, and administrators were interviewed for differences between treatment and control conditions and program usefulness. There was also an observation period for the analysis (Castellano et al., 2012).

Results from the preliminary study included both qualitative and quantitative aspects. The qualitative results suggested that all schools participating in POS met criteria of Perkins IV and control groups did not. The POS schools also had more resources supporting CTE than control groups even though the control groups had the 
same amount of structures put in place for such support. Lastly, it was observed that using innovative teaching strategies that aligned career context and academics helped with POS implementation (Castellano et al., 2012).

The quantitative findings included:

1.) CTE and academic GPA's of treatment and control groups were similar in $10^{\text {th }}$ grade.

2.) The treatment groups were more on track for graduation than control groups.

3). The treatment groups scored higher in state achievement tests.

Reliability and Validity: Triangulation. The RTPOS employed a triangulation approach to control for threats to reliability and validity within the study (Tashakkori \& Teddlie, 2002). Historically, triangulation involves using multiple approaches in the examination of research questions (Denzin, 1978). Triangulation of data allows researchers to achieve certain goals within a data set using as many informational channels as the research study allows. Within the RTPOS, researchers used the triangulation of state level data, school level data, and student level data as well as the mixed methods approach to data collection. Triangulation of data promotes comparisons of different levels of data in order to control for differences in self-report data. For instance, within this RTPOS, researchers compared student and school level data to see similarities and differences between what the students reported and what the school level data reported on variables such as achievement, engagement, and transitions (Castellano et al., 2012). Triangulation of data also allows researchers to learn the most from the data by collecting information from multiple sources across the samples of schools. Data collection from interviews with guidance counselors, students, and archival data, specific 
to the RTPOS, allows researchers to build a better-informed case for the relationship between POS implementation and student outcomes. All of these triangulation methods enable the use of the RTPOS data set in this secondary analysis dissertation. Although measures of reliability and validity were not concretely examined within the RTPOS, the use of triangulation controls for those threats.

\section{Secondary Analysis Study}

\section{Population.}

The RTPOS sampled secondary schools in the United States that received Perkins IV funding and provided at least one POS. High school students in those POS programs were the target population. This secondary analysis used the same target population of secondary students in POS in the United States.

\section{Sample.}

The RTPOS followed two groups of students. Because of the inability of primary researchers to manipulate treatment and control conditions, the study used a quasiexperimental design. The RTPOS study followed two groups or groups of students. One group was enrolled in a POS school and the second in their home high school. These two groups represented a treatment (POS) and a control or comparison group. Students in both groups were surveyed in $9^{\text {th }}$ grade $(\mathrm{N}=1540)$ and again in $12^{\text {th }}$ grade $(\mathrm{N}=840)$, a $54 \%$ response rate. Because these surveys were not linked in the data provided, the $9^{\text {th }}$ and $12^{\text {th }}$ grade surveys were treated separately in the analysis discussed later in this chapter. 


\section{Measures.}

Students in both POS and Non-POS programs were administered surveys for grades 9 and 12. The surveys were developed differently to explore certain aspects within the transitions of $9^{\text {th }}$ graders and $12^{\text {th }}$ graders in POS. For instance, the $12^{\text {th }}$ grade survey was developed mainly to gauge the transition period from graduation to postsecondary education and the workforce, while the $9^{\text {th }}$ grade survey captured selection effects of student school assignments and early POS effects.

$9^{\text {th }}$ grade survey. Students were asked to complete the questionnaire about their student experiences in career and technical education within secondary education. By taking the survey, students were able to give feedback about their career planning experiences in high school.

The survey had 27 total questions with multiple answer formats that included dichotomous "Yes/No" answers and several Likert-type formats. The survey was divided into core components that were used to create variables within the study and examined program participation effects. A more detailed description of how variables were developed can be found in the next section.

The components of the survey included:

1.) "Planning Your Courses" with both dichotomous "Yes/No" and Likerttype questions.

2.) "Your Program of Study, Career Major, Academy, or Program" with dichotomous "Yes/No" and Likert-type questions.

3.) "Planning Your Career" with Likert-type questions and multiple response questions.

4.) "Your Classes and Schoolwork" with Likert-type questions and single response questions. 
5.) "Your plans for the Future" with single response questions and openended questions.

6)."Your Beliefs and Opinions About School" with Likert-type questions.

7.)"About You' which is the demographic section of the survey.

$12^{\text {th }}$ grade survey. The $12^{\text {th }}$ grade survey was administered to students to gather information on student goals after high school. The survey was developed to further understand how high school prepared students for life after secondary education.

There were 22 items within the survey that utilized multiple answer formats similar to the $9^{\text {th }}$ grade survey. The $12^{\text {th }}$ grade survey was also divided into components that were used to create the student outcome variables. A more detailed description of how variables were developed can be found in the next section.

The components included:

1.) "Information About You" that included open ended and dichotomous "Yes/No" question formats.

2.) "Information about Your High School Program" with open-ended questions.

3.) "Graduation" with dichotomous "Yes/No" format.

4.) "Your Plans" with multiple response, open ended, and dichotomous question formats.

5.) "Employment After Graduation" with dichotomous questions.

6.) Employment Plans" with open ended and dichotomous questions.

7.) "Post-High School Educational Plans/Intentions" with dichotomous, multiple response, and open-ended questions.

8.) "Military Service" with dichotomous and single response formats. 


\section{Data}

Variables. The variables that were used in this secondary analysis that examined the implementation of Perkins IV and POS within the two student groups included student academic achievement, student engagement, support, and transitions.

Additionally, a demographic variable was used that examined gender differences on those variables just mentioned. The variables of achievement, student engagement, and transitions were chosen as main dependent variables in the RTPOS and developed before the study was conducted. Extensive research has been conducted on these variables for CTE. "The evidence on the role of CTE and career academies on student engagement, achievement, and transitions reviewed below is mixed but suggests that participation in CTE can (1) improve student engagement as measured by high school graduation, (2) influence achievement, and (3) facilitate the transition to employment" (POS Joint Technical Working Group, 2010, p. 11). These variables were the most researched when it came to the impacts of CTE programs on student outcomes. These were also the variables used in this dissertation. As outlined in the literature review of Chapter II there was an additional variable that came out of the literature and was relevant to the data of the RTPOS. This variable of support was also used in this secondary analysis as a major variable.

Composite variables were computed for this analysis using student survey data from the RTPOS study. Each survey question as well as answer options were included in the data set as individual variables. For each major variable, achievement, student engagement, support, and transitions, composite scores were computed by adding survey item answers together that coincided with the relevant literature on that variable that was 
reported in Chapter II. A description of which survey items were grouped together that measured the major variables in the secondary analysis is below.

Composite variables were created using non traditional variables to measure the major outcome variables in this secondary analysis. Due to the use of student survey data and available information on the survey items, variables were created using items that are empirically correlated to the major variables.

\section{Independent variables.}

POS Participation. Students in both $9^{\text {th }}$ and $12^{\text {th }}$ grades were asked if they were involved in a program of study or a similar program in high school. This survey item became the treatment and control group variable of POS Participation/No POS

Participation.

$9^{\text {th }}$ grade POS survey item: "Do you have or are you in a program of study, career major, academy, or program? Examples of these might be Computer Animation, Automotive, or pre-engineering, but there could be many others."

$12^{\text {th }}$ grade POS survey item: “Are you currently in a program at your high school? A program might also be known as a major, program of study, career major, career pathway, career academy, International Baccalaureate, etc.”

Gender. Gender was the demographic variable of interest in this secondary analysis and was asked through self-report on the $9^{\text {th }}$ grade survey only. Students chose either category of male or female.

Item 22: "What is your gender?"

\section{Dependent variables.}


Achievement. Student academic achievement was measured in this secondary analysis by the student self report survey for both $9^{\text {th }}$ and $12^{\text {th }}$ graders.

For the $9^{\text {th }}$ grade survey, students were asked about their academic achievement within and outside of POS. Achievement was measured with items that directly related to their achievement such as how their program helped them link academics to their career pathway, how their program helped them get better grades, how many credits they have earned toward graduation, and what was the level of their parents education. The actual survey items are as follows:

Item 5: "Is the program you selected related to your career goals?"

Item 6: "Being in a program of study, career major, academy, or program has:

c.) Helped me get better grades."

Item 12: "How many courses in this program do you plan to take that will earn you college credit by the time you graduate high school?"

Item 26: "What is the highest level of education that your mother (or female guardian) completed? Indicate the highest level of education.”

Item 27: "What is the highest level of education that your father (or male guardian) completed? Indicate highest level of education.”

The composite scores for each of the survey items were used to create total achievement composite scores. This score represented the academic achievement variable.

For the $12^{\text {th }}$ grade group, achievement was only measured through a question regarding on time graduation for the senior class.

Item 4: "Will you graduate from high school in the spring of 2012?" 
The achievement score from this question was used to create the achievement variable for the $12^{\text {th }}$ grade group.

Engagement. Student engagement was measured using the self-report student survey that was developed by the RTPOS research team.

The $9^{\text {th }}$ grade student engagement variable was developed with current literature to group survey engagement items into composite scores. Questions of engagement surrounded student's interest and participation, two variables of engagement according to the literature. All survey questions that pertained to the interest and participation of students in POS were used to create the engagement variable. The survey items were:

Item 6: "Being in a program of study, career major, academy, or program has:

a.) Made me more likely to want to come to school.

b.) Made me less likely to want to drop out of school.

d.) Made me feel like I fit in better at school.

e.) Helped me make connections between what I study and what type of career I want.

f.) Made me more likely that I would take courses that I need for the future.

h.) Made me focus my studies so I know where I am headed."

Item 13: "How often have you done each of the following to complete assignments in your classes this year?:

a.) Used knowledge and skills from different courses.

b.) Used math in classes other than mathematics.

c.) Used science in classes other than science. 
d.) Used the internet to retrieve information about a class project or activity.

e.) Wrote in-depth explanations about a class project or activity.

f.) Developed and analyzed tables, charts, and graphs in my school work.

g.) Used word-processing software to complete an assignment or project."

Item 15: "Please respond to the following statements about all of your high school teachers and courses this year:

a.) My courses have repeated content that I had already learned.

b.) I have tried to do my best in school.

c.) I have worked hard to meet high standards on assignments.

d.) I spend a great deal of time on homework.

e.) I have received a grade for my part in a team or small group."

Item 20: "How much do you agree or disagree with the following statements?:

a.) Studying in school rarely pays off later with good jobs.

b.) Even if I study, I will not be able to get into college.

c.) Even if I study, my family cannot afford to pay for me to attend college."

Item 21: "How much do you agree or disagree with the following statements?:

a.) Most of the information we learn in school is useful for everyday life.

b.) Most of the information we learn in school will be useful for college. 
c.) Most of the information we learn in school will be useful for my career."

For the $12^{\text {th }}$ grade survey, engagement was measured with items that pertained to how their programs linked to either their postsecondary plans or their industry plans. $12^{\text {th }}$ graders in this survey were graduating and their transitions after graduation were the topic of their survey. The survey items that were used to create the composite score were:

Item 2: "If you are planning to work or continue your education, will your plans relate to your school program?"

Item 6: "Is this job or will this job be related to your high school program? A program is known as a major, program of study, career major, career pathway, career academy, International Baccalaureate, etc."

Item 12: "If you are not planning to pursue further education at this time, what is the primary reason? Please select as many responses as apply."

Item 18: "Will your studies at this school relate to your high school program? A program might also be known as a major, program of study, career major, career pathway, career academy, International Baccalaureate, etc.”

Item 19: "If you plan to go to college this fall, which of the following might prevent you from attending? Please select as many responses that apply."

Transitions. Transitions were an important variable to explain the relationships between POS implementation and student outcomes. Student level data was collected on this component and was used for analysis through the student survey for $9^{\text {th }}$ and $12^{\text {th }}$ graders. 
For the $9^{\text {th }}$ grade group, students were asked multiple questions under two main categories of transitions taken from the literature: career activities and postsecondary plans. The variable of transitions used in this secondary analysis was developed using composite scores of those survey items that measured career activities and postsecondary plans. The survey items were:

Item 1: "Have you put together a "course plan" or "graduation plan" - that is, a series of courses you will need to complete during high school in order to be successful in your eventual career choice?"

Item 7: "In high school, have you ever done any of the following activities to help you identify jobs or careers that you might be interested in pursuing?:

a.) Answered questions related to jobs and careers on a computer or filled out a questionnaire.

b.) Researched different jobs or careers.

c.) Researched different colleges, universities, military branches, or technical/community colleges.

d.) Spoken with or visited someone in a career that interests me.

e.) Been in a class where someone from a local business talked about working at their company or in their career."

Item 10: "How much thinking and planning have you done in the following areas?

a.) Gathering information about jobs I might be interested in.

b.) Taking classes to help me decide what kind of job I want.

c.) Participating in school or out-of-school activities that will help me decide what kind of job I want. 
d.) Volunteering, interning, or working on a job to help me find out what kind of job I want to have in the future."

Item 16: "As things stand now, how far do you think you will go in school?"

Item 17: "What is the main thing you plan to do the year after graduating from high school?"

Item 19: "Looking ahead to when you are 30 years old, what job do you plan to have at that time?"

For the $12^{\text {th }}$ grade group, the majority of questions on the survey were geared towards transitions as transitioning from POS into postsecondary education or the workforce was a major variable regarding the relevance and effects of POS in secondary education. Transitions were measured through multiple survey items that were supported by literature. Survey items included areas such as transitions, postsecondary planning activities, postsecondary education and education status after graduation, employment, and military. The survey items were:

Item 5: "If you won't be graduating in spring of 2012, what are your plans?" Item 7: "Do you plan on working immediately after graduation?" Item 8: "Will you be employed full time?" Item 10: "Do you plan to attend a four-year college or university, two year community college, or trade/technical school for the fall 2012 semester?" Item 12: "What kind of school is it?" Item 13: "Have you applied to this school?" Item 14: "Have you been accepted to this school?" 
Item 16: "Will you be a full-time student (that is, taking a full course load, usually three or more course per term?"

Item 19: "Have you been accepted into a branch of the military?"

Support. As the literature review suggested, support for students was important to all major variables, which was why it was included as variable in this secondary analysis. Support was only measured in the $9^{\text {th }}$ grade group. Support questions pertained to where a student's support came from such as teachers and parents, as well as areas where support was lacking. Composite scores from those survey items were created to measure support within the $9^{\text {th }}$ grade group. The survey items were:

Item 2: "When you put together your course plan, how often did you?:
a.) Talk with your parents, stepparents, or other adults you live with.
b.) Talk with your teachers.
c.) Talk with your guidance counselor.
d.) Talk with friends.
e.) Take part in a parent-counselor-student conference."

Item 5: "Being in a program of study, career major, academy, or program has: g.)Made it more likely that my parents got involved in my selection of courses."

Item 7: "Between the start of $9^{\text {th }}$ grade and now, who have you talked to about the following topics? (Answer choices were: Parent/guardian, teacher, school counselor, have not discussed with any of these people):
a.) What courses to take this school year.
b.) Going to college. 
c.) Things you've studied in class.

d.) Your grades.

e.) Finding a job after high school.

f.) Steps necessary to pursue your career.

g.) Applying for college or vocational/technical school."

Item 8: "Who provided the most helpful advice? Please select all those people who provided the most helpful advice about the indicated topic. (Answer choices were: Parent/guardian, teacher, school counselor, have not discussed with any of these people):

a.) What courses to take this school year.

b.) Going to college.

c.) Things you've studied in class.

d.) Your grades.

e.) Finding a job after high school.

f.) Steps necessary to pursue your career.

g.) Applying for college or vocational/technical school."

Item 12: "How often have you done each of the following to complete assignments in your classes this year?

h.) In classes other than English, teachers have helped me understand what I have read."

Item 13: "Please respond to the following statements about all of our high school teachers and courses this year:

a.) Most of my teachers make the subject matter interesting and useful. 
b.) Most of my teachers have set high standards for me.

c.) Most of my teachers will not let me get by without doing the work.

d.) Most of my teachers have encouraged students to help each other.

e.) Most of my teachers have encouraged me to do well in school.

f.) Most of my teachers make connections between what they are teaching and how it applies to the real world.

g.) Most of my teachers give me extra help when I need it.”

\section{Research Questions.}

The secondary analysis examined multiple research questions to understand the relationships between Perkins IV and POS student outcomes on the RTPOS data set. The research questions measured effects of POS implementation on variables of achievement, student engagement, support, and transitions and used the student level self-report data to create variables. Gender differences within those variables were also examined for the $9^{\text {th }}$ grade group. Below were the research questions for both groups.

The research questions for the $9^{\text {th }}$ grade survey participants were:

RQ1: Was there a significant POS participation main effect on the linear composite of academic achievement, engagement, support, and transitions of $9^{\text {th }}$ grade secondary students?

RQ2: Was there a significant gender main effect on the linear composite of academic achievement, engagement, support, and transitions of $9^{\text {th }}$ grade secondary students? 
RQ3: Was there a significant interaction effect between POS participation and gender on the linear composite of academic achievement, engagement, support, and transitions of $9^{\text {th }}$ grade secondary students?

The research question for the $12^{\text {th }}$ grade survey participants was:

RQ4: Was there a significant main effect of POS participation on the linear composite of academic achievement, engagement, support, and transitions of $12^{\text {th }}$ grade secondary students?

\section{Methodology.}

The secondary analysis employed two statistical analyses and examined the research questions. Multivariate methods used included two Multivariate Analysis of Variance (MANOVA).

Factorial MANOVA.

RQ1: Was there a significant POS participation main effect on the linear composite of academic achievement, engagement, support, and transitions of $9^{\text {th }}$ grade secondary students?

RQ2: Was there a significant gender main effect on the linear composite of academic achievement, engagement, support, and transitions of $9^{\text {th }}$ grade secondary students?

RQ3: Was there a significant interaction effect between POS participation and gender on the linear composite of academic achievement, engagement, support, and transitions of $9^{\text {th }}$ grade secondary students?

There were two independent variables (IV) in the above research questions. They were POS implementation with two levels: POS and non-POS, and gender with two 
levels: male and female. Students in $9^{\text {th }}$ grade group were divided into POS participation and Non-POS participations as well as either male or female. There were multiple dependent variables (DV) within the research question that were measured:

1.) Academic Achievement, 2.) Student Engagement, 3.) Support, and 4.) Transitions.

The statistical test that examined these research questions was a Factorial Multivariate Analysis of Variance (Factorial MANOVA). This test was chosen because there were multiple IV's and multiple DV's within these three research questions. Factorial MANOVAs are used to examine joint effect differences of IV's on multiple DV's simultaneously so to reduce the number of tests being run. One advantage of using a MANOVA includes reducing the number of statistical tests run decreases the chance of committing a Type I error, which is stating there is a statistically significant difference when there is not. MANOVAs also take into account the correlations among variables. Using multiple variables allows for significant differences among groups of variables to present themselves even if the individual variables do not effect the treatment/intervention groups significantly. Lastly, MANOVAs can examine subtests of variables or tests beyond total test scores of univariate analyses (Stevens, 2009). Factorial MANOVAs allow researchers to examine the main effects of each IV independently as well as the potential interaction effect of IV's on all DV's. If the multivariate significance is detected, post-hoc univariate effects of IV's on each DV, as well as all DV's effects, can be examined.

The assumptions of a Factorial MANOVA include: 1.) independence, 
2.) normality, 3.) linearity, 4.) homogeneity of variances and of covariance's, and 5.)

multicolinearity (Stevens, 2009). Meeting these assumptions was the first step in examining the research questions proposed in this secondary analysis.

Independence is an assumption that considers the participants scores independently from one another (Stevens, 2009). We assumed independence in this data set as students answered their own surveys a part from their peers. Normality was tested along a normal curve and ensured that the data was dispersed on a bell shaped curve. Linearity considers mean values of the outcome variable for each increment of the predictors and if they lie along a straight line. It was assumed we are modeling a linear relationship. The Homogeneity of Variance and Covariance assumption indicated the equality of the variances between the treatment and control groups. This assumption was tested using Box's Test of Equality of Covariances and Levene's Test of Equality of Error Variance to test for equal variation among conditions. Finally, multicolinearity means highly correlated predictor variables. This was tested using the correlation matrix. If correlation coefficients are .8 or higher this may indicate the presence of multicolinearity (Stevens, 2009) in which case these correlations were further examined. One-Way MANOVA.

RQ4: Is there a significant main effect of POS participation on the linear composite of academic achievement, engagement, support, and transitions of $12^{\text {th }}$ grade secondary students?

There was one IV within this research question that examined multiple DV's. The IV was POS implementation with two levels: POS and non-POS. There were 
multiple DV's in this research question that included academic achievement, student engagement, and transitions.

The statistical test that was conducted for this research question was a One-Way MANOVA. A One-Way MANOVA was chosen for this research question because there was one IV with multiple DV's. The assumptions of a MANOVA as well as other characteristics describing the test were explained in the above section under the assumptions of a Factorial MANOVA.

\section{Summary}

The methods chapter presented in this secondary analysis explained the data set provided by the RTPOS and the methodology of the secondary analysis. The RTPOS examined student outcomes of Perkins IV legislation that included POS development and implementation. For the secondary analysis, data from student self report surveys were used from the RTPOS to answer the 4 research questions that used a composite score method for variable development. The analysis of the secondary analysis used 2 different statistical approaches that included a Factorial MANOVA and a One-Way MANOVA. The purpose of this secondary analysis was to explain student differences within POS program implementation and gender differences on CTE evidence-based variables of academic achievement, student engagement, support, and transitions. The general purpose of this dissertation was to inform the field of impacts and relationships surrounding the multiple pathways approach to secondary education through the analysis of Perkins IV and POS. 


\section{CHAPTER IV}

\section{RESULTS}

The results chapter focused on the outcomes of the statistical analysis explained in Chapter III: Methods. Because the secondary analysis was a parallel study of two different groups, grades 9 and 12, two sets of results were reported for each. Data from the $9^{\text {th }}$ grade group was reported and discussed first, then $12^{\text {th }}$ grade group. Descriptive statistics were reported with the major variables following. The results of the MANOVA's for both groups were reported second.

\section{Research Questions}

The research questions for the $9^{\text {th }}$ grade group were:

RQ1: Was there a significant POS participation main effect on the linear composite of academic achievement, engagement, support, and transitions of $9^{\text {th }}$ grade secondary students?

RQ2: Was there a significant gender main effect on the linear composite of academic achievement, engagement, support, and transitions of $9^{\text {th }}$ grade secondary students?

RQ3: Was there a significant interaction effect between POS participation and gender on the linear composite of academic achievement, engagement, 
support, and transitions of $9^{\text {th }}$ grade secondary students?

The research question for the $12^{\text {th }}$ grade group was:

RQ4: Was there a significant main effect of POS participation on the linear composite of academic achievement, engagement, support, and transitions of $12^{\text {th }}$ grade secondary students?

\section{$9^{\text {th }}$ Grade Group}

\section{Descriptive Statistics.}

Tables 1 and 2 reflect the descriptive statistics for the $9^{\text {th }}$ grade group on the major variables in the study that were developed from the student survey.

Table 1 presents means, standard deviations, and t-values for the independent variable, POS vs. Non POS, and major variables of achievement, student engagement, support, and transitions. Students in POS, compared to students in Non-POS, showed higher averages on all major variables as well as statistically significant t-values, which indicated there were statistically significant differences between the two groups. Statistically significant differences between the two groups supported the notion that students within contextually based programs in high school are able to make linkages to their postsecondary or industry plans from the real world experiences they receive in school (Salmela-Aro \& Tuouminen, 2010; Brush \& Saye, 2008; O’Connor, 2008; Yazzie-mintz 2007; Wallace, Venville, \&Rennie, 2005; Rahm, Miller, Hartley, \& Moore, 2003). 
Table 1

Means, Standard Deviations, and T-Tests of the Major Variables for the $9^{\text {th }}$ grade group by POS participation $(\mathrm{N}=1,540)$

\begin{tabular}{lcc}
\hline & POS & Non POS \\
Demographic Variable & $\mathrm{n}=768(49.9 \%)$ & $\mathrm{n}=772(50.1 \%)$
\end{tabular}

\begin{tabular}{lllc}
\hline \multicolumn{1}{c}{ Variables } & Mean(SD) & Mean(SD) & $\mathrm{t}$ \\
\hline Academic Achievement & $25.8(5.4)$ & $21.4(5.9)$ & $-86.3^{* *}$ \\
Student Engagement & $21.9(3.5)$ & $9.7(1.8)$ & $-15.3^{* *}$ \\
Support & $33.8(6.3)$ & $31.2(6.3)$ & $-8.1^{* *}$ \\
Transitions & $22.7(3.7)$ & $22.1(3.8)$ & $-3.1^{* *}$ \\
\hline
\end{tabular}

Note: $* * p<.001$

Table 2 presents means, standard deviations, and t-values for the second independent variable, gender, and major variables of achievement, student engagement, support and transitions. There were statistically significant differences between males and females on each major variable. Males showed higher averages in two variables: student engagement and achievement, while females showed higher averages in the other two variables: support and transitions. This was consistent with literature that female students embrace meaningful relationships, compared to their male counterparts, with their teachers and parents as it pertains to school (Tison, Bateman, \& Culver 2011; Sax, 2008; Zusman, Knox, \& Leiberman 2005). Females also plan more, compared to males, which is a consistent finding across mean differences. As for males, research generally has indicated that males outperform females in vocational-track education but this trend is changing with more females working in male dominant fields (Bursal, 2013). There were also small gaps regarding mean differences and gender overall. 
Table 2

Means, Standard Deviations, and T-tests of the Major Variables in $9^{\text {th }}$ grade group by Gender $(\mathrm{N}=1,539)$

\begin{tabular}{lllc}
\hline & \multicolumn{1}{c}{ Male } \\
Demographic Variable & $\mathrm{n}=725(47.1 \%)$ & $\begin{array}{c}\text { Female } \\
\mathrm{n}=814(52.9 \%)\end{array}$ & \\
\hline \multicolumn{1}{c}{ Variables } & Mean(SD) & Mean(SD) & $\mathrm{t}$ \\
\hline Academic Achievement & $24.3(6.0)$ & $23.1(6.0)$ & $-2.2^{*}$ \\
Student Engagement & $16.1(6.1)$ & $15.4(6.7)$ & $-3.7^{*}$ \\
Support & $32.1(6.4)$ & $32.9(6.4)$ & $2.3^{*}$ \\
Transitions & $22(3.8)$ & $22.8(3.7)$ & $4.1^{*}$ \\
\hline
\end{tabular}

Note: $* p<.05$

Correlations. Table 3, below, depicts inter-correlations among major variables by POS participation and gender. The table presents both independent variables, with the POS participation on top and gender on the bottom, and correlations of major variables. There was a significant, positive, and strong correlation between POS participation and student engagement $(\mathrm{r}=.91)$. There were significant, positive, and moderate correlations between all major variables as well. The correlation between POS and engagement support the literature that POS participation could be linked to higher levels of engagement both in participation and interest. The literature on all of these major variables also support the relationship between them in that achievement, engagement, support, and transitions are all linked (Levpuscek, Zupancic, \& Socan, 2012; Jeynes, 2007; Gonzalex-Dehass, \& Holbein, 2005; Fan \& Chen, 2001; Marchant, Paulson, \& Rothlisberg, 2001). There were statistically significant correlations at both the .05 and .01 
alpha levels. The correlations, however, were weak. This indicated significant but small relationships between the major variables and the variable of gender.

\section{Table 3}

Correlations and Significance (Two-Tailed) of Major Variables by Independent Variables

\begin{tabular}{lcccc}
\hline & $\begin{array}{c}\text { Academic } \\
\text { Achievement }\end{array}$ & $\begin{array}{c}\text { Student } \\
\text { Engagement }\end{array}$ & Support & Transitions \\
\hline $\begin{array}{l}\text { Academic } \\
\text { Achievement }\end{array}$ & -.02 & $.33^{* *}$ & .01 & -.02 \\
Student & -.14 & & $.31^{* *}$ & $.24 * *$ \\
Engagement & $-.13^{* *}$ & $.31^{* *}$ & $-42^{* *}$ \\
Support & & & $.44^{* *}$ & \\
Transitions & & & & \\
\hline
\end{tabular}

Note: $* * p<.01$ level.

\section{Inferential Statistics.}

To address research questions 1-3 a MANOVA was conducted on the $9^{\text {th }}$ grade group. Before conducting a MANOVA, certain statistical assumptions needed to be met as explained in Chapter III. The assumptions were: Independence, Normality, and Homogeneity of Variance and Covariance. The first assumption, Independence, was met before and during data analysis as all participants, in both conditions, did not influence each other's responses to survey data. The second assumption, Normality, was also met because participants in the research study fell along a normal bell-shaped curve (Appendix B). Finally, the Homogeneity of Variance and Covariance assumption was met through two statistical analyses: Box's Test of Equality of Covariances and Levene's 
Test of the Equality of Error Variance. Box's Test measured whether the covariances of the dependent variables were equal across all groups of dependent variables. Box's Test of Equality of Covariance matrix was not statistically significant, $F=12.14, p>.05$, which indicated that covariances across DV's were equal.

Levene's Test of Equality of Error Variance measured whether the error variances of DV's were equal across all groups. A non-significant Levene's Test is desired for variables within an analysis. Two variables, support and transitions reported nonsignificant Levene's Tests (support: $\mathrm{F}=.39, p>.05$; transitions: $\mathrm{F}=.85, p>.05$ ), which indicated error variances were equal across groups. The other two variables, academic achievement and student engagement reported significant Levene's Tests $(p<.05)$. However, Stevens (2009) indicates that MANOVAs are robust enough to still examine variables that have significant Levene's test.

The MANOVA was chosen to address whether POS participation and gender, and their potential interaction, had significant effects on dependent variables of achievement, student engagement, support, and transitions because it allows several variables to be tested at once as opposed to analyzing each dependent variable separately. There were many advantages to conducting a MANOVA instead of multiple ANOVAs as mentioned in Chapter III. In this analysis, a report of the MANOVA results included the multivariate statistics as well as univariate statistics for all variables. There were both significant and non-significant differences of POS participation and gender on the major dependent variables at the .05 alpha levels.

Results from the two-way MANOVA indicated that there was no statistically significant interaction effect of POS participation and gender on major variables. There 
was, however, a multivariate significance of POS participation main effect on major variables $(p=.0001)$, indicating that POS participation was significantly related to the linear combination of academic achievement, student engagement, support, and transitions. This main effect of POS participation was significant $\left(\eta^{2}=.85\right)$ with an observed power of 1.0. According to Cohen (1988), this is a large effect size, indicating that POS participation explained approximately $85 \%$ of the variance in the linear combination of academic achievement, student engagement, support, and transitions.

Following the multivariate significance of POS participation main effect, each dependent variable was examined at the univariate level. The results showed that POS participation was significantly related to academic achievement $(p=.0001)$, student engagement $(p=.0001)$, support $(p=.0001)$, and transitions $(p=.0001)$. Inspections of the effect sizes indicated that POS participation was most meaningfully related to student engagement $\left(\eta^{2}=.83\right.$, large effect), indicating that approximately $83 \%$ of variance in student engagement was accounted for by POS participation. Approximately $13 \%$ (medium effect) of the variance in academic achievement was accounted for by POS participation, followed by $4 \%$ (small effect) of variance in support, and negligible amount in transitions.

There was also a multivariate significance of gender main effect on major variables $(p=.0001)$, indicating that gender was significantly related to the linear combination of academic achievement, student engagement, support, and transitions. This main effect of gender had a small effect size $\left(\eta^{2}=.02\right)$ with an observed power of 1.0. According to Cohen (1988), this is a small effect size, indicating that gender 
explained approximately $2 \%$ of the variance in the linear combination of academic achievement, student engagement, support, and transitions.

Following the multivariate significance of gender main effect, each dependent variable was examined at the univariate level. The results showed that gender was significantly related to academic achievement $(p=.0001)$, student engagement $(p=.0001)$, support $(p=.0001)$, and transitions $(p=.0001)$. Inspections of the effect sizes indicated that gender had small effect sizes, $1 \%$ or less for each of the dependent variables. Results of the one-Way MANOVA and Tests of Between-Subject Effects are presented in tables 4 and 5 .

Table 4 MANOVA Summary

\begin{tabular}{lcccccc}
\hline Source & $\begin{array}{c}\text { Wilk's } \\
\text { Lamdba }\end{array}$ & F & $\begin{array}{c}\text { Hypothesis } \\
\text { DF }\end{array}$ & $\begin{array}{c}\text { Error } \\
\text { DF }\end{array}$ & Sig. & $\begin{array}{c}\text { Partial } \\
\text { Eta }^{2}\end{array}$ \\
\hline POS Participation & .15 & 2178.3 & 4 & 1531 & .00 & .85 \\
Gender & .98 & 9.3 & 4 & 1531 & .00 & .02 \\
POS*Gender & .13 & 1.1 & 4 & 1531 & .41 & .00 \\
\end{tabular}


Table 5

Tests of Between-Subjects Effects Summary

$\begin{array}{llll}\text { Source } & \text { Variable } & \text { Sig. } & \text { Partial Eta } \\ \end{array}$

POS Participation

$\begin{array}{llll}\text { Academic Achievement } & 223.13 & .00 & .13 \\ \text { Student Engagement } & 7278.51 & .00 & .83 \\ \text { Support } & 66.43 & .00 & .04 \\ \text { Transitions } & 13.14 & .00 & .01\end{array}$

Gender

$\begin{array}{lccc}\text { Academic Achievement } & 5.13 & .01 & .00 \\ \text { Student Engagement } & 21.74 & .00 & .01 \\ \text { Support } & 11.74 & .00 & .01 \\ \text { Transitions } & 21.21 & .00 & .01\end{array}$

\section{$12^{\text {th }}$ grade group}

Descriptive Statistics.

The variables within the $12^{\text {th }}$ grade group were similar to the $9^{\text {th }}$ grade group except for a few changes. The $12^{\text {th }}$ grade group had one IV: POS participation, and generally focused on transitions more than any other DV.

Table 7 presents means, standard deviations, and t-values for the POS vs. NonPOS $12^{\text {th }}$ grade group across major variables of academic achievement, student engagement, and transitions. There were statistically significant differences between POS and Non-POS students on academic achievement and student engagement. Non-POS students showed statistically significant higher averages for both of these variables. 
Table 6

Means, Standard Deviations, and T-values of Major Variables in $12^{\text {th }}$ Grade Group by POS Participation $(\mathrm{N}=840)$

\begin{tabular}{lllc}
\hline Demographic Variable & $\begin{array}{c}\text { POS } \\
\mathrm{n}=630(75 \%)\end{array}$ & $\begin{array}{l}\text { Non POS } \\
\mathrm{n}=210(25 \%)\end{array}$ & $\mathrm{t}$ \\
\hline \multicolumn{1}{c}{ Variables } & Mean(SD) & Mean(SD) & $-2.1^{*}$ \\
\hline Academic Achievement & $2.0(.12)$ & $2.0(1.5)$ & $13.1^{*}$ \\
Student Engagement & $2.8(1.2)$ & $4.0(1.15)$ & -1.9 \\
Transitions & $17.0(1.7)$ & $16.7(2.0)$ & \\
\hline
\end{tabular}

Note: $* p<.05$

Correlations. Table 8, below, reflects all correlations among POS participation and the major variables. There were multiple significant correlations at the .05 and .01 alpha levels. There was a significant, negative, and moderate correlation between POS and student engagement $(\mathrm{r}=-.41)$. There was a significant, positive, and moderate correlation between major variables of student engagement and transitions. This was consistent with literature that POS students have the potential to transition smoothly into business/industry due to their work experiences in high school (Plessis et al., 2011; Gørgens \&Ryan, 2006; Phillips et al., 2002). 
Table 7

Correlations and Significance (Two-Tailed) of Major Variables by POS Participation

\begin{tabular}{|c|c|c|}
\hline $\begin{array}{l}\text { Academic } \\
\text { Achievement }\end{array}$ & $\begin{array}{l}\text { Student } \\
\text { Engagement }\end{array}$ & Transitions \\
\hline $\begin{array}{l}\text { Academic } \\
\text { Achievement }\end{array}$ & -.05 & .00 \\
\hline $\begin{array}{l}\text { Student } \\
\text { Engagement }\end{array}$ & 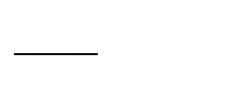 & $.43 * *$ \\
\hline Transitions & & \\
\hline
\end{tabular}

Note: ${ }^{*} p<.05$

$* * p<.001$ 


\section{Inferential Statistics.}

To address research question 4 for the $12^{\text {th }}$ grade group a one-Way MANOVA was conducted. The assumptions for the one-Way MANOVA were the same as the MANOVA and were explained in the inferential statistics of the $9^{\text {th }}$ grade group. The assumptions included: Independence, Normality, and Homogeneity of Variance. Independence was met because group students took exams without influence of other students in their own group in both treatment and control groups. Normality was met because students in both treatment and control groups were assumed to fall along a normal bell curve (Appendix D). Homogeneity of Variance was met through the Box's Test of Equality of Covariance's. For this covariance matrix, Box's Test of Equality was not statistically significant, $F=7.6, p>.05$, which indicated that covariances across DV's were equal.

As with the $9^{\text {th }}$ grade group, Levene's Test of Equality of Error Variance was analyzed. With the Levene's test, one can examine whether the error variance in the DV's are equal across groups. One variable, achievement, reported a non-significant Levene's statistic, $\mathrm{F}=3.5, p>.05$. The other two variables, student engagement and transitions, reported a statistically significant Levene's statistic, student engagement: F= 4.1, $p<.05$; transitions: $\mathrm{F}=10.1, p<.05$. Although student engagement and transitions were significant, they were still analyzed in the one-Way MANOVA due to the robustness of the multivariate statistical test (Stevens, 2009).

A one-Way MANOVA was conducted to measure POS participation and major variables of achievement, student engagement, and transitions. A one-Way MANOVA was conducted because multiple DV's can be tested at one time, which lessens the 
amount of Type I error as explained in the previous section, along with having many other advantages (Stevens, 2009).

Results from the one-way MANOVA indicated that there was a multivariate significance of POS participation main effect on major variables $(p=.0001)$, indicating that POS participation was significantly related to the linear combination of academic achievement, student engagement, support, and transitions. This main effect of POS participation had a small effect size $\left(\eta^{2}=.24\right)$ with an observed power of 1.0. According to Cohen (1988), this was a small effect size, indicating that POS participation explained approximately $24 \%$ of the variance in the linear combination of academic achievement, student engagement, support, and transitions.

Following the multivariate significance of POS participation main effect, each dependent variable was examined at the univariate level. The results showed that POS participation was significantly related to student engagement $(p=.0001)$, and was not significantly related to academic achievement $(p>.05)$ or transitions $(p>05)$. Inspection of the effect size for student engagement indicated that POS participation was related to student engagement $\left(\eta^{2}=.17\right.$, small effect), indicating that approximately $17 \%$ of the variance in student engagement was accounted for by POS participation. Results of the one-Way MANOVA and Tests of Between-Subject Effects are presented in tables 9 and 10. 
Table 8

One-Way MANOVA Summary

\begin{tabular}{lcccccc}
\hline Source & $\begin{array}{c}\text { Wilk's } \\
\text { Lamdba }\end{array}$ & F & $\begin{array}{c}\text { Hypothesis } \\
\text { DF }\end{array}$ & $\begin{array}{c}\text { Error } \\
\text { DF }\end{array}$ & Sig. & $\begin{array}{c}\text { Partial } \\
\text { Eta }^{2}\end{array}$ \\
\hline POS participation & .76 & 88.14 & 3 & 836 & .00 & .24 \\
\hline
\end{tabular}

Table 9

Tests of Between Subjects-Effects Summary

$\begin{array}{lll}\text { Source } & \text { Variable } & \text { Sig. }\end{array}$

POS Participation

$\begin{array}{llll}\text { Achievement } & .90 & .40 & .00 \\ \text { Student Engagement } & 171 & .00 & .17 \\ \text { Transitions } & 3.53 & .10 & .00\end{array}$

\section{Summary}

Two multivariate statistical procedures were conducted on two groups of students that analyzed 4 research questions of this secondary analysis. The secondary analysis examined the RTPOS, a quasi-experimental study of POS participation effects on student outcomes.

For the $9^{\text {th }}$ grade group, the research questions asked whether there was a significant main effect of POS participation on major variables of achievement, student engagement, support, and transitions, if there was a significant main effect of gender on major variables, as well as a significant interaction effect between POS participation and 
gender on major variables. A MANOVA was conducted and all assumptions were met except Levene's Test of Equality of Error Variance. However, because of the robustness of MANOVAs, analysis continued (Stevens, 2009). Results suggested a main effect of POS participation on all major variables, a significant main effect of gender on all major variables, and no significant interaction effect of POS participation and gender on major variables. There was a large effect size for POS participation on major variables that explained $85 \%$ of the variance in dependent variables, and a small effect size for gender on major variables that explained $2 \%$ of the variance in dependent variables. These statistical results suggested that POS students presented as well as believed to have high achievement, engagement, support, and were able to transition to postsecondary education or the workforce, compared to their Non-POS counterparts.

For the $12^{\text {th }}$ grade group, the research question asked whether there was a significant main effect of POS participation on major variables of achievement, student engagement, and transitions. A one-Way MANOVA was conducted and all assumptions were met except the Levene's Test of Equality of Error Variance. However, because of the robust nature of one-Way MANOVAs the analysis continued (Stevens, 2009). There was a significant main effect of POS participation on major variables. There was a small effect size of POS participation that explained $24 \%$ of the variance in dependent variables. The main effect of POS participation was significant for the student engagement variable. There was no significant main effect of POS participation on the other two variables of achievement and transitions. Results suggested POS students were more engaged in their high school program compared to their Non-POS counterparts. Results also suggested POS students were not presenting or believing that they were 
achieving or transitioning compared to their counterparts. A full discussion of the results will be provided in Chapter V. 


\section{CHAPTER V \\ DISCUSSION}

This dissertation was a secondary analysis that examined the impact of a major Career and Technical Education Act, Perkins IV, on secondary student outcomes. The secondary analysis was conducted on a primary quasi-experimental research study named the RTPOS (Castellano et al., 2012). The RTPOS collected and analyzed longitudinal state and student level data from two states in the U.S. The RTPOS examined POS participation effects on highly studied student outcome variables of academic achievement with sub-variables of student engagement and transitions. This secondary analysis took one state and two groups from the RTPOS and specifically examined student level self-report survey data on POS participation effects on three, sometimes four (depending on the group) student variables of academic achievement, student engagement, support, and transitions, as well as a demographic variable of gender.

Studying POS participation effects is an important part of Perkins IV accountability. Measuring student success within these programs on such variables of achievement, engagement, and transitions is the goal of several research endeavors by the National Research Center for Career and Technical Education (NRCCTE.org, 2014). This secondary analysis was another piece to the puzzle that contributed to the field of CTE where the goal is to give high school students a multiple pathways approach to 
education for the purpose of a smoother and more relevant transition to business/industry and continuing education. The final chapter of this dissertation provides a summary of findings as well as discussion of the analysis that ties in the contribution this study makes to the current literature of CTE and Workforce Development.

\section{Summary of Major Findings}

The RTPOS, the study that this secondary analysis examined to further the understanding of POS participation effects, was quasi-experimental in nature. Researchers in the RTPOS could not manipulate treatment and control condition participation placement. Because of the inability to manipulate the conditions, an important factor within the analysis of quasi-experimental designs is the interpretation. The major independent variable of this secondary analysis was POS participation.

\section{$9^{\text {th }}$ Grade Group.}

For the $9^{\text {th }}$ grade group, POS participation as well as gender effects were examined on student outcome variables of academic achievement, student engagement, support, and transitions. The results of the multivariate analysis on student self-report survey data indicated significant differences between treatment and control conditions for both POS participation and gender, but no significant difference between treatment and control conditions for the interaction effects of those variables on the dependent variables. Significant POS and gender main effects differences were found for all dependent variables. There was a large effect size for POS participation that explained $85 \%$ of the variance in the dependent variables. For gender, there was a small effect size (2\% explained variance). 
The variables of academic achievement, student engagement, and transitions were chosen to examine POS participation effects because they are the most studied student outcome variables within CTE (USDE, 2013; Tison, Bateman, \& Culver, 2011). These student outcome variables were also extremely important for understanding any school related initiative as achievement, in many ways, outlines the educational success of a student, while engagement speaks to the individual interest that a student experiences within school (Appleton, 2008). With the addition of the support variable, the secondary analysis was able to touch upon several spheres that coincide and influence a student's secondary experience within a POS. Results suggested that POS participation, compared to no POS participation, played a positive role in student academic achievement, their student engagement, support from teachers and parents, and their ability to transition through career planning activities.

Literature supports the use of POS within secondary education to positively impact a student's academic achievement, student engagement, support, and ability to transition (Castellano et al., 2012; Hammond et al., 2012; Hanushek \& Woessmann, 2008, Appleton et al., 2006). The findings in this secondary analysis for the survey data were consistent with that literature. Reasons for the consistency can be further extended into the literature in that real world, context-specific applications learned within a POS can increase achievement, engagement, and transitions because of the mental understanding, meaning, and linkages that can be made from classroom to real world (Alarcon et al., 2011; Lichtinger \& Kaplan, 2011; Zimmerman, 2008; Gonzalez et al., 2006). Learning with a more hands-on approach, and building curricula's that fit industry standards, enables secondary students to learn more context specific lessons on 
their industry of choice as well as allows them to start building their general, employability, and job specific skills (Stone \& Lewis, 2013; Shulman, 2002). Linking business and industry standards with education sets a career pathway for students to follow from secondary school into postsecondary school or right into business and industry. The ability of POS to set these career pathways within secondary education provides a stable and contextual learning environment for students regardless of what pathway they choose and enables them to transition smoothly into the industry (Connor \& Pope, 2013; Levpuscek et al., 2012; Carini et al., 2006). Furthermore, POS enables students to transition smoothly into pathways after graduation from secondary school through achievement and engagement initiatives, supporting the interaction between dependent variables within this secondary analysis (Carini et al., 2006). By earning postsecondary credits within secondary school, participating in career based activities such as shadowing, internships, or co-ops, or planning out their course sequences with supportive staff, all contribute to the end goal of a smooth transition (King \& Gaerlan, 2014; Tison, Bateman, \& Culver, 2011; Martin, 2009; Hanushek \& Woessmann, 2008; Phillips et al., 2002). That is what POS intends to achieve with the structures set in place for students who choose career pathways.

The students within this group were at the end of their $9^{\text {th }}$ grade year in secondary school when the RTPOS data was collected. These were students at the very beginning of their POS who were two semesters into their chosen career pathways. The findings of significant associations of POS participation on new POS participants speak to the ability of the career pathways system to prepare their students for success in the programs from the beginning. Ninth grade students in POS, compared to their non-POS counterparts, 
reported higher achievement, engagement, support, and preparation to transition, with just one academic year of experience in their programs. From the beginning of $9^{\text {th }}$ grade, the components of POS and their structures, support, and resources seem strong and salient to the students within these programs. Consistent with findings in this secondary analysis, the intentions and goals of POS were achieved for the $9^{\text {th }}$ grade group.

Gender also plays a positive role in student's achievement, student engagement, support, and ability to transition but was mixed between males and females within this secondary analysis. Gender was significantly related to males' academic achievement and student engagement, while gender was associated with females' support structures and abilities to transition. Literature on gender and student outcomes is mixed (Bursal, 2013; Tison, Bateman, \& Culver, 2011; Shih, 2010; Bacharack, Baumeister, \& Furr, 2003; Evans, Schweignruber, \& Stevenson, 2002). The findings of this secondary analysis were consistent with literature on mixed gender effects on student outcomes. Some research also indicates no gender difference on these variables (Goldin, Katz, \& Kuziemko, 2006; Spelke, 2005; Cole, 1997).

Research worldwide supports male achievement as being higher than female achievement (Bursal, 2013; Bacharack, Baumeister, \& Furr, 2003). Other research points to females achieving higher than males (Ilgan, 2013; Lupart, Cannon, \& Telfer, 2004; Jose \& Ratcliffe, 2004). Males in this secondary analysis performed better perhaps because of the hands-on approaches to education that provide a contextual based learning environment, such as with POS. With a more hands-on approach that is aligned to their interests, males may also then be more engaged in the learning process as both variables are related, as the results suggested. It may not be that females performed worse than 
males in POS, but rather, males' academic performance was enhanced through the use of non-traditional CTE lessons and in turn also increased their engagement.

Females may report more supportive structures within school because they generally have stronger ties and relationships with teachers, guidance counselors, peers, and parents. They place value on these relationships (Sax, 2008; Zuzman, Knox \& Leiberman, 2005; Murgberg \& Bru, 2004 \& Bru, 2004). Also, females tend to plan and participate in extra curricular (aside from sports) activities compared to males, making some of the transitional components of POS aligned to their existing perspectives. Girls also experience stress and academic burnout more than boys, which may put all variables at risk (Salmeloaro, Tuouminen-Soini, 2010; Matud, 2004; Jose \& Ratcliffe, 2004).

Literature on gender and education is certainly mixed, this secondary analysis supported mixed results.

\section{$12^{\text {th }}$ Grade Group.}

Students were surveyed again in the $12^{\text {th }}$ grade on the major variable of POS participation effects. The effects of POS were examined on three dependent variables of academic achievement, student engagement, and transitions. The results of the multivariate analysis on student self-report survey data indicated there was a multivariate significance of POS participation on the dependent variables. There was a small effect size for POS participation which accounted for $24 \%$ of the variance in academic achievement, student engagement, and transitions.

The univariate level significance, however, was only found for one dependent variable, student engagement. This univariate significance suggested that POS participation had a positive effect for POS student engagement but not their academic 
achievement or ability to transition through career activities or planning. The association POS participation had with $12^{\text {th }}$ grade student engagement was consistent with the literature. Many of those reasons are mentioned in the $9^{\text {th }}$ grade section of this chapter. Other speculated reasons include the association of engagement and the life stage the $12^{\text {th }}$ graders are at compared to $9^{\text {th }}$ graders. Transitioning from secondary to postsecondary school is one of the biggest transitions a person goes through in their lifetime (Litalien, Ludtke, Parker \& Trautwein, 2013; Leftkowitz, 2005; Shiner \& Masten, 2002).

Twelfth graders are about to embark on a new journey and perhaps the career pathway system sustains their engagement in school because the students are learning what they want to learn and can directly link that to their studies or job for the next year. Most of these students will have internships that can turn into a job or put them on a track to the industry credential that they need. Studying what interests a person in the context of the interest can have positive impacts on that person's engagement, well being, and ability to see the pathway through (Litalien et al., 2013; Salmela-Aro \& Tuominen-Soini, 2010). Perhaps that is what supported these $12^{\text {th }}$ graders into having increased engagement in this group.

However, what is inconsistent in the literature is that the control condition in this study reported higher levels of achievement and ability to transition compared to the treatment condition. Literature supports POS participation on all three dependent variables and only one dependent variable in this secondary analysis (student engagement) had a significant impact. Students reported achieving lower and lacking preparation through transitional activities but reported being more engaged. The three 
variables usually coincide and often influence each other but not with this group of students.

Students in the $12^{\text {th }}$ grade, especially at the end of their $12^{\text {th }}$ grade year, may not be performing academically as well as they once had since they are almost done with high school and may be feeling academic burnout (Shih, 2010; Gonzalez-Roma, Schaufeli, Bakker, \& Lloret, 2006; Maslach et al, 2001). Most students in the $12^{\text {th }}$ grade know what college they are attending, what industry test they need to take, or what branch of the military they are going into, sometimes as early as junior year, making senior year a transition year instead of an academic year. This may also be the reason why there was not a significant effect of POS participation on transitions. Students do a lot of transition work their first three years of high school to promote what they will be doing out of high school. By the time they are seniors they have already been locked into a transition and may be transitioning already, leaving secondary school-related transition activities a smaller priority. Tasks that seem unimportant or irrelevant to the students, such as secondary transitional activities at the end of their senior year, could produce feelings of burnout (Sullivan, 2009; Luke et al., 2003). The students may still be performing transitional activities but they are probably not planning for their transitions anymore, which was one of the ways this secondary analysis measured transitions.

\section{Study Conclusions}

The findings from the secondary analysis that examined the RTPOS's West district contributed to the understanding of POS participation of secondary students in the United States. The secondary analysis took students from one district in the RTPOS and examined academic achievement, student engagement, support, and transitions to see if 
POS participation had any relationship to secondary student outcomes. There was also a gender effects analysis run on the $9^{\text {th }}$ grade group. Results and interpretation suggested that POS participation had a positive association with POS student outcomes, which was consistent with literature as well as the goals of POS under Perkins IV. Findings also suggested that gender had a positive association on student outcomes, but results were mixed between male and female participants on specific student outcome variables.

The effect of POS participation on the $9^{\text {th }}$ grade group was more consistent with the literature base on the relationship between POS participation and students' academic achievement, student engagement, support, and transitions compared to non POS students. This could also be due to the selection effect of school assignments. The $9^{\text {th }}$ grade group reported higher academic achievement, student engagement, support, and transitions from their participation in their POS. The $12^{\text {th }}$ grade group reported only higher student engagement from participation in their POS and did not report higher achievement or transitions. It was speculated in the above $12^{\text {th }}$ grade section why $12^{\text {th }}$ graders in this group may not have had higher achievement and transitions due to being in the last year of high school and already transitioning out of high school beyond what the secondary analysis measured.

There seemed to be a gap between what the $9^{\text {th }}$ grade group reported and what the $12^{\text {th }}$ grade group reported for their POS participation effects on student outcomes. $9^{\text {th }}$ grade students were at the beginning of their POS, fresh to the career pathway system and new to choosing their own career pathway that espoused a non-traditional way of teaching with contextually based curriculums. $12^{\text {th }}$ grade students were at the end of their POS, almost finished with the academic curriculum for secondary school, seasoned in the 
career pathway system and transitioning into that career or into the requirements of that field whether it is postsecondary education or industry credential. The findings of this secondary analysis raised three questions based on above statements: 1.) How can the field keep $12^{\text {th }}$ grade students achieving academically throughout the entire POS? 2.) How can the field better measure transitions to include the actual transitioning out of high school? and 3.) What can be further developed in POS in the middle parts of high school to keep $12^{\text {th }}$ graders on track? It seemed there might be either a structural or resource gap between $9^{\text {th }}$ and $12^{\text {th }}$ grade that might decrease the academic involvement of $12^{\text {th }}$ graders in POS. Since they were two different groups, however, this relationship cannot be established, only speculated.

Gender was also examined in the $9^{\text {th }}$ grade group and results were consistent with literature on POS and general education. Gender studies in education are mixed and this secondary analysis was consistent with that literature. These findings suggested that POS aligned with male and female perspectives and behaviors of education but lack in others. Males did not report higher supportive structures or transition activities compared to females, which is an important area of POS under Perkins IV. Females did not report higher achievement or student engagement, which are important constructs to POS and Perkins IV as well. Findings from the current study underscore the importance of finding ways to help students to improve in these lacking areas.

\section{Limitations}

There were several limitations to this secondary analysis that attempted to examine the RTPOS's data on POS participation effects of student outcomes. 
One limitation of this study was that it was a secondary analysis. Although secondary analyses contribute to the field, they are not first-hand analyses. The RTPOS was conducted before this secondary analysis began so this writer was acting as an external researcher to this project. As such, this writer was not part of the research efforts that were made to develop and conduct the study. The writer could only analyze and report on what has been presented. A positive aspect of conducting a secondary analysis, however, is that this writer was an objective researcher to this project, a variable uncommon to primary research efforts.

Another limitation to this study was the student surveys that were used as a method of data collection for the research study. There were two surveys developed: one for $9^{\text {th }}$ grade and one for $12^{\text {th }}$ grade. The surveys that were developed were different for each group. The survey developed for $9^{\text {th }}$ graders was comprehensive on all research variables of achievement, engagement, support, and transitions, the major variables in this secondary analysis. The $12^{\text {th }}$ grade survey was developed to gauge transitions and planning for the senior group and did not directly ask about engagement or other variables as they relate to POS. The surveys were also self-report evaluations of a student's perceived participation as high school students.

The survey format was also a limitation. The surveys had multiple answer options, Likert-type options, single, and multiple response answer formats. The majority of the surveys were dichotomous, yes/no answers, which limited the ability of the researcher to perform more sophisticated data analytic techniques, such as structural equation modeling or factor analysis. Instead, the researcher grouped and categorized the survey items into the variables for which the survey was developed and performed 
analysis on those variables through extensive literature analysis and conversations with primary researchers. A reliability test could not be run on the survey data because the data was aggregated. Usually for survey data, internal consistency is reported for different subscales. In this case it was not possible. It is always useful to develop and use survey items that have high quality psychometric properties and could be piloted. Surveys that can have measureable psychometric properties add to the reliability and validity of the scores generated from the instrument used in the study. Going back to the first limitation, this is a function of the secondary analysis method of analyzing data.

Lastly, composite variable creation was a limitation of this study due to the survey items. This secondary analysis used non-traditional ways to measure constructs such as achievement, engagement, support, and transitions. For example, achievement is usually measured through student test scores. In this analysis, achievement was measured by self report grades, parental education, and on time graduation. Instead of using traditional measures of the constructs, this analysis used correlated variables that are known to be relevant to the constructs.

This secondary analysis used the student level self-report data to add the existing RTPOS analyses that used the state level data. Through these procedures this secondary analysis, limitations included, was able to contribute to the knowledge base on POS participation effects of student outcomes from the students perspectives in both groups.

\section{Future Recommendations}

Policymakers, researchers, educators, and students could benefit from the findings, implications, and contributions of this study to the fields of CTE, Educational Leadership, and Workforce Development. 
It is mandated within Perkins IV that accountability studies need to be conducted to measure the effectiveness of POS participation on student outcome variables. That is the contribution of this study as well as several other research studies across the nation. The first recommendation is that more studies need to be conducted, both primary and secondary, to ensure that POS participation is being measured for effectiveness across diverse regions, demographics, career pathways, etc. If the true goal is to create a career pathway system for all secondary students to help them achieve and transition better and more efficiently within their chosen industry, more studies need to be conducted to find gaps within the career pathway system. An example of a gap found within this secondary analysis was the report of higher student engagement and no report of achievement or transitions for the $12^{\text {th }}$ grade group. If this finding is consistent across studies, than more structures can be put into place to remedy this gap.

Another recommendation lends to the use of psychometrically sound surveys for data collection and analysis. In the absence of information on psychometric properties of instruments used in a study, it is difficult to draw valid conclusions. Furthermore, when constructing a survey that will not be tested for psychometric properties, it is important to use specific survey items that measure exactly what the researcher wants to ask or know about the participant. Vague items may be confusing and interpreted wrong by the participant as well as difficult for the researcher to analyze the data. Using principles of survey design is a way to combat these issues.

Finally, it is recommended to use these results as well as results from other POS studies to further link academic curriculums with CTE curriculums that incorporate business and industry standards. It is recommended to do this because the effects of 
industry based contextual learning have had a large and positive impact on student outcome variables of achievement, engagement, and transitions. These student outcome variables are not only important to the field of CTE, but are also important to all educational pursuits that support student success. Bridging the gap between academic and vocational education is one of the ways to build a $21^{\text {st }}$ century workforce through secondary education, an important implication to the success of the next generation. 


\section{REFERENCES}

Achieve Inc. (2004). Ready or Not: Creating a high school diploma that counts. The American Diploma Project. Retrieved from http://www.achieve.org/ReadyorNot.

ACTE. (2013). About ACTE: Who we are. Retrieved from https://www.acteonline.org/general.aspx?id=2389\#.Up7QYGRDuaI.

Alarcon, G.M., Edwards, J.M., \& Menke, L.E. (2011). Student burnout and engagement: A test of the conservation of resources theory. The Journal of Psychology, 145(3), 211-227.

Aliaga, O. A., Kotamraju, P., \& Stone, J. R., III. (2012, October). A typology for understanding the career and technical education credit-taking experience of high school students. Louisville, KY: National Research Center for Career and Technical Education, University of Louisville.

Allen, J.P. and Miga, E.M. (2010), “Attachment in adolescence: a move to the level of emotion regulation", Journal of Social and Personal Relationships, Vol. 27 No. 2 , pp. 181-90.

Angus, D.L., \& Mirel, J.E. (1999). The failed promised of the American High School 1890- 1995. Columbia University, New York: NY, Teachers College Press. 
Anlezark, A., Karmel, T. and Ong, K. (2006), "Have school vocational education and training programs been successful?", NCVER (National Centre for Vocational Education Research), Adelaide.

Appleton, J.J., Christenson, S.L., \& Furlong, M.J. (2008). Student engagement with school: Critical conceptual and methodological issues of the construct. Psychology in the School, 45(5), 369-386.

Appleton, J.J., Christenson, S.L., Kim, D., \& Reschly, A.L. (2006). Measuring cognitive and psychological engagement: Validation of the student engagement instrument. Journal of School Psychology, 44, 427-445.

Archambault, I., Janosz, M., Fallu, J.S., \& Pagani, L.S. (2009). Student engagement and its relationship with early high school dropout. Journal of Adolescence, 32, (651$670)$.

Arnett, J.J. (2000). Emerging adulthood: A theory of development from the late teens through the twenties. American Psychologist, 55, 469-480.

Bacharach, V.R., Baumeister, A.A., \& Furr, M. (2003). Racial and gender science achievement gaps in secondary education. The Journal of Genetic Psychology: Research and Theory on Human Development, 164 (1), 115-126.

Baker, J. (2006). Contributions of teacher-child relationships to positive school adjustment during elementary school. Journal of School Psychology, 44, 211229.

Barak, M. (2006). Instructional principles for fostering learning with ICT: teachers' perspectives as learners and instructors. Education and Information Technologies, $11,121-138$. 
Basow, S.A., Phelan, J.E., Capoloslo, L. (2006). Gender patterns in college students' choices of their best and worst professors. Psychology of Women Quarterly, 30, 25-35.

Bellei, C. (2013). Supporting instructional improvement in low-performing schools to increase students' academic achievement. The Journal of Educational Research, $106(3), 235-248$.

Benavot, A. (1983). The rise and decline of vocational education. Sociology of Education, 56(2), 63-76.

Biggs, J., and Tang, C. (2011). Teaching for Quality Learning at University: What the Student Does (4th ed.). The Society for Research into Higher Education. Maidenhead: Open University Press.

Bishop, J.H., \& Mane, F. (2004). The impacts of career-technical education on high school labor market success. Economics of Education Review, 23, 381-402.

Bjornebekk, G., Diseth, A., Ulriksen, R. (2013). Achievement motives, selfefficacy, achievement goals, and academic achievement at multiple stages of education: A longitudinal analysis. Psychological Reports; Human Resources \& Marketing, 112(3), 771-787.

Blustein, D.L., Schultheiss, D.E., \& Flum, H. (2004). Toward a relational perspective of the psychology of careers and working: A social constructionist analysis. Journal of Vocational Behavior, 64(3), 423-440.

Brush, T., \& Saye, J. (2008). The effects of multimedia-supported problem-based inquiry on student engagement, empathy, and assumptions about history. The Interdisciplinary Journal of Problem-Based Learning, 2(1), 21-56. 
Buijs, M., \& Admiraal, W. (2013). Homework assignments to enhance student engagement in secondary education. European Journal of Psychology Education, $28,767-779$.

Bursal, M. (2013). Longitudinal investigation of elementary students' sciences academic achievement in $4-8^{\text {th }}$ grades: Grade level and gender differences. Educational Sciences: Theory \& Practice, 13(2), 1151-1156.

Carini, R.M., Kuh, G.D., \& Klein, S.P. (2006). Student engagement and student learning: Testing the linkages. Research in Higher Education, 47(1), 1-32.

Carolan, B.V. (2013). School transitions and students' achievement in the fifth grade. The Journal of Educational Research, 106(5), 372-383.

Carnevale, A.P., Smith, N., \& Strohl, J. (2010). Help wanted: Projections of jobs and education requirements through 2018. George Town University Center on Education and the Workforce, Washington D.C.

Carter, K. (1998). The changing face of vocational education. Technology \& Learning, $18(6), 50-57$.

Chiu, M.M., \& Klassen, R.M. (2010). Relations of mathematics self-concept and its calibration with mathematics achievement: Cultural differences among fifteenyear-olds in 34 countries. Learning and Instruction, 20, 2-17.

Cieslik, M., \& Simpson, D. (2006), Skills for life? Basic skills and marginal transitions from school to work. Journal of Youth Studies, 9(2), pp. 213-29.

Clark, M.R. (2005). Negotiating the freshman year: Challenges and strategies among first-year college students. Journal of College Student Development, 46(3), 296316. 
Common Core State Standards Initiative. (2012). Students who are college and career ready in reading, writing, speaking, listening, and language. Retrieved from http://www.corestandards.org/ela-literacy/introduction/students-who-are-college andcareer-ready-in-reading-writing-speaking-listening-language.

Conley, D.T., \& McGaughy,C. (2012). College and career. Educational Leadership, 69(7), 28-34.

Conner, J.O., Pope, D.C. (2013). Not just robo-students: Why full engagement matters and how schools can promote it. Journal of Youth Adolescence, 42, 1426-1442.

Covington, M.V. (2000). Goal theory, motivation and school achievement: An integrative review. Annual Review of Psychology, 51, 171-200.

Creed, P.A., Muller, J., \& Patton, W. (2003). Leaving high school: The influence and consequences for psychological well-being and career-related confidence. Journal of Adolescence, 26, 295-311.

Deary, I.J., Watson, R., \& Hogston, R. (2003). A longitudinal group study of burnout and attrition in nursing students. Journal of Advanced Nursing, 43, 71-81.

DeLuca, S., Plank, S., \& Estacion, A. (2006). Does career and technical education affect college enrollment? National Research Center for Career and Technical Education: University of Minnesota, St. Paul, MN.

Denzin, N. K. (1978). The research act: A theoretical introduction to sociological methods (2nd ed.). New York, NY: McGraw-Hill.

Diaz, A. L. (2003). Personal, family, and academic factors affecting low achievement in secondary school. Electronic Journal of Research in Educational Psychology and Psycho Pedagogy, (1), 4. 
Diseth, A., (2013). Personality as an indirect predictor of academic achievement via student course experience and approach to learning. Social Behavior and Personality, 41(8), 1297-1308.

Dockery, M., Koshy, P., and Stromback, T. (2005). From school to work: the role of traineeships. Adelaide: National Centre for Vocational Education Research.

Doolittle, P.E., \& Camp, W.G. (1999). Constructivism: The career and technical education perspective. Journal of Vocational and Technical Education, 16(1), $23-46$.

Downden, T. (2007). Relevant, challenging, integrating and exploratory curriculum design: Perspectives from theory and practice for middle level schooling in Australia. The Australian Educational Researcher, 34(2), 51-71.

Ducksworth, A.L., \& Seligman, M.E.P. (2005). Self-discipline outdoes IQ in predicting academic performance of adolescents. Psychological Science, 16, 939-944.

Dunn, D.S. (2001). Statistics and data analysis for the behavioral sciences. St. Louis, MO: McGraw-Hill.

Dyer, R.R., Reed, P.A., \& Berry, R.Q. (2006). Investigating the relationship between high school technology education and test scores for algebra 1 and geometry. Journal of Technology Education, 17(2).

Eccles, J.S., Barber, B.L., Stone, M., \& Hunt, J. (2003). Extracurricular activities and adolescent development. Journal of Social Issues, 59(4), 865-889.

Elliot, A.J., \& Church, M.A. (1997). A hierarchical model of approach and avoidance achievement motivation. Journal of Personality and Social Psychology, 72, 218232. 
Evans, E.M., Schweingruber, H., \& Stevenson, H.W. (2002). Gender differences in interest and knowledge acquisition: The United States, Taiwan, and Japan. Sex Roles, 47 (3/4), 153-167.

Ewell, P.T. (2002). An analysis of relationships between NSSE and selected student learning outcomes measures for seniors attending public institutions in South Dakota. Boulder, CO: National Center for Higher Education Management Systems.

Fakeye, D.O., \& Amao, T.A. (2013). Classroom participation and study habit as predictors of achievement in literature-in-English. Cross-Cultural Communication, 9(3), 18-25.

Feldman, A.F., \& Matjasko, J.L. (2005). The role of school-based extracurricular activities in adolescent development: A comprehensive review and future directions. Review of Educational Research, 75(2), 159-210.

Finn, J.D. (1989). Withdrawing from school. Review of Educational Research, 59, 117142.

Fischer, F. (1996). The Argumentative turn in policy analysis and planning. F. Fischer \& J. Forester (Ed.). Durham, NC: Duke University Press.

Flum, H. (2001). Relational dimensions in career development. Journal of Vocational Behavior, 59, 1-16.

Fredericks, J.A., Blumenfeld, P.C., \& Paris, A.H. (2004). School engagement: Potentials of the concept, state of the evidence. Review of Educational Research, 74, 59109. 
Freudenberg, N., \& Ruglis, J. (2007). Peer reviewed: Reframing school dropout as a public health issue. Preventing chronic disease, 4(4).

Fritschner, L.M. (2000). Inside the undergraduate college classroom: Faculty and students differ on the meaning of student participation. Journal of Higher Education 71(3), 342-62.

Gillham, J., \& Reivich, K. (2004), Cultivating optimism in childhood and adolescence. Annals of the American Academy of Political and Social Sciences, 591(1), 146-63.

Goldin, C., Katz, L. F., \& Kuziemko, I. (2006). The home- coming of American college women: The reversal of the college gender gap, Journal of Economic Perspectives, 20 (4), 133-56.

Goldin, C. (1999). A brief history of education in the United States. National Bureau of Economic Research Historical Paper No. 119, 1-76.

Gordon, H.R.D (2008). The history and growth of Career and Technical Education in America ( $3^{\text {rd }}$ ed.). Long Grove, Il: Waveland Press, Inc.

Gørgens, T., \& Ryan, C. (2006). The impact of additional educational qualifications for early school leavers. Canberra: Department of Education Science and Training.

Gonida, E.N., Voulala, K., \& Kiosseoglou, G. (2009). Students' achievement goal orientations and their behavioral and emotional engagement: Co-examinig the role of perceived school goal structures and parent goals during adolescence. Learning and Individual Differences, 19, 53-60.

Gonzalez-DeHass, A.R., Willems, P.P., \& Holbein, M.F.D. (2005). Examining the relationship between parental involvement and student motivation. Educational Psychology Review, 17(2), 99-123. 
Gonzalez-Roma, V., Schaufeli, W.B., Bakker, A.B., \& Lloret, S. (2006). Burnout and work engagement: Independent factors or opposite poles? Journal of Vocational Behavior, 68, 165-174.

Grigg, W., Donahue, P., \& Dion, G. (2007). The nation's report card: $12^{\text {th }}$-grade reading and mathematics 2005 (NCES 2007-468). Washington, DC: U.S. Department of Education, National Center for Education Statistics.

Guay, E, Marsh, H.W, \& Boivin, M. (2003). Academic self-concept and academic achievement: Developmental perspectives on their causal ordering. Journal of Educational Psychology, 95, 124-136.

Halbesleben, J.R.B. (2006). Sources of social support and burnout: A meta-analytic test of the conservation of resources model. Journal of Applied Psychology, 91, 11341145.

Hammond, C. Drew, S. F., Withington, C., Griffith, C., Swiger, C. M., Mobley, C., Sharp, J. L., Stringfield, S. C., ... Daugherty, L. (2012). Programs of study as a state policy mandate: A longitudinal study of the South Carolina personal pathways to success initiative. Final technical report: Major findings and implications. Louisville, KY: National Research Center for Career and Technical Education, University of Louisville.

Hammond, C., Drew, S., Withington, C., Mobley, C., Sharp, J., Stringfield, S., \& Stipanovic, N. (2011). Programs of study as a state policy mandate: A longitudinal study of the South Carolina Personal Pathways to Success initiative: Year 3 technical report. Louisville, KY: National Research Center for Career and Technical Education, University of Louisville. 
Hanushek, E.A., \& Woessmann, L. (2008). The role of cognitive skills in economic development. Journal of Economic Literature, 46(3), 607-668.

Hayward, G.C., \& Benson, C.S. (1993). Vocational-technical education: Major reforms and debates 1917-Present. Office of Vocational and Adult Education, Washington, DC.

Herrmann, K.J. (2013). The impact of cooperative learning on student engagement: Results from an intervention. Active Learning in Higher Education, 14(3), 175187.

Hu, S., \& Kuh, G.D. (2002). Being (dis)engaged in educationally purposeful activities: The influence of student and institutional characteristics. Research in Higher Education 43(5), 555-76.

Hu, S.P., \& Wolniak, G.C. (2010). Initial evidence on the influence of college student engagement on early career earnings. Research in Higher Education, 51(8), 750766.

Hughes, J., Luo, W., Kwok, O., \& Loyd, L. (2008). Teacher-student support, effortful engagement, and achievement: A 3-year longitudinal study. Journal of Educational Psychology, 100, 1-14.

Hull, D. (2004). Career pathways: The next generation of Tech Prep. Wasco, TX: CORD. Ilgan, A. (2013). Predicting college student achievement in science courses. Journal of Baltic Science Education, 12(3), 322-336.

Jeynes, W.H. (2007). The Relationship Between Parental Involvement and Urban Secondary School Student Academic Achievement: A Meta-Analysis. Urban Education, 42(1), 82-110. 
Jimerson, S.R., Campos, E., \& Greif, J.L. (2003). Toward an understanding of definitions and measures of school engagement and related terms. California School Psychologist, 8, 7-27.

Kahu, E.R. (2013). Framing student engagement in higher education. Studies in Higher Education, 38(5), 758-773.

Karp, M. M., Calcagno, J. C., Hughes, K. L., Jeong, D. W., \& Bailey, T. R. (2007). The postsecondary achievement of participants in dual enrollment: An analysis of student outcomes in two states. St. Paul, MN: National Research Center for Career and Technical Education, University of Minnesota.

Kenny, M.E., Blustein, D.L., Haase, R.F., Jackson, J., \& Perry, J. C. (2006). Setting the stage: Career development and the student engagement process. Journal of Counseling Psychology, 53(2), 272.

Keppel, G., Saufley, Jr, W.H., \& Tokunaga, H. (1996). Introduction to design \& Analysis: A student's handbook. (2 ${ }^{\text {nd }}$ eds.). New York, NY: W.H. Freeman and Company.

King, R.B., Gaerlan, M.J.M. (2014). High self-self control predicts more positive emotions, better engagement, and higher achievement in school. European Journal of Psychology Education, 29, 81-100.

Klem, A.M., \& Connell, J.P. (2004). Relationships matter: Linking teacher support to student engagement and achievement. Journal of School Health, 74(7), 262-273.

Kokko, K., Bergman, L.R., \& Pulkkinen, L. (2003). Child personality characteristics and selection into long-term unemployment in Finnish and Swedish longitudinal samples. International Journal of Behavioral Development, 27, 134-144. 
Larson, R.W., \& Richards, M.H. (1991). Boredom in the middle school years: blaming schools versus blaming students. American Journal of Education, 99, 418-443.

Lee, J.S. (2012). The effects of the teacher-student relationship and academic press on student engagement and academic performance. International Journal of Educational Research, 53, 330-340.

Lee, J. \& Wong, K. K. (2004). The impact of accountability on racial and socioeconomic equity: Considering both school resources and achievement outcomes. American Educational Research Journal, 41(4), 797-832.

Lekes, N.L., Bragg, D.D., Loeb, J.W., Oleksiw, C.A., Marszalek, J., Brooks-LaRaviere, M., ... Hood, L.K. (2007). Career and technical education pathway programs, academic performance, and the transition to college and career. National Research Center for Career and Technical Education, University of Minnesota: St. Paul.

Levpuscek, M.P., Zupancic, M., \& Socan, G. (2012). Predicting achievement in mathematics in adolescent students: The role of individual and social factors. The Journal of Early Adolescence, 33(4), 523, 551.

Levesque, K., Lauen, D., Teitelbaum, P., Alt, M., \& Librera, S., \& Nelson, D. (2000). Vocational education in the United Sates: Toward the year 2000. National Center for Education Statistics. US Department of Education, Washington, DC.

Levy, G. D., \& Peters, W. W. (2012). Undergraduates' views of best college courses. Teaching of Psychology. 29,46-48.

Lewis, A.D., Huebner, E.S., Malone, P.S., Valois, R.F. (2011). Life satisfaction and student engagement in adolescents. Journal of Youth Adolescence, 40, 249-262. 
Lichtinger, E., \& Kaplan, A. (2011). Purpose of engagement in academic selfregulation. New Directions For Teaching and Learning, 126, 9-19.

Litalien, D., Ludtke, O., Parker, P., \& Trautwein, U. (2013). Different pathways, same effect: Autonomous goal regulation is associated with subjective well-being during the post-school transition. Motivation \& Emotion, 37, 444-456.

Lizzio, A., Wilson, K., \& Simons, R. (2002). University students' perceptions of the learning environment and academic outcomes: Implications for theory and practice. Studies in Higher Education, 27, 27-52.

Lowe, H., \& Cook, A. (2003). Mind the Gap: are students prepared for higher education?. Journal of Further and Higher education, 27(1), 53-76.

Luke, A., Elkins, J., Weir, K., Land, R., Garrington, V., Dole, S., Pendergast, D.,Kapitzke, G., van Kraayenoord, G., Moni, K., Mclntosh, A., Mayer, D., Bahr, M., Hunter, L., Ghadboume, R., Bean, T., Alvermann, D., \& Steven, L. (2003). Beyond the middle: A report about literacy and numeracy development of target group students in the middle years of schooling, 1. Canberra: Commonwealth Department of Education, Science and Training.

Lynch, R. (2000). High school career and technical education for the first decade of the $21^{\text {st }}$ century. Journal of Vocational Education Research, 25(2), 1-28.

Mahoney, M.J. (2004). What is constructivism and why is it growing? Contemporary Psychology, 49, 360-363.

Marks, H.M. (2000). Student engagement in instructional activity: Patterns in elementary, middle, and high school years. American Educational Research Journal, 37(1), 153-184. 
Martin, A.J. (2009). Motivation and engagement across the academic life span: A developmental construct validity study of elementary school, high school, and university/college students. Educational and Psychological Measurement, 69(5), 794-824.

Martin, M.O., Mullis, I.V.S., Foy, P., Olson, J.F., Erberger, E., Preuschoff, C. et al. (2008). TIMSS 2007: International science report. Boston College, MA: TIMSS \& PIRLS International Study Center.

Martin, M. O., Mullis, I.V.S., Gonzales, E.J., Chrostowski, S.J. (2004). TIMSS 2003: International science report. Boston College, MA: TIMSS \& PIRLS International Study Center.

Marsh, H.W., \& Craven, R.G. (2006). Reciprocal effects of self-concept and performance from a multidimensional perspective: Beyond seductive pleasure and unidimensional perspectives. Perspectives on Psychological Science, 133163.

Marsh, H. W., Hau, K.T, \& Kong, C. K. (2002). Multi-level causal ordering of academic self-concept and achievement: Influence of language of instruction (English compared with Chinese) for Hong Kong students. American Educational Research Journal, 39, 727-763.

Masdonati, J. (2010). The transition from school to vocational education and training: a theoretical model and transition support program. Journal of Employment Counseling, 47, 20-29.

Maslach, C., Schaufeli, W.B., \& Leiter, M.P. (2001). Job burnout. Annual Review of Psychology, 52, 397-422. 
McInerney, D.M., Cheng, R.W., Mok, M.C.M., \& Lam, A.K.H. (2012). Academic selfconcept and learning strategies: Direction of effect on student academic achievement. Journal of Advanced Academics, 23(3), 249-269.

Mullis, I.V.S., Martin, M.O., Fierros, E.G., Goldberg, A.L., \& Stemler, S.E. (2000). Gender differences in achievement: International association for the evaluation of educational achievement (IEA)'s third international mathematics and science study (TIMSS). Boston College, MA: TIMSS International Study Center.

Moreira, P., Dias, P., Vaz, F., \& Vaz, J. (2013). Predictors of academic performance and school engagement - integrating persistence, motivation, and study skills perspectives using person-centered and variable-centered approaches. Learning and Individual Differences, 24(117-125).

National Association of State Directors of Career Technical Education Consortium (2013). Career Clusters. Retrieved from http://www.careertech.org/careerclusters/glance/.

National Commission on Excellence in Education. (1983). A Nation at risk: The imperative for educational reform. United States Department of Education, Washington, DC.

National Research Council. (2004). Engaging schools: Fostering high school students' motivation to learn. Washington, DC: The National Academies Press.

National Research Council and the Institute of Medicine. (2004). Engaging schools: Fostering high school students' motivation to learn. Washington, DC: The National Academies Press. 
Newman, F. (1992). Student engagement and achievement in American secondary schools. New York, NY: Teachers College Press, Columbia University.

Nixon, S., Williams, L. (2014). Increasing student engagement through curriculum redesign: deconstructing the "apprentice" style of delivery. Innovations in Education \& Teaching International, 51(1), 26-33.

O’Connor, E., Dearing, E., \& Collins, B. (2011). Teacher-child relationship and behavior problem trajectories in elementary school. American Educational Research Journal, 48, 120-162.

O’Connor, E., \& McCartney, K. (2007). Examining teacher-child relationships and achievement as part of an ecological model of development. American Educational Research Journal, 44, 340-369.

O’Connor, K.J. (2013). Class participation: Promotion in-class student engagement. Education, 133(3), 340-344

Parnell, D. (1986). The neglected majority. Washington DC: Community College Press.

Parsad, B., \& Lewis, L. (2003). Remedial education at degree-granting postsecondary institutions in fall 2000 (NCES 2004-010), Table 4. Data from U.S. Department of Education, NCES, Postsecondary education Quick Information System (PEQIS), "Survey on Remedial Education in Higher Education Institutions," Fall 2000 .

Pekrun, R. (2006). The control-value theory of achievement emotions: Assumptions, corollaries, and implications for educational research and practice. Educational Psychology Review, 18, 315-341. 
Perkins Collaborative Resource Network. (2013). Programs of Study Design Framework. Retrieved from http://cte.ed.gov/nationalinitiatives/rposdesignframework.cfm.

Phillips, S.D., Blustein, D.L., Jobin-Davis, K., \& White, S.F. (2002). Preparation for the school-to-work transition: The views of high school students. Journal of Vocational Behavior, 61, 202-216.

Pinquart, M., Juang, L.P., \& Silbereisen, R.K. (2003). Self-efficacy and successful school-to-work transition: A longitudinal study. Journal of Vocational Behavior, 63, 329-346.

Pinxton, M., De Fraine, B., Damme, J.V., \& D’Haenens, E. (2010). Causal ordering of academic self-concept and achievement: Effect of type of achievement measure. British Journal of Educational Psychology, 80, 689-709.

Plank, S. (2001). Career and technical education in the balance: An analysis of high school persistence, academic achievement, and postsecondary destinations. National Research Center for Career and Technical Education. Office of Vocational and Adult Education, Washington, DC.

Plessis, K.D., Corney, T., Broadbent, R., \& Papadopoulos, T. (2011). Socio-emotional support of apprentices during the school-to-work transition. Education and Training, 54(5), 344-354.

Programs of Study Joint Technical Working Group. (2011). Programs of study: Year 3 joint technical report. Louisville, KY: National Research Center for Career and Technical Education, University of Louisville.

Programs of Study Joint Technical Working Group. (2010). Programs of study: Year 2 joint technical report. Louisville, KY: National Research Center for 
Career and Technical Education, University of Louisville.

Prince, M. (2004). Does active learning work? A review of the research. Journal of Engineering Education, 93,223-231.

Rahm, J., Miller, H. C., Hartley, L., \& Moore, J. C. (2003). The value of an emergent notion of authenticity: Examples from two student/teacher-scientist partnership programs. Journal of Research in Science Teaching, 40(8), 737- 756.

Rahman, F.A., Jalil, H.A., Hassan, A. (2008). An exposition of constructivism account to construct knowledge and to create meaningful learning environment for teacher education. International Journal for Educational Studies, 1(1), 17-30.

Ravitch, D. (2010). The life and death of the great American school system: How testing and choice are undermining education. New York: NY, Basic Books.

Reeve, J., \& Tseng, M. (2011). Agency as a fourth aspect of student engagement during learning activities. Contemporary Educational Psychology, 36, 257-267.

Reeve, J. (2013). How students create motivationally supportive learning environments for themselves: The concept of agentic engagement. Journal of Educational Psychology, 105(3), 579-595.

Richardson, J.T.E. and Price, L. (2003), Approaches to studying and perceptions of academic quality in electronically delivered courses. British Journal of Educational Technology, 34: 45-56.

Rocca, K.A. (2010). Student participation in the college classroom: An extended multidisciplinary literature review. Communication Education 59(2), 185-213.

Rosenbaum, J.E. (2001). Beyond college for all: career pathways for the forgotten half. Russell Sage Foundation. 
Salanova, M., Schaufeli, W.B., Martinez, I., \& Breso, E. (2010). How obstacles and facilitators predict academic performance: The mediating role of study burnout and engagement. Anxiety, Stress \& Coping, 23, 53-70.

Salmela-Aro, K., \& Tuouminen-Soini, H. (2010). Adolescents' life satisfaction during the transition to post-comprehensive education: Antecedents and consequences. Journal of Happiness Studies, 11, 683-701.

Salmelo-Aro, K., Kiuru, N., \& Nurmi, J-E. (2008). The role of education track in adolescents' school burnout: A longitudinal study. British Journal of Educational Psychology, 78(663-689).

Schaufeli, W.B., Martinez, I.M., Pinto, A., Salanova, M., \& Bakker, A.B. (2002). Burnout and engagement in university students: A cross-national study. Journal of Cross-Cultural Psychology, 33, 464-481.

Schaufeli, W.B., Salanova, M., Gonzalez-Roma, V., \& Bakker, A.B. (2002). The measurement of engagement and burnout: A two sample confirmatory factor analytic approach. Journal of Happiness Studies, 3, 71-92.

Schulenberg, J.E., Bryant, A.L., \& O’Malley, P.M. (2004). Taking hold of some kind of life: How developmental tasks relate to trajectories of well-being during the transition to adulthood. Development and Psychopathology, 16, 1119-1140.

Seaton, M., Marsh, H.W., \& Craven, R.G. (2010). Big-fish-little-pond effect: Generalizability and moderation-Two sides of the same coin. American Educational Research Journal, 47, 390-433.

Serbin, L.A., Stack, D.M., \& Kingdon, D. (2013). Academic success across the transition from primary to secondary schooling among lower-income adolescents: 
Understanding the effects of family resources and gender. Journal of Youth Adolescence, 42, 1331-1347.

Shanahan, M. J. (2000). Pathways to adulthood in changing societies: Variability and mechanisms in life course perspective. Annual Review of Sociology, 26, 667692.

Sheridan, V., \& Dunne, S. (2012). The bigger picture: undergraduate voices reflecting on academic transitions in an Irish university. Innovations in Education and Teaching International, 49(3), 237-247.

Shih, S.S. (2012). An examination of academic burnout versus work engagement among Taiwanese adolescents. The Journal of Educational Research, 105, 286-298.

Shochet, I.M., Dadds, M.R., Ham,D., \& Montague, R. (2006). School connectedness is an underemphasized parameter in adolescent mental health: Results of a community prediction study. Journal of Clinical Child and Adolescent Psychology, 35(2), 170-179.

Shulman, L.S. (2002). Making differences: A table of learning. Change, 34(6), 36-45

Shumer, R., Stringfield, S., Stipanovic, N., \& Murphy, N. (2011, November). Programs of study: A cross-study examination of programs in three states. Louisville, KY: National Research Center for Career and Technical Education, University of Louisville.

Shih, S.S. (2012). An examination of academic burnout versus work engagement among Taiwanese adolescents. The Journal of Educational Research, 105, 286-298.

Sirin, S.R. (2005). Socioeconomic status and academic achievement: A meta-analytic review of research. Review of Educational Research, 75(3), 417-453. 
Slade, P.D., \& Owens, R.G. (1998). A dual process model of perfectionism based on reinforcement theory. Behavior Modification, 22, 372-390.

Steinmayr, R., Bipp, T., \& Spinath, B. (2011). Goal orientations predict academic performance beyond intelligence and personality. Learning and Individual Differences, 21, 196-200.

Stevens, J.P. (2009). Applied multivariate statistics for the social science. ( $5^{\text {th }}$ Ed.). New York, NY: Taylor \& Francis Group.

Stipanovic, N., Lewis, M. V., \& Stringfield, S. (2012). Situating programs of study within current and historical career and technical educational reform efforts. International Journal of Educational Reform, 21, 80-97.

Stone, III, J.R., \& Lewis, M.V. (2012). College and career ready in the $21^{\text {st }}$ century: Making high school matter. New York: NY, Teachers College Press.

Stone, III, J.R., Alfeld, C., \& Pearson, D. (2008). Rigor and relevance: Enhancing high school students' math skills through career and technical education. American Educational Research Journal, 45(3), 767-795.

Swanson, G. (1991). Vocational education and the United States Congress. "The worst piece of legislation every passed..." Vocational Education Journal, 66(3), 30-45.

Symonds, W. C., Schwartz, R. B., \& Ferguson, R. (2011). Pathways to prosperity: Meeting the challenge of preparing young Americans for the 21st century. Cambridge, MA: Harvard University.

Tangney, J.P., Baumeister, R.F., \& Boone, A.L. (2004). High self-control predicts good adjustment, less pathology, better grades, and interpersonal success. Journal of Personality, 72, 271-322. 
Tashakkori, A., \& Teddlie, C. (2002). Handbook of mixed methodology. Thousand Oaks, CA: Sage.

Tate, S., \& Swords, J. (2013). Please mind the gap: students' perspectives of the transitions in academic skills between A-level and degree-level geography. Journal of Geography in Higher Education, 37(2), 230-240.

Tsai, M.H., \& Liu, F.Y. (2013). Multigroup structural equation approach: Examining the relationship among family socioeconomic status, parent-child interaction, and academic achievement using TASA sample. International Journal of Intelligent Technologies and Applied Statistics, 6(4), 353-373.

Tison, E.B., Bateman, T., \& Culver, S.M. (2011). Examination of the gender-students relationship at one university. Assessment \& Evaluation in Higher Education, 36(1), 27-49.

U.S. Department of Education. (2013). Carl D. Perkins Career and Technical Education Act of 2006: Reauthorization of Perkins. Retrieved from http://www2.ed.gov/policy/sectech/leg/perkins/index.html.

Vinokur, A., \& Schul, J. (2002). The web of coping resources and pathways to reemployment following a job loss. Journal of Occupational Health Psychology, 7, 68-83.

Vitaro, F., Trembley, R.E., Brendgen, M., \& Larose, S. (2005). Kindergarten disruptive behaviors, protective factors, and educational achievement in early adult- hood. Journal of Educational Psychology, 97, 617-629.

Wallace, J., Sheffield, R., Rennie, L., \& Venville, G. (2007). Looking back, looking forward: Re-searching the conditions for curriculum integration in the middle 
years of schooling. The Australian Educational Researcher, 34(2), 29-49.

Wallenborn, M. (2010). Vocational education and training and human capital development: current practice and future options. European Journal of Education, 45(2), 181-198.

Watters, J.J., \& Diezmann, C.M. (2013). Community partnerships for fostering student interest and engagement in STEM. Journal of STEM Education, 14(2), 47-55.

Wang, Y., Cullen, K.L., Yao, X., \& Li, Y. (2013). Personality, freshman proactive social behavior, and college transition: Predictors beyond academic strategies. Learning and Individual Differences, 23, 205-212.

Weimer, D.L., \& Vining, A.R. (2005). Policy analysis: Concepts and practice (4 ${ }^{\text {th }}$ eds.). Upper Saddle River, NJ: Prentice Hall.

Williams, J.D. (2003). Student engagement at school: A sense of belonging and participation. Paris, France: OECD.

Woods, D. (2008). The impact of VET on transitions to work for young people in Australia. Education \& Training, 50(6), 465-473.

Wu, M. (2003). Effects of a generalizable mathematics skills instructional interventions on the mathematics achievement of learners in Secondary CTE programs. Journal of Industrial Teacher Education, 40(2), retrieved from http://scholar.lib.vt.edu/ejournals/JITE/v40n2/wu.

Yazzie-Mintz, E. (2010). Charting the path from engagement to achievement. Bloomington, IN: Center for Evaluation and Education Policy. Yoder, J.D., \& Hochevar, C.M. (2005). Encouraging active learning can improve students' performance on examinations. Teaching of Psychology, 32. 91-95. 
Zarrett, N., \& Eccles, J. (2006). The passage to adulthood: Challenges of late adolescence. New Directions for Youth Development, 2006, 13-28.

Zimmerman, B. J. (2008). Investigating self-regulation and motivation: Historical background, methodological developments, and future prospects. American Educational Research Journal, 45, 166-18 
Appendix A

\section{U N I V E R S I T Y O F LOUISVILLE}

Human Subjects Protection Program Office

MedCenter One - Suite 200501 E. Broadway Louisville, KY 40202-1798

Office: 502.852 .5188

Fax: 502.852.2164

DATE: November 19, 2014

TO: Namok Choi

FROM: The University of Louisville Institutional Review Board

IRB\#: 14.1200

STUDY TITLE: SECONDARY STUDENT OUTCOMES AND PERSPECTIVES

ON A MULTIPLE PATHWAYS APPROACH TO EDUCATION:

ENGAGEMENT, ACHIEVEMENT, AND TRANSITIONS

REFERENCE \#: 341270

DATE OF REVIEW: 11/19/2014

IRB STAFF CONTACT: Name: Jacqueline S. Powell

Phone: $852-4101$

Email: jspowe01@Louisville.edu

This study was reviewed on 11/19/2014 and determined by the Chair of the Institutional Review Board that the study is exempt according to 45 CFR 46.101(b) under category 4: Existing data/specimens, publicly available, un-linkable to individuals. 
This study was also approved through 45 CFR 46.116 (D), which means that it has been granted a waiver of informed consent because it meets the following criteria:

-The research involves no more than minimal risk to the subjects.

-The waiver or alteration will not adversely affect the rights and welfare of the subjects.

-The research could not practicably be carried out without the waiver or alteration.

-Whenever appropriate, the subjects will be provided with the additional pertinent information after participation.

Documents/Attachments reviewed and approved:

Please be advised that any study documents submitted with this protocol should be used in the form in which they were approved.

Since this study has been approved under the exempt category indicated above, no additional reporting, such as submission of Progress Reports for continuation reviews, is needed. If your research focus or activities change, please submit an Amendment to the IRB for review to ensure that the indicated exempt category still applies. Best wishes for a successful study. Please send all inquiries to our office email address at hsppofc@1ouisville.edu.

Submission Components

12th grade survey $\quad$ Version $1.0 \quad 11 / 17 / 2014 \quad$ Approved

9th grade survey $\quad$ Version $1.0 \quad 11 / 17 / 2014 \quad$ Approved

IRB Protocol Version $1.0 \quad 11 / 17 / 2014 \quad$ Approved

Thank you for your submission.

Sincerely,

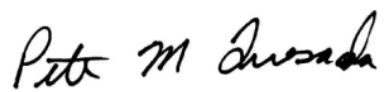

Peter M. Quesada, Ph.D., Chair Social/Behavioral/Educational Institutional Review Board PMQ/jsp

Full Accreditation since June 2005 by the Association for the Accreditation of Human Research Protection Programs, Inc. 


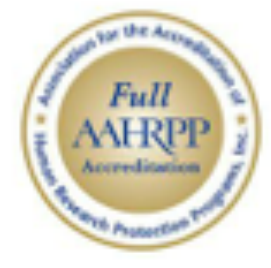




\section{Appendix B}

Normal Q-Q Plot Distribution of Independent and Dependent Variables

\section{$9^{\text {th }}$ Grade:}

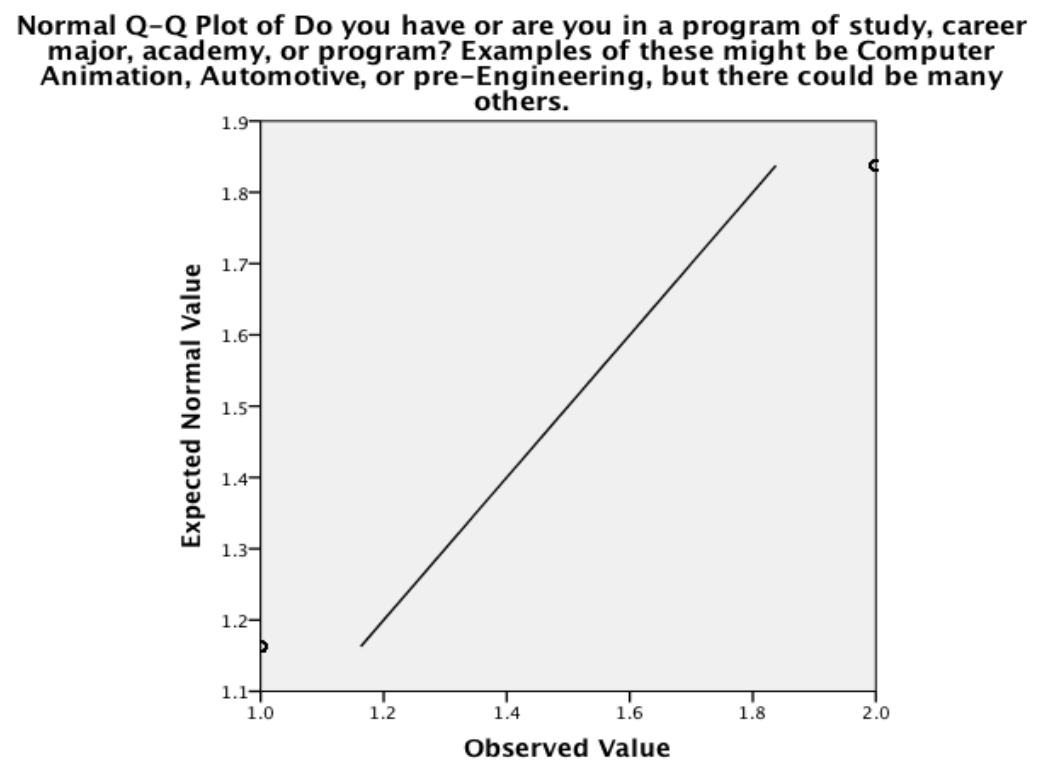




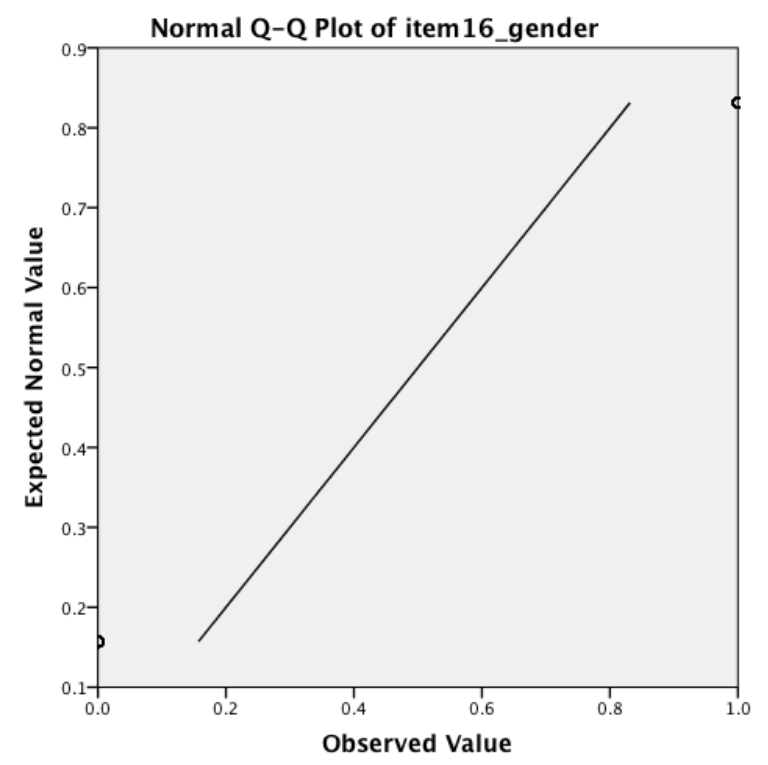

Normal Q-Q Plot of final_achievement

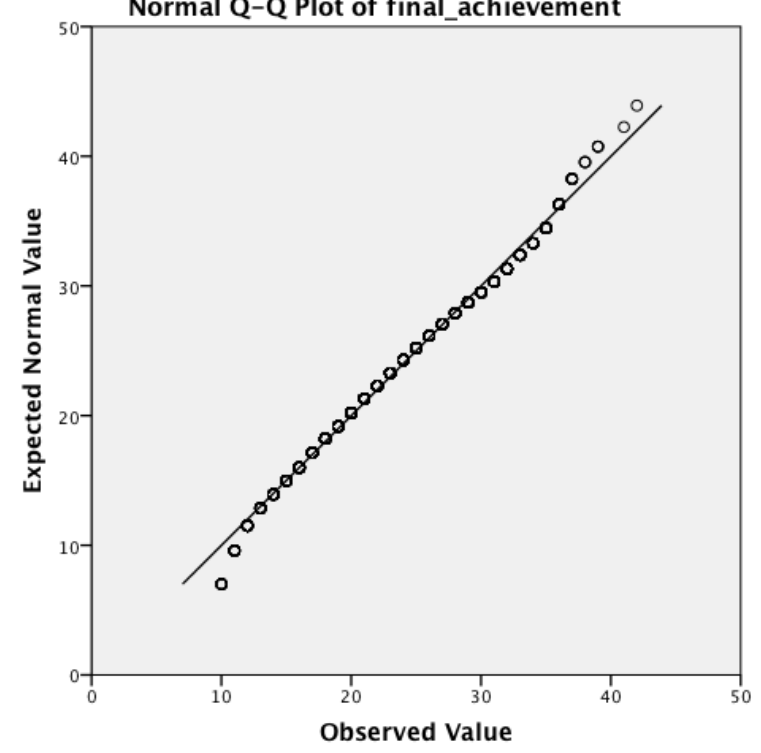



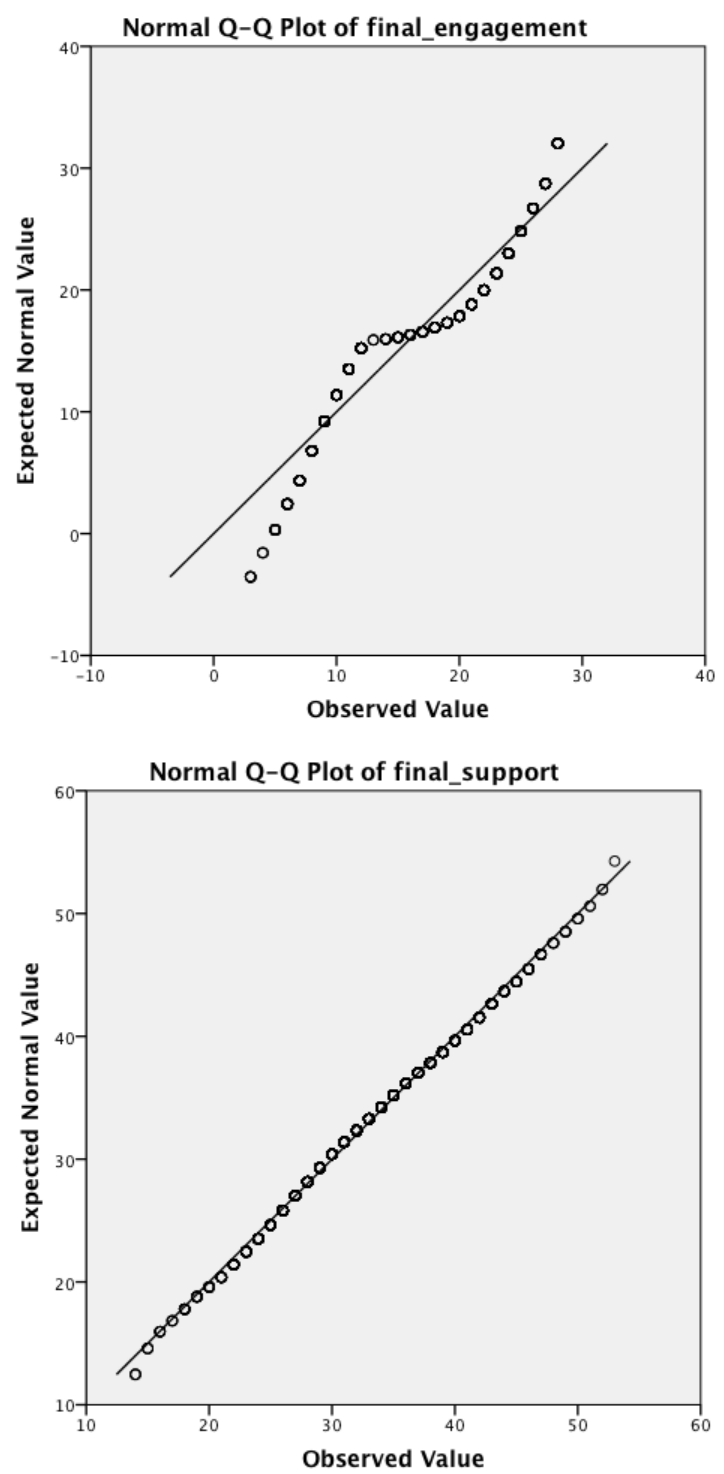


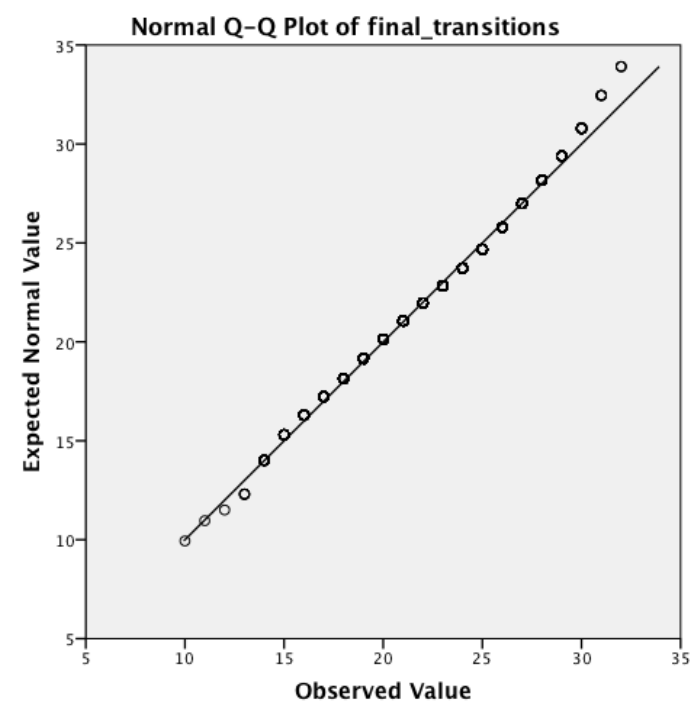




\section{$12^{\text {th }}$ Grade:}

Normal Q-Q Plot of Are you currently in a program at your high school? A program might also be known as a major, program of study, career major, career pathway, career academy, International Baccalaureate, etc.

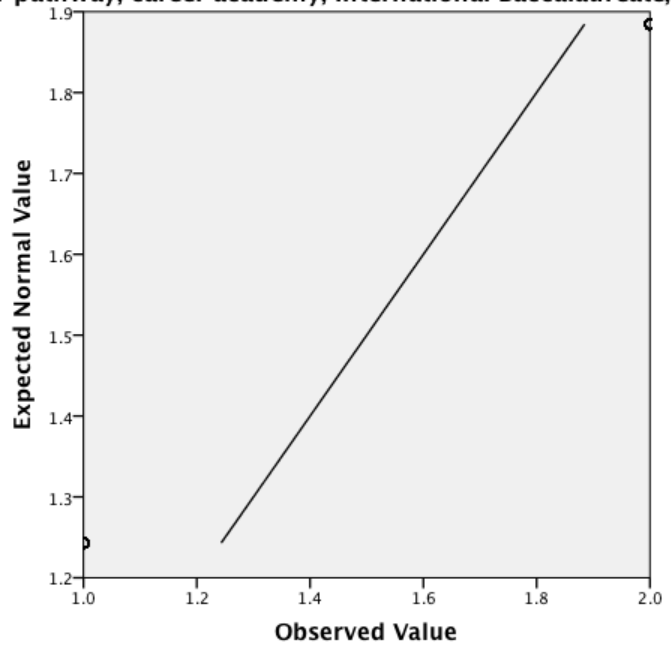

Normal Q-Q Plot of Will you graduate from high school in the spring of

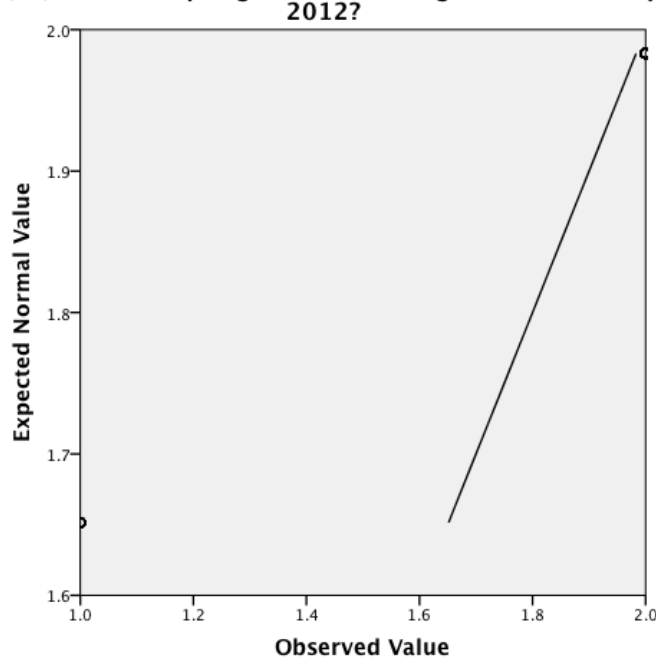



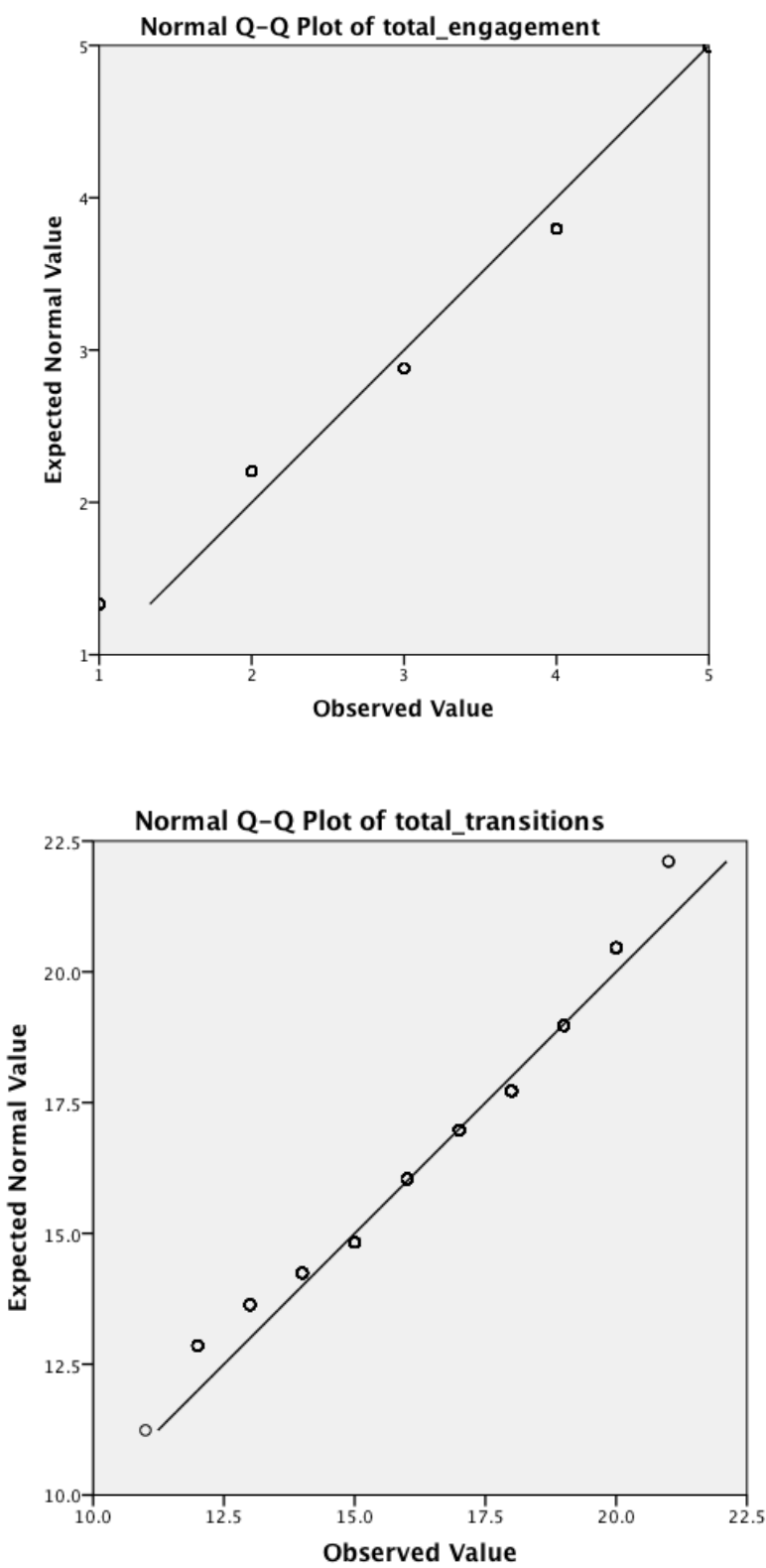


\title{
CURRICULUM VITAE
}

\section{Lisa-Anne Ferris, Doctoral Candidate}

\author{
Curriculum \\ vitae \\ Address: 1511 S. $3^{\text {rd }}$ St. \#5 \\ Louisville, KY 40208 \\ Phone: (732) 682-0694 \\ Email: lisa.anne.ferris@gmail.com

\section{EDUCATION} \\ 2012-2014 (expected) Ph.D. University of Louisville \\ Educational Leadership and Organizational Development \\ Concentration: Human Resource and Organization \\ Development \\ 2011 \\ M.Ed. University of Louisville \\ Counseling and Personnel Services \\ Concentration: Counseling Psychology \\ 2008 \\ B.A. University of Kentucky \\ Major(s): Psychology and Sociology
}

\section{TEACHING \& RESEARCH EXPERIENCE}

January 2014-Present

June 2013-Present

August 2008-Present
University of Louisville Co-Instructor

Graduate Level Workforce Development

Louisville, KY

Graduate Education Fellow

National Endowment for Financial Education

Denver, $\mathrm{CO}$

Research Assistant

National Research Center for Career and Technical

Education

Louisville, KY 
Sept. 2007-August 2008 Researcher/Experimenter

University of Kentucky Psychology Lab, Lexington, KY

Jan. 2007- May $2007 \quad$ Researcher/Experimenter

University of Kentucky Psychology Lab, Lexington, KY

\section{PROFESSIONAL EXPERIENCE}

Jan. 2013-April 2013 Career Specialist/Projects Intern

Jewish Family and Career Services, Louisville, KY

Sept. 2012-Dec. 2012

Instructional Design and Training Development Project

National Occupational Competency Testing Institute

Louisville, KY

Jan. 2012-May 2012 Organizational Needs Assessor

Process of Quality Patient Care

Outpatient Clinic, Louisville KY

September 2011-Present Communication and Coordination Specialist

National Occupational Competency Testing Institute

Louisville, KY

Sept. 2011-Dec $2011 \quad$ Performance Interventionist

Ma201nagement, Communication, and Fundraising

Improvement

East Louisville Community Ministry, Louisville, KY

COUNSELING EXPERIENCE

August 2010-July 2011 Counseling Practicum

Communicare Inc., Elizabethtown, KY

May 2010-August $2010 \quad$ Counseling Practicum

Central State Hospital, Seven Counties Services, Inc.

Louisville, KY

Jan. 2010-April $2010 \quad$ Counseling Practicum

University of Louisville Counseling Center

University of Louisville, Louisville, KY

August 2009-Dec. 2009 Counseling Practicum

Maloney Center, Archdiocese of Louisville, Louisville, KY

May 2009-August 2009 Counseling Practicum 
Central State Hospital, Seven Counties Services, Inc.

Louisville, KY

July 2006-August $2007 \quad$ Undergraduate Clinical Intern

Guiding Light Behavioral Health, LLC, Neptune, NJ

\section{RESEARCH PAPERS AND PRESENTATIONS}

Ferris, L. (2013). Book Review: The engagement equation: Leadership strategies for an inspired workforce. Human Resource Development Quarterly, 24(3), 413-417.

DiMattina, C., \& Ferris, L. (2013). Taking charge of your career path: A future trend of the workforce. Techniques, (88)3, 16-19.

Ferris, L. (2012). Analysis of stakeholder interpretations for Programs of Study in Oklahoma: Addendum to Moving from POS to RPOS in Oklahoma: National Programs of Study Institute final report. National Research Center for Career and Technical Education, Louisville, KY.

Ferris, L., \& Alagaraja, M. (2012). Quality of patient care services: An organizational analysis. (Manuscript accepted to present at the Academy of Human Resource Development Conference of the Americans, Feb 14-16, 2013).

Pearson, D., \& Ferris, L. (2011). Kentucky CTE Teacher Mentoring Project. (White Paper). National Research Center for Career and Technical Education, Louisville, KY.

Hardesty, P., Discont, S., Ferris, L., \& Greenwell, L. (2010, August). The effects of job satisfaction among adolescent workers. Poster presented at the annual meeting of the American Psychological Association, San Diego, CA.

Hardesty, P., Discont, S., Ferris, L., Greenwell, L., \& Jeppsen, B. (2010, August). Who are the Directors of campus career services? Poster presented at the annual meeting of the American Psychological Association, San Diego, CA.

\section{HONORS AND AWARDS}

Dissertation Completion Scholarship, University of Louisville, Louisville, KY, Spring 2014.

ELFH Samuels Scholar, University of Louisville, Louisville, KY, Fall 2013.

Travel Grant Award, Graduate Student Council, University of Louisville, Louisville, KY, 2013 and 2010. 
Student Development Grant, College of Education \& Human Development, University of Louisville, Louisville, KY, 2010.

Research Assistantship, National Research Center for Career and Technical Education, Louisville, KY, 2008-Present.

Member, National Psychology Honors Society, 2006-Present.

Member, Delta Epsilon Iota Academic Honors Society, 2006-Present.

Dean's List, University of Kentucky, 2006-2008.

\section{LEADERSHIP}

Committee Member, Graduate Student Conference Travel Funding, 2012-Present

President, Educational and Counseling Psychology Doctoral Student Organization, 2009-2010.

Registration Chair, Tri-University Spring Research Conference, University of Louisville, 2009.

Treasurer, Educational and Counseling Psychology Doctoral Student Organization, 2008-2009.

Student Member, Department of Educational and Counseling Psychology, Faculty Search Committee, University of Louisville, 2008-2009.

Vice President, National Psychology Honors Society, University of Kentucky, Lexington, KY, 2007-2008.

\section{PROFESSIONAL MEMBERSHIPS}

Society for Human Resource Management (University of Louisville Student Chapter)

American Psychological Association (APA)

Kentucky Psychological Association (KPA)

Psi Chi (National Psychology Honors Society)

VOLUNTEER EXPERIENCE 
September 2011

Sept. 2010-Present

Resource

Louisville, KY

Summer, 2010

pervasive

Counselor, Louisville, KY
Court Appointed Special Advocate Association (CASA) Fundraiser

Intermediate and Applied Statistics Tutor

Department of Leadership, Foundations, and Human Education, University of Louisville,

Discover a Friend Summer Camp for children with developmental disabilities, Senior 